\title{
Siting Controversy - the Place of Dialogue in Community Consultation on Special Needs Residential Facilities
}

\author{
by \\ Natalie Brulé, B.A. (Hons.) \\ A thesis submitted to the Faculty of Graduate Studies and Research \\ in partial fulfillment of the requirements for the degree of \\ Master of Arts \\ School of Journalism and Communication \\ Carleton University \\ Ottawa, Ontario \\ December, 2010 \\ (C) 2010. Natalie Brulé
}




$\begin{array}{ll}\begin{array}{l}\text { Library and Archives } \\ \text { Canada }\end{array} & \begin{array}{l}\text { Bibliothèque et } \\ \text { Archives Canada }\end{array} \\ \begin{array}{l}\text { Published Heritage } \\ \text { Branch }\end{array} & \begin{array}{l}\text { Direction du } \\ \text { Patrimoine de l'édition }\end{array} \\ \begin{array}{l}\text { 395 Wellington Street } \\ \text { Ottawa ON K1A ON4 } \\ \text { Canada }\end{array} & \begin{array}{l}395, \text { rue Wellington } \\ \text { Ottawa ON K1A ON4 } \\ \text { Canada }\end{array}\end{array}$

Your file Votre référence

ISBN: 978-0-494-79574-3

Our file Notre référence

ISBN: 978-0-494-79574-3

NOTICE:

AVIS:

The author has granted a nonexclusive license allowing Library and Archives Canada to reproduce, publish, archive, preserve, conserve, communicate to the public by telecommunication or on the Internet, loan, distribute and sell theses worldwide, for commercial or noncommercial purposes, in microform, paper, electronic and/or any other formats.

The author retains copyright ownership and moral rights in this thesis. Neither the thesis nor substantial extracts from it may be printed or otherwise reproduced without the author's permission.

L'auteur a accordé une licence non exclusive permettant à la Bibliothèque et Archives Canada de reproduire, publier, archiver, sauvegarder, conserver, transmettre au public par télécommunication ou par l'Internet, prêter, distribuer et vendre des thèses partout dans le monde, à des fins commerciales ou autres, sur support microforme, papier, électronique et/ou autres formats.

L'auteur conserve la propriété du droit d'auteur et des droits moraux qui protège cette thèse. $\mathrm{Ni}$ la thèse ni des extraits substantiels de celle-ci ne doivent être imprimés ou autrement reproduits sans son autorisation.

In compliance with the Canadian Privacy Act some supporting forms may have been removed from this thesis.

While these forms may be included in the document page count, their removal does not represent any loss of content from the thesis.
Conformément à la loi canadienne sur la protection de la vie privée, quelques formulaires secondaires ont été enlevés de cette thèse.

Bien que ces formulaires aient inclus dans la pagination, il n'y aura aucun contenu manquant. 


\begin{abstract}
This thesis explores the public communication surrounding two special needs residential facilities: The Oaks, a facility that recently opened in Ottawa, Ontario and Edmond Place, a combined supportive and independent residential project in Toronto, Ontario. Both of these projects were met with local opposition, but the respective organizers handled public consultation quite differently. In Ottawa, a traditional public engagement process was used that focused on unidirectional information-sharing; in contrast, the organizers of the second project used a dialogic approach to address public concerns on the ground level through a client-based ambassador program. This thesis problematizes the use of dialogue in community consultation as a practical means for issue-resolution and consensus. The literature on consultation has largely failed to recognize the important contributions of dialogue to these discussions. It is argued that the ambassador program reconceptualised consultation via dialogic commitments. Although this precise method of public engagement cannot be uncritically exported to other projects in other contexts, the dialogic principles it used should be carefully reflected upon. Consideration must also be given to the context of the neighbourhood within which these projects operate.
\end{abstract}




\section{Acknowledgements}

I would like to extend my sincere gratitude to my supervisor, Josh Greenberg, who agreed to take me on even though the writing of this thesis extended into his sabbatical year. Without his initial suggestion, this project would not have taken shape. His steady support and feedback only made this research stronger.

I would also like to thank my other committee members: Professors Chris Russill and Tim Aubry. I am grateful to Professor Russill for his theoretical insights, which helped me ground my study and clarify its contributions to the existing literature. Professor Aubry's keen interest in the practical application of these research insights was also appreciated. Thank you both for making my defence an enjoyable experience.

To everyone at Carleton who has made my time there memorable. The support from administrative staff and faculty members has not gone unnoticed or unappreciated. Thanks also to my fellow graduate students, whose shared research topics, challenges, struggles, and successes, made me feel saner than I felt on my own!

To my family who supported me throughout this process. Their unwavering encouragement means more than I can say. Mom, Dad, Val and Steph: I love you all. Thank you for knowing when to let me talk and when to snap me out of it!

To everyone I spoke to through the course of my interviews: thank you for sharing with me.

Finally, a special thank you to the Social Sciences and Humanities Research Council (SSHRC) whose financial support made this research possible. 


\section{Abstract \\ Acknowledgements}

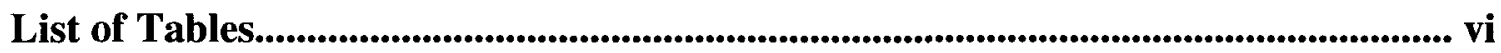

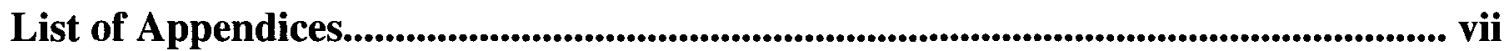

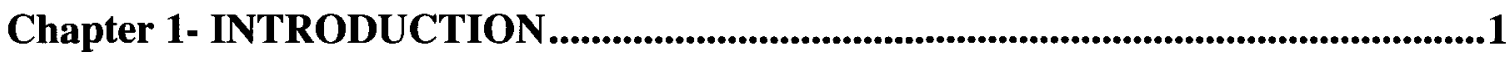

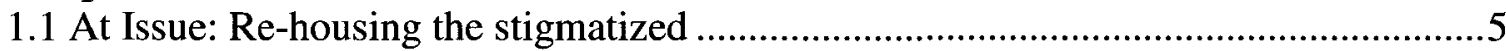

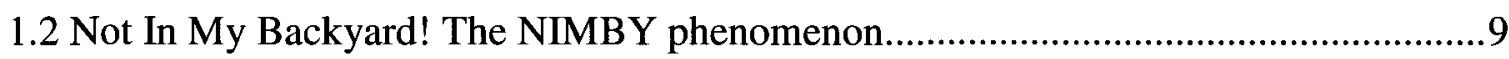

1.3 Central research focus and questions .............................................................. 19

Chapter 2- THEORETICAL FRAMEWORK ..........................................................22

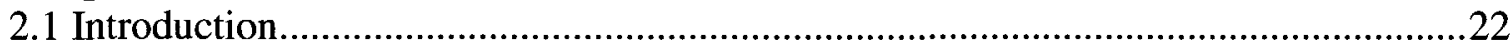

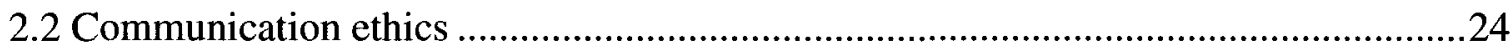

2.3 What is dialogue? A brief outline of the term and its usage ...................................26

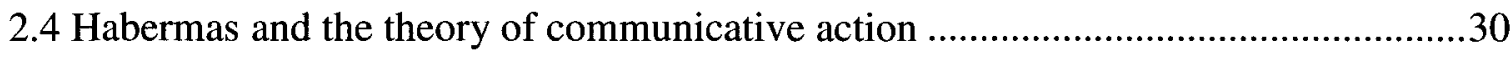

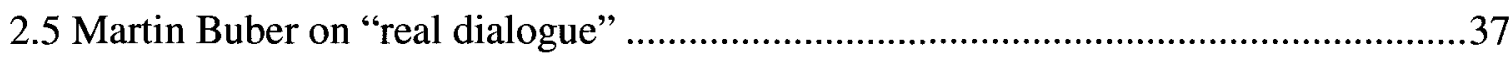

2.6 David Bohm: the dimensions of dialogue .......................................................43

2.7 Dialogue in Practice: Community consultation \& information sessions ....................47

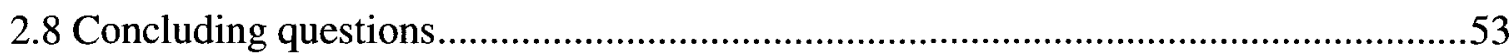

Chapter 3- RESEARCH METHODOLOGY .............................................................55

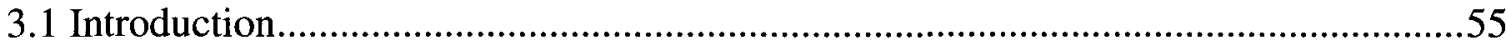

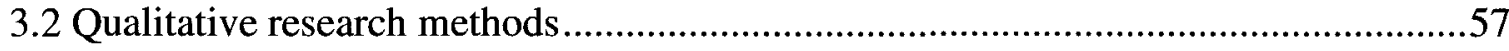

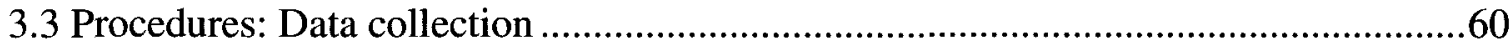

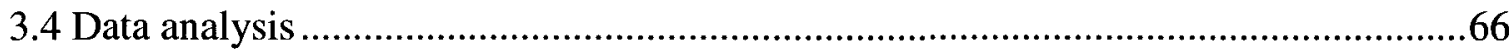

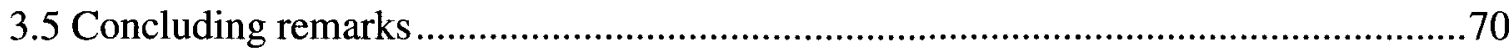

Chapter 4- CASE STUDIES: Local Community Engagement Efforts ......................71

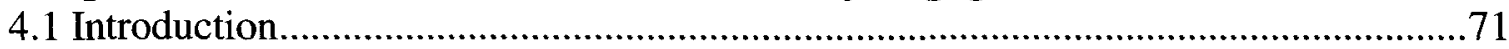

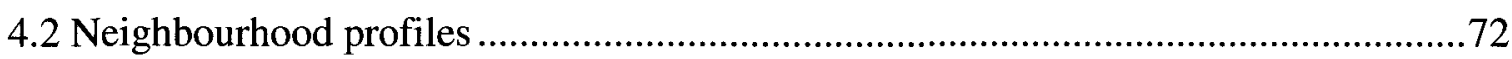

Case \#1: The Oaks (Carlington; Ottawa, ON, Canada) ......................................75

Case \#2: Edmond Place (Parkdale, Toronto, $\mathrm{ON}$ )..............................................83

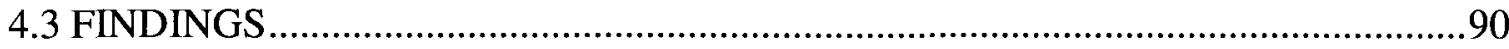

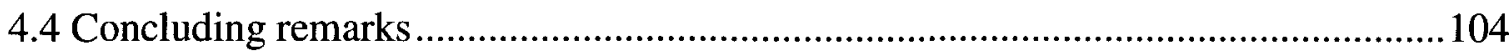


5.2 Buber, Habermas, \& Bohm: Is true dialogue possible and desirable? ........................108

5.3 Some methodological limitations ....................................................................112

5.4 Moving forward: The disallowed discussion (or how many are too many?) …........113

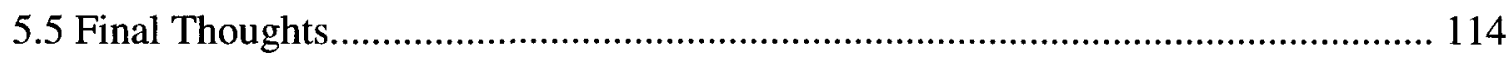

REFERENCES .............................................................................................................116

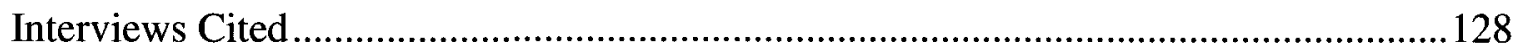




\section{List of Tables}

Table 2.1: The Five Dimensions of Dialogue (As articulated by Bohm)..................... 46

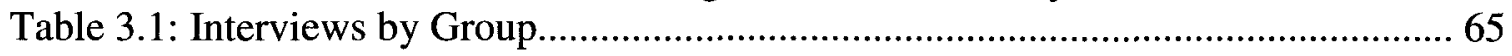

Table 4.1: Community Introduction to Project: Carlington versus Parkdale.................. 89

Table 4.2: Barriers to Communicate (by area) ......................................................... 93 


\section{List of Appendices}

Appendix A: Poster, City of Toronto campaign for housing rights .................................129

Appendix B: Sample Interview Questions ..............................................................130

Appendix C: Interview Guide...........................................................................131

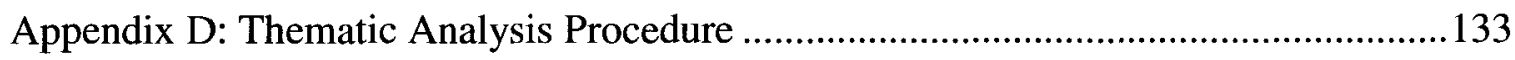

Appendix E: Interview Transcription Procedure …………........................................134

Appendix F: Letter of Information \& Consent Form ....................................................135

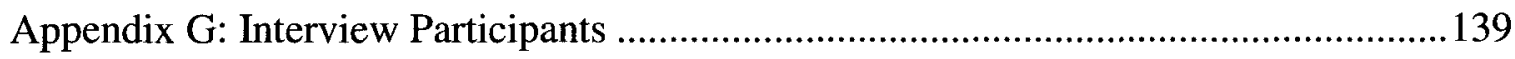

Appendix H: Reader Comments (Posted online) ..........................................................140

Appendix I: OHRC: Letter to the Editor ....................................................................144 
Your immediate problem is not so much the right of the soul to expand, but the necessity for everybody to have a decent dwelling; not to make all homes mansions, but to ensure that none of them will be hovels. It is only a very rare soul that can expand in a hovel.

This objective of decent housing simply has to be achieved in our democratic society.

\section{-Lester B. Pearson, Speech to the Ontario Association} of Housing Authorities, September $1965^{1}$

Housing is not just a roof; it's not just walls. It's much more than that. Housing must have a community attached to it, and a territory. A territory where people can have access to the means of livelihood-to land, to water, to resources, to sources of income-and not only being sheltered somewhere

\section{-Raquel Rolnick, United Nations Special Rapporteur on the Right to Adequate Housing ${ }^{2}$}

The room was filled to capacity with expectant neighbours. Some of them, judging by their appearance, had come straight from work; others arrived, children in tow, to hear what the speakers had to say. It was September 1, 2009, in a medium-sized gymnasium at a local community centre in the Carlington neighbourhood, located in the west end of Ottawa. All of the seats were filled and still people lined the walls. At the front of the room, the speakers readied themselves. The panel consisted of three executive directors

\footnotetext{
${ }^{1}$ Cited in: The Subcommittee on Cities of the Standing Senate Committee on Social Affairs, Science and Technology. (2009, May 28). "Proceedings of the Subcommittee on Cities-Issue 3- Evidence". Retrieved from http://www.parl.gc.ca/40/2/parlbus/commbus/senate/com-e/citi-e/03evbe.htm?Language=E\&Parl=40\&Ses=2\&comm_id=604; and in: Hulchanski, J. D. (2009, Feb. 18). "Homelessness in Canada: Past, Present, Future," Conference Keynote Address. Retrieved from: http://www.scribd.com/doc/ 14126679/Homelessness-Past-Present-Future-Hulchanski-2009, p. 3. ${ }^{2}$ From: Housing is a Human Right (2009, Oct.7). Who We Are. Retrieved from http://housingisahumanright.org/whoweare/
} 
from social service agencies in Ottawa's non-profit sector, members of the Ottawa Police Services, and the local ward Councillor. They were there to inform the community about a new supportive housing project, scheduled to open within the year.

I attended the meeting as an observer. Standing at the back of the room, I was well-positioned to hear the frequent grumbles that accompanied statements made at the front of the room. As the meeting progressed, it became evident that the channels of communication were being blocked. It didn't appear as though opponents on either side of the issue came to the session with an open mind. The professed intention of the meeting, to have a dialogue about the project, floundered almost before it began. Later, reflecting on this failure of communication, I decided that I wanted to pursue a research topic in this area-more specifically, dealing with this idea of ongoing barriers to communication in relation to the siting of special needs facilities. It was clear from that session that several sources of conflict were rooted in more peripheral issues relating to the makeup of the neighbourhood, rather than to the project itself. It also seemed that individuals on both sides of the issue had a different perception of rights and how they should be prioritized. The project partners grappled with the need to justify a housing project that they were legally permitted to operate, and which they felt morally compelled to do; for their part, local residents who opposed the project felt that their right to have a say in the goings-on of their community had been violated by a lack of consultation before it had become a 'done deal'. These overlapping claims converged on several issues: expectations about consultation, the meaning and importance of dialogue, organizational transparency, and the context (both social and historical) of the planned site. 
The need for supportive housing ${ }^{3}$ has been well-documented by service providers and government agencies who both wrestle with growing demand. Service providers contend that giving special needs individuals structure and housing provides a greater social benefit than providing them with haphazard supports while they remain insufficiently housed, or lack housing altogether. Additional literature on site-based conflicts (commonly known as 'Not In My Backyard' or NIMBYism) reveals that these quarrels are many times based on fears and misperceptions (e.g. decreased housing values, negative impacts) or result from objections to the decision-making and information-sharing processes. Public consultation, in particular, has been identified as an effective communication strategy to address anticipated opposition; nevertheless, the literature lacks a comprehensive theorization of consultation and dialogue in the context of housing services for people with special needs. Given current and projected housing demands, conflicts such as these are poised to continue in the years to come. Unlike industrial, technical, or environmental projects where the expected externalities and health concerns may be more obvious and less contested (e.g. strip malls, nuclear waste sites, garbage dumps), housing projects are unique in that they are more singularly entrenched in questions of rights—questions that are not easily resolved.

Lois Takahashi, a Professor in the Department of Urban Planning at the UCLA School of Public Affairs, has written extensively on NIMBYism and community

\footnotetext{
${ }^{3}$ The Canadian Mental Health Association defines supported housing as "affordable housing where the tenants have access to support services in addition to housing. These services vary and can include: Training around key life skills such as managing money or medications, or help towards employment; Medical care; Social and leisure activities; Treatment and recovery programs for alcohol and/or other drug use problems; Individual support known as case management" (2009, May, p.1). Supportive housing is also sometimes known as "alternative housing" or "transitional housing." Sylvestre et al. (2007) distinguish "supported" housing from "supportive" housing explaining that the former is "a strengths-based approach to housing, focusing on ensuring consumers can get and keep normal housing in the community such as apartments", while the latter tends to involve some "form of congregate [living] settings" (p. 82).
} 
opposition to "human service facilities" (Takahashi, 1997; Takahashi \& Dear, 1997; Takahashi, 1998). Her work traces the stigma attached to certain kinds of facilities stemming from the population that they serve. Takahashi argues that NIMBY attitudes are born of normative social constructions about which groups and individuals are acceptable and desirable, and which are not. While her work has made important contributions to the literature on community opposition, her research does not take up the communicative aspects of NIMBYism; in particular, the processes by which information among service providers, beneficiaries and the communities in which they are located, is shared, discussed and problematized. This thesis examines the public communication about two residential projects for special needs groups in Ontario, Canada: the first is the aforementioned supportive living facility that recently opened in Ottawa, Ontario; and the second is a combined supportive and independent housing project opening in November, $2010^{4}$ in Toronto, Ontario. This thesis explores broad perceptions of these housing projects and of service providers' efforts to communicate about them with neighbouring residents. The findings are placed within a broader theoretical discussion about the tensions of dialogue as a practical means for achieving mutual understanding and consensus.

This thesis contributes broadly to the field of communication studies, and in particular to two sub-fields. Firstly, in attempting to offer insights into the most effective way for non-profit service providers to have dialogue with the public, as well as ongoing barriers to these discussions, this research will contribute to the area of organizational communication. Contributions will also be made to the field of communication ethics by

\footnotetext{
${ }^{4}$ According to the project website (edmondplace.ca/timeline) the building is to be completed in November 2010, with tenants scheduled to move in beginning in January, 2011.
} 
addressing questions of organizational responsibility and ethical dialogue — as informed by Habermas' theory of communicative action, Buber's "I-Thou" philosophy, and Bohm's principles of dialogue. Ultimately, these discussions can be extended to other sectors, and applied in business circles, for example, where community engagement, managing public opinion, and consultation are all valued practices. As a result, this study will be of direct value to providers of social services, the public, politicians, the media organizations that report on these events, and other types of organizations involved in community discourse. It is the hope that these insights will enable community organizations to communicate more effectively with their "new neighbours."

\subsection{At Issue: Re-housing ${ }^{5}$ the Stigmatized}

Fifty years ago, the terms "homelessness" and "the homeless" had not yet entered the popular lexicon. It was not until the 1980 s that these terms, and what they represent, became commonplace (Hulchanski, 2009). While there have always been people who lack consistent shelter, the number of individuals who lack adequate housing (and the general pervasiveness of homelessness in Canada) has been amplified, in part, because of government inattention since the 1970s (Ibid.). Quite telling is the fact that the responsibility for social housing has been passed down the different levels of the

\footnotetext{
${ }^{5}$ Rather than the need to "house" the homeless, there is a need to "re-house" them. People are almost always born into a home, but a set of circumstances lead them to become homeless at some point in their lives. Government decisions (e.g. the deinstitutionalization of individuals with pressing mental health concerns) have aggravated the situation by diminishing available, adequate housing. These individuals lost their "housing" so to speak, and now seek new places to live; as such, there is a need to properly "re-house" such individuals and supportive housing is a hopeful model that combines the need for decent housing with a consideration of ongoing health needs.
} 
Canadian government over the years. ${ }^{6}$ In his keynote address at the Growing Home:

Housing and Homelessness in Canada conference, Hulchanski (2009) called upon all

Canadians to help eliminate homelessness saying,

We need to recognize that action must take places (sic) at three levels: the level of individuals and families; the community level, with initiatives at the local and municipal level; and at the macro (federal and provincial) level, where the resources for the most part, our tax dollars are located. The failure to act appropriately at all three levels means that partial efforts have little chance of success-if success means having fewer homeless people and a dramatically smaller need for expensive services for [them] (p. 7).

When the Canadian social housing sector grew in the 1960s, "so did public antipathy" (Hackworth, 2009, p. 260). In fact, it grew so much that it even became (in spite of size, location, or type of tenant) "acutely stigmatized" (Ibid.). While "Canadian social housing is less marginalized politically than the same sector in the US" (Hackworth, 2009, p. 259) it still lacks the support that Germany, Britain and several other foreign governments have given it. Hulchanski's (2009) comments serve as an important reminder that lasting solutions to housing woes rest on the cooperative efforts of various networks of people.

\section{Housing as a human right}

The notion that housing is a human right has gained some traction in the last few years thanks to the efforts of proponents both within and outside of government. In Ontario, this belief was bolstered by the October 2009 release of the Policy on Human Rights and Rental Housing by the Ontario Human Rights Commission (OHRC). This policy

\footnotetext{
${ }^{6}$ Beginning in the 1990s, the federal Liberal government made the provinces accountable for social housing. In response, Mike Harris' Ontario government downloaded the task even further to local municipalities who lack the proper resources to deal with demand.
} 
followed a comprehensive consultation process that examined existing barriers to housing in the province and ways that they could be eliminated. Barbara Hall, the OHRC's Chief Commissioner, explained, "Discrimination occurs in many forms in rental housing across Ontario. Vulnerable and marginalized people have a much tougher time getting the housing they need because they face a number of barriers" (OHRC, 2009, Oct., para. 3). Discriminating against someone on the basis of mental health or addiction violates the province's Human Rights Code (OHRC, 2010, Jun. 21).

The city of Toronto has also adopted a "pro-housing for all" stance as evidenced by the Toronto Housing Charter-Opportunity for All. This charter is expressly "intended to discourage the not-in-my-backyard reaction to the creation of new affordable housing" (OHRC, 2010, Mar., para. 3). Closely following the adoption of this Charter, the city launched a related month-long poster campaign in partnership with the OHRC, the Federation of Rental-Housing Providers of Ontario, the Greater Toronto Apartment Association and the Human Rights Legal Support Centre-all of whom have lent their support to promoting the message that housing is a human right (See Appendix A).

In addition to these efforts, numerous international instruments have also recognized the moral right to housing. Sadly, they observe that "among all the components of basic human rights outlined in the Declaration [UDHR] and major international human rights instruments such as ICESCR, the human right to adequate housing is among the most frequently violated" (UN-HABITAT, 2004, p. 5). Complicating matters is the fact that internationally-recognized rights are often inconsistently interpreted and implemented domestically. The 'right to housing' does not mean that national governments must provide free housing to everyone, simply that there 
be measures in place to ensure that affordable housing is accessible to all citizens (UNHABITAT, 2004, p. 10). How this accessibility is provided depends on nationallyselected policies and procedures.

Canada was recently singled out and chastised by the United Nations for its shortcomings in housing provisions. Partly responsible are the country's welfare reforms and its deinstitutionalization of human service delivery that began in the 1980s. These put a strain on the social system and sparked inequitable access to existing housing (Wolch, 1996; Teeple, 2000). Current cycles of economic depression, such as the recent economic crisis, have served as ready reminders of how close North Americans are to needing outside aid. Food bank use is up in most cities, and in the United States, home foreclosures have created a completely new strata of homeless. Marion Wright, the CEO of the Canadian Mental Health Association (CMHA) Ottawa-Branch, described the impact of the current economic environment on service provision as "more, more, more demand" (Critical Conversations, 2010). Besides growing need, there is a downturn in available resources and "an increase in funder requirements" (Ibid.). This long-term trend explains the increased call for human service programs and social housing (Alliance to End Homelessness, 2008), as well as the endemic shortage of both. Wright explains, "in a downturn [service providers are] working with the most marginalized people and those are the people who are already at the bottom $[. .$.$] but what will happen is that more people$ will drop into that category and we will be unable to serve them" (Critical Conversations, 2010). Service providers like the CMHA must ration their resources and prioritize need. Unfortunately, this often means that they are unable to provide assistance until there is a desperate need (Ibid.). 
If families with an average income are vulnerable to homelessness, then individuals who also juggle a substance use disorder and/or a mental illness will find it nearly impossible to make ends meet without considerable, regular supports. Groups like the Toronto-based Dream Team, a non-profit group of psychiatric consumer/survivors, have had some success in rallying around housing rights for people with mental health issues and in challenging legal procedures that exclude particular forms of housing from select neighbourhoods. While important, legal battles are only one dimension of the issue. Once a supportive housing project has been approved through formal channels, there remain normative challenges associated with winning public support. A lot of time and resources go into the planning and execution of new projects; consequently, managing local responses to them can be the determining factor between an on-time and on-budget facility, or a drawn-out, expensive, and perhaps incomplete venture. Although most Canadians agree with 'housing rights' in theory, supporting low-income, social, or supportive housing when it enters their city block, is a recurrent challenge.

\subsection{Not In My Backyard! The NIMBY phenomenon}

When it comes to fighting NIMBYism, the best defense may be a strong offense. -North Carolina Housing Coalition ${ }^{7}$

What is the root cause of quarrels over land use? Is there anything that can be done during the planning stages to reduce or eliminate the probability of such conflict? These and similar questions have been the driving force behind a body of research initiatives on the so-called NIMBY (not-in-my-backyard) syndrome. The term 'NIMBY' was first

\footnotetext{
${ }^{7}$ Overcoming the challenges of NIMBYism (n.d.) p. 90
} 
popularized in the environmental literature in reference to disputes over the siting of incinerators, garbage dumps, and nuclear power plants. More recently, the concept has gained currency within planning circles and the media ${ }^{8}$ to describe local opposition to all kinds of problematic facilities; from incinerators to prisons, homeless shelters to addictions centres, and low-income housing projects.

A recurrent concern within the NIMBY literature is the overuse or misuse of the acronym itself. It has been argued that "[d]istinguishing NIMBY from non-NIMBY campaigns and individuals is... part of siting disputes" (Burningham, 2000, p. 66). Because NIMBYism tends to be based upon binaries of 'us versus them' (or self-interest versus the common good), the term is questioned for being 'out of vogue' and for limiting certain discussions. At its most basic, it provides a handy and provocative way of describing the "protectionist attitudes" (Dear, 1992, p. 288) of residents when unwanted developments or projects are being sited locally. Definitions of what comprises a NIMBY-event vary by source, with some opting for a broad and inclusive definition; and others identifying specific markers of these conflicts, such as sustained or organized activism (e.g. Hubbard, 2005). Wolsink (2006) refers to the Oxford English Dictionary definition of NIMBYism to qualify the phrase as resistance to a facility in one's own neighbourhood - the implication here being that these same individuals would not oppose the facility elsewhere. As such, NIMBYism is framed as resistance to the site, not to the type of facility/land use per se. In this sense, NIMBYism is both a "qualified acceptance as well as qualified rejection" (Wolsink, 2006, p. 86). In contrast, Hubbard (2006) challenges this line of reasoning by pointing to the literature on environmental activism.

\footnotetext{
${ }^{8}$ A recent online search of the term ("nimby") over the past five years (January 2005 to January 2010) returned over 1700 newspaper articles.
} 
Environmental activists tend to oppose land features in greater measure, and on a much larger scale, than opposition to local developments (i.e. opposition to a nuclear waste site or deforestation by a corporate enterprise, versus a new mall or low-income housing). Accordingly, it may be more accurate to say that there is a continuum of acceptance and rejection (or tolerance and avoidance-see Groothus \& Miller, 1994) to developments. This concept of a continuum has also been expressed by Takahashi and Dear (1997) who found that a facility's level of acceptance reflects both the services provided and the clientele.

Lake (1993) alleges that "NIMBYism is blamed for virtually all of our failures to solve pressing social problems," (p. 87). Although the impression is frequently given that NIMBYism consists of broad opposition, studies have shown that NIMBY reactions quite often stem from a small group of neighbours who are effective at mobilizing political allies and lobbying against developments (Rasmussen, 1992, p. 129; Taylor, 198999). Regardless of their level of activity in the debate, most citizens take offense to being called a NIMBY. Not only does describing opponents as such "inflam[e] the debate" (Allen, 2002a, p.1), it also simplifies their arguments. McClymont and O'Hare (2008) caution, "In order to assess the value and propriety of participation, an in-depth consideration of the motivations, actions and outcomes of groups is needed, rather than relying upon the labels that they may either adopt or are assigned" (p. 333). Even though the term 'NIMBY' has been criticized for being value-laden and damaging (Burningham, 2000), lacking in explanatory power (Wolsink, 2006) and reflecting unattainable ideals (Gibson, 2005), it remains salient in most discussions of locational disputes.

\footnotetext{
${ }^{9} \mathrm{~S}$. M. Taylor (1989) has noted the role that media plays in these impressions. Media coverage of site disputes has tended to "exaggerate both its prevalence and intensity" (p. 316).
} 


\section{Neighbours on the Defence: NIMBY Attitudes towards Housing}

Opposition to facilities that serve the mentally ill is not a new phenomenon; it was witnessed in the nineteenth century in rather the same fashion and with similar concerns as those voiced in contemporary cases (Philo, 1987). Several years ago, Cowan (2003) studied community attitudes towards people with mental illness in the midst of a "hot situation"-in this case, the establishment of a living facility for a small group of longterm psychiatric patients. Using public documents, group discussions and individual interviews, Cowan determined that those who objected to the facility oriented their arguments around three points: (1) they objected to the lack of consultation and the secrecy they perceived surrounded the project (e.g. procedural issues); (2) they believed the location to be undesirable and unsuited to the project in question; and (3) they objected to the client base who would be housed in the facility. In general, the arguments made by those who supported the facility were much more varied, but still commonly framed within a moral discourse of 'human rights'. Zippay and Lee (2008) similarly found that among residents who viewed residential facilities as a benefit to the community, there was a strong moral belief that "the sites serve a humane purpose and the collective good in providing services for those in need" (p. 409). Frequently, human rights claims embedded in conflicts over space (and the ownership and control of that space) are eclipsed by the dramatization of organized protest in media reports; yet, the spoken and unspoken issue of rights is a foundational cause of housing site-disputes and thus an important consideration in their resolution. ${ }^{10}$

\footnotetext{
${ }^{10}$ Additional concerns that have been raised in the literature are: (1) problems with the physical features of the proposed housing; (2) concerns about the possible negative impacts of this housing (e.g. property
} 
Since it is common for community members to inflate fears of unlikely outcomes (at least as perceived by project organizers; see Cook, 1997), initial studies on NIMBY reactions tended to dismiss emotion-filled community opponents. Yet Perinbanayagam (1991) and others have explained that emotions cannot be separated from social acts (p. 142-166). Pettigrew (1998) adds, "Emotion is critical in intergroup contact" and "[s]uch anxious, negative encounters [that are commonly associated with NIMBYism] can occur even without intergroup prejudice" (p.71). It is now more acceptable to frame opposition as a multidimensional response that reflects an individual's sense of place and ownership, as well as broader socio-economic fears and political frustrations (Takahashi, 1998; Lyon-Callo, 2001).

NIMBY-reactions are most common when the development in question is a large project that is likely to produce many benefits on a macro level, but several annoyances or risks at the local level (such as increased traffic, noise, air pollution etc.) (See Boyer, 2008, p. 1). This is what Kim (2003) calls the "siting problem of publicly provided indivisible goods" (p. 357). As discussed, special needs housing is promoted on the basis of its broad benefits, but fears about its interference with existing community dynamics are locale-specific. As Fischel (2001) reflected, [...] NIMBYism is weird only if you think solely about the first moment, the rationally expected outcomes from development. NIMBYism makes perfectly

values, safety, traffic, neighbourhood services); and (3) negative past experiences with a similar type of housing or with the same developer (p. 4; See also Dear, 1992; Antos Arens 1993, p. 238; Colón \& Marston, 1999; HomeComing, 2005). Yet, as supporters have been keen to point out, some of these concerns are not based on likely outcomes, but rather misperceptions (HomeComing, 2005, Oct. 11). For example, a study by Galster et al. (2004) found that contrary to popularly-voiced concerns about impacts on property values, the value of homes near a supportive housing facility may actually increase. Other research has also confirmed that supportive or affordable housing does not impact the market value of neighbouring homes (see Dear \& Taylor, 1982, p. 133-144; NCHC, n.d., p. 21-24; and City of Calgary, 2006, p.8-10; de Wolff, 2008). A Toronto-area study, We are Neighbours (deWolff, 1998), also reported that supportive housing does not negatively impact area crime rates and can in fact add to the vibrancy of the neighbourhood. 
good sense if you think about the second moment, the variance in expected outcomes, and the fact that there isn't any way to insure against neighbourhood or community-wide decline (p. 144-145).

Wolsink (2000) calls NIMBYism "a specific social dilemma or game-situation" (p. 51)

but challenges the notion that opposition is born of individual self-interest alone (a widely held opinion underlying many economic articulations of NIMBY); instead, perceptions of risk must be considered (McAvoy, 1999). Thornton and Knox (2002) found that opposition, rather than being predicted by personality traits, is better explained by a "situation involving high vested interest" (i.e. perceived risk) (p. 2570); and a Colorado-based study on opposition to group homes, found that it was the process - the way in which the housing project was introduced into the community - that distressed residents. Researchers

found that opposition ...came less from a bias against the clientele but rather from a sense of anger, frustration, and powerlessness with the process for addressing their concerns about how supportive facilities are sited, approved, and managed. Respondents did not feel comfortable with the information provided by developers and did not expect these service providers to be responsive to their concerns (Galster et al., 1999, p. 2-19).

This finding reinforces the important communicative dynamic of project disputes. The quality, timing and flow of information about a project can be significant points of contention. Establishing trust between incoming project partners and the community during the initial planning stage is crucial. Trust is a cornerstone of effective dialogue and is a strong indicator of facility acceptance; again, implicit in establishing trust is strong reassurances about community-wide risks that projects may present (perceived or real). Keith and Pile (1993) explain, “...space cannot be dealt with as if it were merely a passive, abstract arena on which things happen" (p. 2). In their study of a proposed 
landfill site in Edmonton, Alberta from 1989-1990, Guidotti and Abercrombie (2008) found that history can be an important, but less perceptible, reason for opposition. Community-wide shared experiences and beliefs (for example, feelings of political disempowerment) can be carried over from one event and associated with another. This has implications for community behaviour and reactions to new incoming projects.

For the most part, researchers who have studied the NIMBY phenomenon concede that there will never be a perfect mechanism or formula that can eliminate negative responses altogether; yet, there are certainly measures that can be taken to lessen their impact and to resolve public concerns more efficiently. Housing providers have produced numerous "NIMBY-guides" for just this purpose. A recurring trend among them is linking site-based opposition to veiled discrimination. It is commonly suggested that discrimination is couched in a variety of concerns linked to infrastructure and the operations of a facility (i.e. more socially-acceptable objections). For example, HomeComing (2005) wrote in a guide intended for service providers dealing with NIMBYism that "Sophisticated people will say the project does not 'fit' the neighbourhood, or that it is 'not appropriate,' or even that the site is 'not in the best interests of the future tenants"' (p. 9). The belief is that underneath these concerns is a basic fear stemming from misinformation or a lack of understanding of the project itself.

Joel Roberts, CEO of PATH Partners (People Assisting The Homeless), believes that NIMBY should actually be renamed FIMBY — Fear In My Backyard. Roberts (2010) saw the spatial conflict that his own organization's facility for the homeless experienced, not as a "combat”, but “...as an educational crusade" ("A Battle or a Marketing Campaign," para. 1). He argues, there is a tendency for people to idealize what a 
neighbourhood should be like; but, he adds, “...this is 2010 . We can wish for perfect neighborhoods that might look like a 1950s sitcom, but the reality is today's neighborhoods are more like Wisteria Lane on TV's 'Desperate Housewives', where murder, deceit, and crime lurk behind those perfect residential facades" (Ibid., para. 3). Stated otherwise, special needs housing is not any more or less safe than what is currently in neighbourhoods; even so, service providers are obligated to assure people that their housing projects and clients will adhere to these old-fashioned ideals.

As a first step in building goodwill with neighbours for affordable housing projects, Allen (2007) advocates extensive planning. He explains further: it is necessary to meet and develop strategies for gaining political and public support, as well as how to deal with community issues, to gain awareness of one's legal rights and responsibilities, and to develop a public relations strategy. Some practitioners have noted that service providers generally fail to take advantage of community leaders and pockets of local support in the earliest stages of planning (Cook, 1997, p. 298-299; HomeComing, 2005, p. 16). Aligning with a trusted group of individuals can help ease the transition into the community and perhaps also suppress hasty judgements. Allen (2007) also encourages project groups to conduct an analysis of the neighbourhood and to come up with a list of potential concerns neighbours might have. It is important to be prepared. "Only when you understand why a person opposes, can you select the best response" (slide 17).

After the planning stage is complete, it is traditional for service providers/project planners to hold a large town hall meeting with all area neighbours to discuss the project. This tactic is seen as the most efficient way to inform local residents about a housing initiative, but it is not the only way. In the last several years, consideration has been given 
to "alternative methods for community outreach" (Allen, 2007, slide 17) such as door-todoor canvassing (Ibid.) or smaller community meetings, which may be more effective at developing "community rapport" (Zippay, 1997, p. 306; see also NCHC, n.d., p. 14; Multi-Housing News, 2008). Keeping in mind that both of these strategies involve a considerable output of time and resources that non-profit housing providers often lack; both their goal and their strength (when successful) is to personalize interactions so as to ameliorate intergroup dialogue and thus, understanding.

Broadly speaking, information-sharing and public education schemes are two elements considered important in the management of opposition. Equally important is: (1) maintaining a dialogue with the concerned group, (2) early consultation, and (3) cooperation with media to facilitate message proliferation (Cheung, 1990). A lack of information interferes with successful communication between groups. It also leads to distrust with project organizers. Although this link between ignorance and facilityrejection is not explicitly clear, the value placed upon education to change public attitudes towards special needs housing facilities is shared among most service providers (see for example NCHC, n.d., p. 6). Understood in this focus is the idea that service providers are the teachers, not the ones being taught. This insistent hierarchy of communication flows and the strategic orientation of this 'education' may actually act as a barrier to dialogue and meaningful change. "It is important to recognise that public information is not a magic cure-all for all community resistance" (Stein, 2008, para. 10). When opposition stems from something other than misperceptions or ignorance, more information can even be damaging. It could, for example, introduce new fears where none existed before. For this reason, public information must be handled carefully since it 
can perceived as "inherently condescending, suggesting that the developer is entitled to make unilateral decisions affecting neighbors, but has only a patronizing obligation to inform residents of those decisions after the fact"(Ibid.). Emphasis would be better placed on dialogic interactions that include hearing and responding to neighbours; not just talking, but listening to them as well.

Regardless of the particulars of a communications strategy, it is essential that project organizers be open and sincere in their interactions. After all, it is how consultation is conducted that determines its positive or negative outcome. Barbaro (2006) found that the most successful consultations occur when solutions are determined as a group, and organizations are willing to listen to, and consider, local knowledge and expertise. Our Place Society, a social service agency in Victoria B.C., followed some of these practices and as a result, had a very successful consultation process with the closest neighbours (associations, organizations, churches) of their new location; they even continue to hold small monthly meetings to gather input. In contrast, consultation on a different project by another organization that did not value community input, led to complaints that people "didn't have any say in [the consultation process] whatsoever. ..." and that their questions were evaded (cited in Antos Arens, 1993, p. 240). This set the tone for bad continuing relations between organizers and local citizens.

Expectations about consultation are a recurring stumbling block. Implicit in discussions about consultation is the belief that dialogue is a natural extension of these efforts, yet this has rarely been critically-assessed and evaluated. The problem is that prevailing assumptions about communication in the consultation literature emphasize information-sharing models of message-transference, but effectively ignore the important 
contributions of the 'dialogic turn' in communication studies that conceives of consultation and education dialogically. Thus, while service providers might signal the opening of a dialogue with citizens, they may actually disregard the dialogic markers of these interactions and focus almost entirely on information transference. This is often to their detriment since true dialogue leads to active community engagement and assists in the building of positive long-term relationships with area residents.

\subsection{Central Research Focus and Questions:}

This chapter outlined some of the dominant themes found in the literature on NIMBYism.

Far from being a clear-cut description, NIMBY characterizations are tension-filled, tenuous and deeply embedded in situational context. In the empirical study that follows, several questions will be explored:

(1) What ongoing barriers to successful communication exist between service organizations and community members?

(2) How do service organizations view public communication?

(3) What strategies can service organizations use to successfully communicate with citizens when introducing a controversial housing project into their neighbourhood?

(4) What additional value does dialogue bring to community consultation versus straightforward information-sharing processes?

(5) What tensions exist between approaches to consultation that focus on achieving long-term consensus and those that emphasize short-term strategic gains?

(6) What obligation and responsibility (perceived or real) do service organizations have towards members of the host community?

(7) Is there any evidence to suggest that the history and makeup of the site-host neighbourhoods is a factor in how these housing projects were received by area residents (cf. Keith and Pile, 1993)? 
Although several dimensions of these questions have already been discussed above, they will be revisited in the context of two cases where supportive housing experienced some level of community opposition. The actions of residents and service providers in these instances, and the extent to which community engagement techniques were successful, will be discussed.

Recall that designating a site-conflict as a case of "NIMBY" is not without its criticisms. The term has been used so freely that Gibson (2005) recently advocated for the designation to be removed from all discussions of social service facility-siting on the premise that an ideal "rational", NIMBY-free society is unattainable. He argues, the more that service providers attempt to create this environment, the less effective their interactions with the public will be. Gibson (2005) claims it is actually in the contested spaces and arguments that the way is paved for a more democratic siting-process. In a manner of speaking, the next chapter will test this premise with an outline of the theoretical foundations of ethical communication. In particular, the works of Habermas, Buber, and Bohm will be used to isolate several ideal characteristics of intergroup dialogue and their potential application to resolve differences in real world contexts. Their philosophies are tempered with some of the literature on consultation practices. In the third chapter, the method of analysis is described in detail. The rationale behind the choice of methods is also commented on, with a brief overview of the qualitative research strategies of case study analysis and semi-structured interviewing. In the fourth chapter, the case studies are outlined in detail. Background information is given on the neighbourhoods in which these housing projects are located, which is used 
to situate each project in its particular context. Findings from the interview analysis are also presented here, which reveals how dialogue was used, its importance, and ways that it could be improved upon.

Finally, the fifth chapter summarizes the major findings and offers some concluding remarks looking forward. 


\section{Chapter 2}

\section{THEORETICAL FRAMEWORK}

When I meet a person I am not concerned with their opinions; I am concerned with the person.

-Martin Buber

Ethics, too, are nothing but reverence for life. This is what gives me the fundamental principle of morality, namely, that good consists in maintaining, promoting, and enhancing life, and that destroying, injuring, and limiting life are evil.

- Albert Schweitzer, Civilization and Ethics (1949)

\subsection{Introduction}

The term "dialogue" is used to denote an ideal form of discussion, especially in attempts to resolve differences, break down social barriers (e.g. stigma, bias), and to reach consensus on an issue; yet the dialogic process is much more complex than the simple desire to have symmetrical communication. Anderson, Baxter and Cissna (2004) write, "Understanding the potential for dialogue complicates any study of communication, because it necessarily widens our conversation about value, ethics, relation, reflexivity, mutually engaged performance, community, and responsibility," (p. 1); nevertheless, reflecting on the place of dialogue in site disputes is not only important, it is necessary.

In the previous chapter, we saw that NIMBYism is present in many land-use conflicts and is inextricably tied into moral and legal debates about one's right to have a say in decisions that affect them; this is an attitude that is often attributed to democratic principles that favour individual over group rights. In this chapter, these ideas will be revisited within a theoretical framework anchored by a discussion of the philosophic ideals of dialogue, and within the broader domain of communication ethics. It will be 
argued that open dialogue with another individual, or with a group of individuals, involves a set of ideals rarely attainable in regular communication efforts; even so, Martin Buber's concept of the "I-Thou" relationship and Jürgen Habermas' theory of "communicative action" lay the foundation of an ethic of [dialogic] communication that should be strived for if intergroup understanding is to be attained. Buber and Habermas' works are complemented by David Bohm's theory of dialogue. Bohm recommended that dialogue take place between large groups of individuals (Wreme, 1999, p.7) and for this reason, his dialogic principles have been discussed in relation to organizations and in institutional settings ${ }^{1}$ (e.g. Ellinor and Gerard, 1998; Wreme, 1999). With this in mind, Bohm's work provides a reasonable framework upon which to extend Buber and Habermas' more theoretical undertakings. Taken together, these theorists expound the potentials for meaningful dialogue and interaction; potentials which are often overlooked, or not even attempted, in common usage due to a number of factors. A final section will consider the place of consultation as an accepted practice aimed at eliminating or reducing conflict. Where consultation intersects with dialogic practices will be highlighted.

\footnotetext{
' Don Factor, who was a close friend of Bohm's, "doesn't much credit the organizational consulting approach to dialogue, and... likes the idea that the practice of dialogue might expose any tacit assumptions holding an organization together and [which could] thus limit its evolution" (Gryn, 2003, p. 98). Factor holds that dialogue "can wreck [an] organization" because it challenges their conservative nature. In dialogue, "people are going to look at their own presumptions and presuppositions [which is] likely to change everything" (Gryn, 2003, p. 98). Eventually organizations abandon dialogue in lieu of preserving themselves. Factor's position is not to say that dialogue cannot work, simply that it is often abandoned due to practical or self-preservation reasons. His wife, Amy Factor, cited an instance where the use of dialogue helped to resolve issues at a Danish hospital (Ibid.). The lesson is therefore that there must be a commitment to dialogue if it is to be successfully practiced, regardless of the setting it is practiced in.
} 


\subsection{Communication Ethics}

Ethics fills a space between laws and actions. While recognizing their similarities, scholar

Susan Bracci (2007) distinguishes communication ethics from moral philosophy saying that the former

is a more focused inquiry into what it means to be an ethical dialogical self in terms of the communicative process itself and the dialogical virtues required to participate well in that process. We ask 'Who can speak?' and then, 'How are specific patterns going to do a better or worse job of building understanding and, importantly, developing the will to engage difference, not only respectfully, but critically?' So, the questions focus on access, the quality of the language once that access is gained, and the dialogical virtues required to sustain engagement through deliberation (p. 23).

As Bracci explains, the ethical dimension of communication asks thoughtful and philosophical questions, but seeks practical responses. This chapter engages with the questions posed above, and attempts to answer them in relation to consultation methods surrounding residential facilities for special needs clients.

In many cases, NIMBYism results from a lack of consultation prior to actions being taken. ${ }^{2}$ Citizens report feeling steamrolled and believe their democratic right to have a say in proposed community changes has been compromised. There are also numerous fears to contend with about the potential ways that a new facility could impact the neighbourhood and the lives of residents. As an example, at the Carlington community meeting, several parents of young children were concerned about the quality of "neighbour" moving into the area—especially since Carlington already has a

\footnotetext{
${ }^{2}$ Even when consultation has been used, NIMBY attitudes can persist if the decisions made do not favour majority opinion. Having said that, NIMBY is almost guaranteed when consultation is absent; in these instances, calls for consultation are common and the lack thereof is pointed out as justification for project/development hostility.
} 
reputation for having many "high-risk" residents. In all instances, communication is central to dealing with concerns. Writing an issue off as unreasonable, improbable, or discriminatory simply labels the communicators (sometimes inaccurately) and creates a barrier towards understanding. In a sense, it allows the underlying issues to worsen. These issues are also complicated by expectations in dialogue and conversation parameters (e.g. we can discuss this, but not that). As the quote by Bracci above reminds us, an ethic of communication requires one to engage with difference: respectfully and critically; and this means on both sides of the issue.

\section{When Rights collide}

Lana Frado, a psychiatric survivor and the Executive Director of Sound Times - a member-driven consumer-survivor support group located in Toronto - indicates that it is much simpler to pay lip service to housing rights than it is to act on them. "Imagine," she writes, "having to stand up in your local community centre and having to argue for your right to move. But righteousness prevails and supportive housing is built" (Frado, 2006, p.20). Some credit the success of a project to good planning and communication, others to legal rights. Here, Frado equates the successful construction of supportive housing as a moral action.

The belief that housing is a basic human right is often part of the dialogue about new special needs housing projects. Service providers may argue for their legal right to build/move in and for the rights of their clients as human beings to be treated the same as everyone else. In contrast, area residents may argue for their right to know details about 
the project (why a site was chosen, who made the decision, was an assessment completed, etc.) and its progression; to choose who can move into their neighbourhood, and for reassurances about safety. It truly is a battle of right versus rights.

Amitai Etzioni lists several "rules of engagement" in dialogue. These "rules are designed to reflect-and reinforce--the tenet that people whose ideas conflict are still members of the same community" (quoted in Tannen, 1998, p. 288). One rule of particular interest to this study is his advice to "Talk less of rights, which are nonnegotiable, and more of needs, wants, and interests" (Ibid). Etzioni also advises speakers to avoid demonizing their ideological opponents since not every issue needs to be discussed. Questioning an opponent's moral convictions only impedes communication and it is difficult to recover from. The dichotomy between "yes, move in" or "no, not in my backyard!" is too rigid. Recall, if we consider opinions as placed upon a continuum, there are a lot of people who fall into that middle area. These individuals may approve of the project in theory, but require more information before they will actively support it; or they may be unsure about the project based on a minor concern that can be easily dealt with. Dialogue is a natural component of human interactions that should be mobilized to introduce and settle different appeals.

\subsection{What is dialogue? A brief outline of the term and its usage}

What exactly is dialogue? How can we distinguish it from other forms of communication? These are important questions since the act of dialogue is often assumed to be an ordinary part of conversation, particularly in group settings where the goal is 
intergroup agreement or acceptance. Even the most casual use of the term 'dialogue' invokes the thought of a deeper level of discussion than the simple exchange of words. For this reason, dialogue holds a privileged place in the study of communication, and for many years, philosophers have debated its merits and the level of control one has over its use.

The Oxford English Dictionary (1989) lists 'dialogue' as both a noun and a verb ("to dialogue'). This serves as a reminder that entering into dialogue is an act that requires effort, not simply desire. In both cases, 'dialogue' is defined in the same way that it is popularly understood, as "a conversation carried on between two or more persons" (OED, 1989; definition 1a); a "verbal interchange of thought..." (OED, 1989; def. 1b); or in political circles: "discussion or diplomatic contact between the representatives of two nations, groups, or the like...valuable or constructive discussion or communication" (OED, 1989; def. 1c). In all of these definitions, the emphasis is placed on discussion and conversation, but no details are given on how such a conversation should be carried out.

Markovà and Foppa (1990) define dialogue as "face-to-face interaction between two or more persons using a system of signs, is transparently dynamic" (p.1). They also stress the importance of immediacy. To them, dialogue is interactional. Interlocutors must respond to each other without delay (p. 6). This adds two more dimensions to our understanding of dialogue: that it must occur in the flesh, and that it must take place in real time. Thus, information passed along in writing between parties would not be considered dialogic by these standards. 
Discussion and dialogue is not the same thing. Ellinor and Gerard (1998) distinguish the two saying, "dialogue is about gathering or unfolding meaning that comes from many parts, while discussion is about breaking the whole down into many parts" (p. 20; see also p. 21-23). These authors emphasize the intention of the interaction as distinguishing between the two (p. 63-64). From this premise, they conceptualize a continuum of conversation much like the continuum of support/opposition mentioned earlier. If the "underlying dynamic in a meeting is to learn and expand what is known about something or to generate new perspectives from the views of many" (p. 20) then this exchange is towards the dialogic end. ${ }^{3}$ Dialogue is thus "divergent conversation" such that it opens up interactions and interpretations to multiple, possible solutions or answers; in contrast, discussion or debate is convergent. Its goal is to come to one best solution or answer (Ellinor \& Gerard, 1998, p. 22-23).

The root of the word dialogue is in the Greek "dia" meaning 'to pass through' and "logos" meaning logic (Ellinor \& Gerard, 1998, p. 19). In contemporary circles, dialogue has been extended to include exchanges between groups of all sizes. The definitive origin of the study of dialogue is unknown, although people frequently trace it back to Plato's "Socratic dialogues". ${ }^{4}$ The study of dialogue intensified in the 1970 s and today, it

\footnotetext{
${ }^{3}$ Kensen (2000) outlines three different types of democratic discourse- as if on a continuum- and each with separate outcomes. The first is a "closed discourse" where discussion is made more complex and the government jeopardizes criticism; the second is a "half-open dialogue" where either the goals or the process is fixed, and the aim is expediency in action. Public support is limited in this case and is only valued insofar as "it helps in making a decision" (p. 122). The third is "open dialogue," and like it implies, involves extensive public participation —either for effectiveness, knowledge, or that it comprises the ethical thing to do (See Kensen, pp. 122-123).

${ }^{4}$ Extending the term 'dialogue' to these Ancient Greek texts has been questioned since the figure of Socrates does not model many of the accepted markers of dialogue, such as non-judgment and openness. Socrates is accused of manipulating responses and delivering a monologue, rather than leaving his speaking partner the opportunity to answer (See for example: Birnbacher \& Krohn, 2004, p. 9-10). To his credit, Socrates' ability to focus on one topic/question for an extended period of time is an important element of modern dialogic practices (Ellinor \& Gerard, 1998, p. 31). Sally Goerner writes, "Socrates changed an earlier method of discourse - designed for arguing and winning an argument - into a method for learning.
} 
remains a key research area within communication studies and other related disciplines. In an era progressively characterized by racial and social diversity, a greater understanding and acceptance of others' humanity is even more important for working together, a process that begins with the study of dialogue.

\section{Speaking carefully-the craft of narratives as a foundation of dialogue}

"More often than not, we use expressions without thinking about their metaphoric implications. But that doesn't mean those implications are not influencing us" (Tannen, 1998, p. 13). Word choice is important and when a service provider says that they want to 'engage' the public, or have a 'dialogue' with them, it implies a certain amount of responsibility and openness to the process-one that they must be willing to give. Tannen (1998) warns, "[t]he terms in which we talk about something shape the way we think about it-and even what we see" (p. 14). To be clear, this caution works both ways. Residents who wish to have a dialogue with service providers must also be willing to listen, not only seek to be heard. The latter would consist of doing the same thing many accuse project organizers of doing: controlled, purposive one-way communication.

Boholm \& Löfstedt (2004) write that a successful facility siting process is “characterized by cooperation or dialogue between involved parties, [thus] leading to trust on all sides" (xiii). This posits that dialogue is foundational to trust, but perhaps trust is also foundational to dialogue? Tailoring messages to an audience is a common practice and a pillar of communication studies. Consultation is a soft-tactic that "involves asking 
the targets for input and ideas on proposed projects to get their support" (Berson \& Sosik, 2007, p. 679). Often overlooked is the use of "inspirational appeals" that "arouse targets' emotions and gain their commitment by appealing to their values and ideals" (Ibid, p. 679). In a sense, this is already a principle adopted by many service providers who work to humanize their clients by sharing personal stories about them - a practice that has been recommended by the OHRC (2008, Jul. 8; also see for example Kensen, 2000, p. 126127; NCHC, n.d., p. 7). While message-tailoring may seem like a rational communication strategy, intentionality is of primary importance; Habermas, Buber and Bohm all believe that any form of deception (even if it is simply strategic messaging) impedes dialogue. Dialogue is not about strategy, it is about openness; it is not about "winning," its aim is mutual understanding. Thus, the philosophical ideals of dialogue conflict with much of the practical advice regarding intergroup communication. In dialogue, unlike discussion, demands for efficiency and specific "ends" are deterred. In the next section, these ideals will be explored in more detail through the work of Habermas, Buber, and Bohm.

\subsection{Habermas and the theory of communicative action}

Habermas (1989) has written extensively on 'the public' and public deliberation. He is frequently associated with his notion of the bourgeois public sphere, which described the changing relationship between civil society and public authorities, where the former was emancipated when citizens began to take part in public affairs and to actively be involved in their own governance (Habermas, 1989; see also Allen, 2002b, p.101-102). ${ }^{5}$ "Civil

\footnotetext{
${ }^{5}$ Many have since criticized this view for its romanticized view of the public as a cohesive unit. Habermas failed to recognize that many citizen groups were historically excluded from public life such as women and
} 
society is the sphere wherein we form constitutive attachments. It is the sphere where intersubjective relationships are formed and we become the subjects that we are...Our institutions and value systems shape our consciousness and the very thought processes that we employ in the public sphere" (Farr, 2009, p. 134). In response to several criticisms about the lack of empirical support for this characterization of public deliberation, Habermas conceded that "the public sphere in modern societies must necessarily be conceived in a fairly abstract manner, as a structure of mediated communication rather than as a group of individuals who in principle could meet and discuss in a single space" (Outhwaite, 1996, p. 19).

Beginning in the 1970s, Habermas' work took a deliberate communicative turn when he wrote of "communicative rationality" and the speech-conditions necessary for a functional democracy:

Only communicative ethics guarantees the generality of admissible norms and the autonomy of acting subjects solely through the discursive redeemability of the validity claims with which norms appear. That is, generality is guaranteed in that the only norms that may claim generality are those on which everyone affected agrees (or would agree) without constraint if they enter into (or were to enter into) a process of discursive will-formation (Habermas, 1975, p.89; emphasis in original)

Allen (2002b) summarizes the ideal speech situation in which these norms are determined in three points: (1) everyone who is able to communicate can participate; (2) individuals can participate under the conditions that “... (a) All proposals can be questioned; (b) New proposals can be introduced; and (c) Attitudes, sincere beliefs, wishes, and needs can be

non-property owners. Nancy Fraser's "Rethinking the Public Sphere" (1992) is perhaps the most famous critique of Habermas' original notion of the public sphere. Fraser calls his articulation of historical processes "revisionist" and sets out to delineate a number of ways that low-class citizens, and especially women, were excluded from these public debates and discussions. In response, Habermas revisited his work and agreed with many of his critics. 
expressed" (p. 107); and (3) any form of compulsion (internally or externally-derived) is prohibited (p. 107). This last point has also been described elsewhere as discourse that is free of constraint (McCarthy, 1978/1981, p. 308). Thus, Habermas' conceptualization of the ideal speech situation emphasizes inclusiveness, freedom, and openness. McCarthy $(1978 / 1981)$ writes that the ideal speech situation is more interesting in terms of what it attempts to do, than in its theoretical expression which he calls unrealistic and unattainable in practice (p. 308-310); still, he believes this ideal "can serve as a guide for the institutionalization of discourse and as a critical standard against which every actually achieved consensus can be measured" (McCarthy, 1978/1981, p. 309). Stated another way, the dialogic principles of consensus - although rarely, if at all, attainable - should be strived for because they comprise the ethical and democratic measuring sticks by which to appraise communicative interactions between social actors.

Habermas holds that "the goal of coming to an understanding...is to bring about an agreement...that terminates in the intersubjective mutuality of reciprocal understanding, shared knowledge, mutual trust, and accord with one another" (Habermas, 1989; in Outewaite, 1996, p. 119; See also McGann, 2005, p. 20). The question of process nevertheless remains: how is agreement reached? Habermas' (1989) pathway to agreement is seemingly tautological: agreement is reached when understanding is reached; understanding is reached after agreement is reached. Habermas links rationality with speech acts believing that "through the logic of the best argument, agreement will be reached" (Allen, 2002b, p. 107). This is premised on the attainment of a "rational consensus" that is only arrived at through critical discussion from which truth claims may be derived. 
Truth claims are inevitably intertwined with claims of "rightness". Speech acts occur against a background of recognized values and norms, roles and institutions, rules and conventions. The relationship established (or 'offered') by the performative component of a given speech act can either 'fit' this normative background by actualizing an established pattern of relations or clash with it. Thus it is possible for any speech act to fail or to be challenged on the grounds that it is 'wrong' or 'inappropriate' when measured against accepted norms (McCarthy, 1978/1981, p. 311).

It must not be overlooked that "the claim to truth requires a stronger justification than our matter-of-fact agreement; it requires that we attach to our agreement the normative sense of being well grounded" (McCarthy, 1978/1981, p. 307). In other words, the best argument, and the one that leads to truth claims, is the rational argument. If there is any form of constraint, then the "the resultant agreement is open to the charge of being less than rational, of being the result not of the force of the better argument but, for example, of open or latent relations of domination, of conscious or unconscious strategic motivations" (McCarthy, 1978/1981, p. 308).

Habermas' blueprint to attain agreement and understanding conflicts with real world practices whereby intergroup conversations are oriented towards success. Habermas calls this "instrumental action" since it follows "technical rules of action" and is measured "by the efficiency of an intervention"; in social situations, these actions would be called "strategic action" since efforts are oriented towards "influencing the decision of a rational opponent" (Habermas, 1984; in Outhewaite, 1996, p. 160). In contrast, communicative action serves a higher communicative purpose. Rather than seeking to influence decisions to reach a desired end, communicative action occurs "whenever the actions of the agents involved are coordinated not through egocentric calculations of success but through acts of reaching understanding" (Habermas, 1984; in 
Outhewaite, 1996, p. 161). Here, the orientation is towards longer-term goals, not the efficient means to an end or coercion. Reaching understanding is often rearticulated as reaching agreement, but Habermas qualifies that "A communicatively achieved agreement has a rational basis; it cannot be imposed by either party....Agreement rests on common convictions. The speech act of one person succeeds only if the other accepts the offer contained in it by taking (however implicitly) a 'yes' or 'no' position on a validityclaim that is in principle criticizable" (Habermas, 1984; in Outhewaite, 1996, p. 162).

McGann (2005) makes a case for a strategic orientation towards communication since the ideal speech situation is "logically impossible" in relation to political decisionmaking. He writes, "unconditional consensus is not possible if a decision needs to be made, as is always the case in politics" (p. 4). Although Habermas' conception of the ideal speech situation may be salvaged for questions that remain in the theoretical domain (for example, unresolved moral questions that consider the validity of moral principles) McGann says that it does not hold for practical questions that ask "'What are we to do?" (2005, p. 7). In response, Habermas has "emphasized that the ideal speech situation is intended as a counterfactual" (ibid). ${ }^{6}$ McGann (2005) explains that Habermas has agreed in the past that "majority rule is legitimate in political institutions precisely because it represents a provisional and temporary stopping point [caesura] in the road to the ideal of consensus" (p. 7; See Habermas, Between Facts and Norms). As such, even if communication is not "perfect" by Habermasian standards, modern communication

\footnotetext{
${ }^{6}$ As cited in Baynes (1995) “...validity claims display a Janus-face: as claims they overshoot every context; at the same time, they must be both raised and accepted here and now if they are to support an agreement effective for coordination - for in this case there is no null-context. The universality of asserted rational acceptability enables validity claims to bear the load of a context-bound everyday practice" (p. 204).
} 
processes that seek, rather than screen out, dialogic ideals will always result in a positive contribution to an ethic of communication within actual operational contexts.

The value placed on democracies as the ideal form of public representation can be justified as either "the most efficient way to satisfy the wants and needs of members of society [instrumental justification]" or (2) that it "is good because of the intrinsic value of political participation or because of its ability to generate character among its citizens [intrinsic justification]" (Allen, 2002b, p. 100; based on Miller, 1983, p. 151). Allen (2002b) views Habermas' theories as operating in the space between these two ends. In his words, "Habermas's work is a struggle to find a compromise between these two worldviews - the attempt to maintain the functional aspects of the state, yet provide citizens with the ability to steer action through public opinion" (p. 100). Because there are forces at work to colonize the lifeworld using steering media—understood primarily as money or power-the steering impact of dialogic ideals tends to be undermined. While Habermas has written that "There are elementary social functions which can only be satisfied by means of communicative action," (Habermas, The Past as Future, p. 11 quoted in Outhwaite, 1996, p. 14), in addressing the question of steering media, he acknowledged that political/ functional systems that value efficiency "can sometimes serve aims of mutual understanding" (Hove, 2008, p. 244). As such, although communicative action (which leads to true dialogue) can pave the way for ameliorated group interactions and understanding; as well as representing a high moral and ethical standard of communication; accepting the fact that Habermas' ideal speech situation is not reflected in practice does not undercut Habermas' contributions to discussions on dialogue. The steering effects present in communication, as it is practiced, results in 
tangible outcomes that are important to encourage. In rejecting the binaries of strategic/ instrumentalist or dialogic as the only two options, this third path sees intersubjective relations as falling somewhere between the two sides. Those interactions that are modelled more closely after dialogue should be acknowledged and promoted.

Several scholars have written about the need to substantiate Habermas' critical theory with the work of other theorists. For example, Farr (2009) critiques Habermas' theory of discourse ethics for being "one-dimensional" (p. 152) and claims that his work fails to recognize that "norms are themselves produced by narratives which may be exclusionary" and that norms are created through "a narrative form of discourse, which is situated within a certain kind of community" (Farr, 2009, p. 153). Habermas does not interrogate the relationship between the development of identity, the formation of norms, and the creation of public spheres. As a result, the ability to discern "which norms are oppressive and how" (Ibid, p. 153) is diminished. Farr (2009) also argues that Habermas' discourse ethics is too deeply rooted in logic and rational dialogue and as such, it privileges norms that were developed and validated by the higher classes of Western societies. A similar criticism has been made by Fraser (1992) and Herbst (1994) who write that Habermas' public sphere "is a normative one" (Herbst, 1994, p. 14) that speaks about "what public space should be like" (Ibid.) (e.g. equality, inclusion) not about the reality of what public space actually is like (i.e. based on practices of exclusion, fragmentation, oppression). Those who had historically been excluded from this process (women, marginalized populations, and people of different races), who now enter into this dialogue, are bound by norms which may conflict with their own life worlds. In essence, the markers of a rational and valid dialogue are being evaluated outside of an 
examination of "systematically distorted communication" (Farr, 2009, p. 156). Recalling Bracci (2007), the question "Who can speak" is once again raised. In a dialogue, it is assumed that all parties have the same ability to speak and to share and to discover; in practice, this is not always the case. Still, as McCarthy (1978/1981) explained, Habermas' work should be seen as a guide or sensitizing framework. While it is true that communication is often distorted in practice, dialogue continues to aspire to a higher form of communication where norms do not exclude or oppress. What should be taken from Habermas is that dialogue and interactions oriented towards understanding profit from communal decision-making where all those affected by a decision have equal opportunity to contribute and to judge the legitimacy of debated norms. Changes can therefore be made from within. Acknowledging these conceptual shortcomings is a springboard towards improved interactions.

\subsection{Martin Buber on "real dialogue"}

Martin Buber (1878- 1965) is best known for his philosophy of dialogue and his writings on dialogic relationships. He has been called "a great philosopher, [and] a consummate writer" (Freidman, 2006, p. xi), as well as "the most profound and insightful formulator of the philosophy of dialogue" (Vogel, 1996, p. 51). During his lifetime, Buber wrote with keen insight on dialogue and his best-known work is related to this theme: I and Thou. ${ }^{7}$ In it, Buber argues that "the way of dialogue" is only possible if "we address real beings in their actual concrete situation, not treat them as ethnic stereotypes or remote abstractions-which are outside the realm of address and response" (Cain, 1996, p. 136).

\footnotetext{
${ }^{7}$ Translated from the German Ich und $D u(1923)$.
} 
Far from avoiding conflict, Buber's philosophy anticipates it, but maintains that only by recognizing the particularity of individuals and groups will it be possible to "stee[r] us away from the... dehumanization of our adversaries, of those who differ with us" (Cain, 1996, p. 136). Buber's philosophy of dialogue has important implications when applied to communication about socially-isolated groups.

\section{Relating to others: "I-Thou" versus "I-It"}

Buber's conceptualization of "I-It and I-Thou describe different modes of being-in-theworld, one instrumental and the other relational" (Murray, 2004, p. 337). There are several characteristics of an "I-Thou" relationship. They include: directness, total involvement, openness, mutuality, presentness, ineffability, and fragility ${ }^{8}$ (see Edwards, 1970, p. 6-22 for a good overview). Without going into detail, one can glean from this list a sense of what Buber envisioned was the pathway to true dialogue with another. Cursory discussions or debates would not qualify; rather, "real dialogue" means that both parties are fully present in the exchange, each with an open attitude and undetermined response. ${ }^{9}$ Johannesen (1996) explains, "In dialogue, although interested in being understood and perhaps in influencing, a communicator does not attempt to impose his or her own truth

\footnotetext{
${ }^{8}$ Johannesen (1996) adds to this list the following: honesty, spontaneity, frankness, lack of pretense, nonmanipulative intent, communion, intensity, and love (p. 68; cited in Murray, 2004, p. 336-337).

${ }^{9}$ Edwards (1970; p. 9-10) questions the incompatibility of freedom and determinism that Buber seems to advocate with his emphasis on openness. According to his interpretation of Buber, dialogue must be void of attempts to predict or control responses. In so doing, dialogic determinism is eliminated. While Edwards agrees to an extent, he writes that even if the attempt is not made, it does not mean that within a dialogue one partner could not have caused the other's response, nor does it mean that one could not have predicted the other's reaction if they had been inclined to. The implication here is that true dialogue cannot exist where one partner influences the other; Edwards is less inclined to believe that it is possible to have an open dialogue without impacting another response, but this does not mean that a true dialogue did not occur. Edwards believes that what is of importance is that a conscious attempt not be made to influence another. Edwards cautions against Buber's notion that all effects are oppressed by their cause; it is perhaps possible that an action is "both caused and free" (p. 10).
} 
or view on another.... The essential movement in dialogue, according to Buber, is turning toward, outgoing to, and reaching for the other," (p. 64-65; cited in Murray, 2004, p.336).

In a public lecture entitled Buber and Buberism (1970), Paul Edwards, a Professor of Philosophy at Brooklyn College, attempted to break down these two types of relationships (I-It and I-Thou). Unlike the more complex "I-Thou" relationship that Buber describes, the "I-It" relationship is quite easy to explain. Edwards describes it in this way: "Another person is an 'It' to me if I regard him or her simply as a means to the achievement of one or other of my goals" (p. 4). This is a form of monologic communication that "is characterized in varying degrees by self-centeredness, deception, pretense, display, appearance, artifice, using, profit, unapproachableness, seduction, domination, exploitation, and manipulation.... The monological communicator is interested in the personal attributes of receivers only to the extent that he or she can capitalize on those attributes to achieve selfish ends" (Johannesen, 1996, p. 68; cited in Murray, 2004, p. 336-337)

Cain (1996) applied Buber's work on dialogue to studies of difference. In particular, he contrasted Edward Said's imperialistic “othering” to Buber's own teachings. Cain explains,

Said wants us to see the other as same, not as other, in his generality as a human being, to see her in a sense as 'one of us.' Buber wants us to confirm the other in his particularity, in his difference [...] not in his partaking in a general, abstract humanity. The dialogic relation, for Buber, is one of 'I' or 'We-uns' in our own cultural and spiritual heritage to 'Thou' or 'You-all' in your particular culture and traditions. As opposed to the 'We' versus 'They' stance, which Said sees as the dominant response of Euro-American culture to the non-European peoples, the way of dialogue points to the meeting of two realities-two selves or two communities —each in its ownness, its concrete particularity (Cain, 1996, p. 136) 
Cain explains further, "The dialogical stance does not foreclose the possibility of conflict or division. In fact, it includes it as real possibility.... But it steers us away from the demonization of the other person, nation, religious community, or socio-political party, from the dehumanization of our adversaries, of those who differ with us" (p. 136). Too often we treat others that we encounter as an 'It' not as a 'Thou' to be met. We view the other as an abstraction, not his or her true being. Here again is a barrier to dialogue: abstract reductionism. When we proceed with this perception, "There is no interhuman meeting, no real dialogue between human beings, just barrages of abstract ideas or ideals, partisan slogans, condemnations, and fanaticisms which block off even the possibility of encounter," (Ibid, p. 137).

Given the historical exclusion of people who are homeless, mentally ill and those living with addictions, service providers tend to passionately promote their clients' interests as equal to other citizens. At times, their actions may be interpreted as attempts to circumvent the majority desires of the community. Building trust among two groups who vary ideologically is possible, but it takes reciprocal effort. Symbolic 'bridges' between groups require maintenance since distrust and suspicion remain close by. Cain (1996) writes, “...the price of dialogue is eternal vigilance and flexibility in the concrete situation" (p. 142).

Buber called listening "a critical communication function" (Anderson et al., 2004, p. 3) and explained that true dialogue must occur in real time. "In a real dialogue the other person has not only ears but a mouth and can say something that will surprise you. That is why real dialogue takes place in time. You cannot know the answer in advance..." (Friedman, 1996, p. 19). Having a set goal of what should happen is a 
problem. If you already know what you want, then all of your communication is going to be oriented towards getting others to agree with you. The question then becomes, what is lost in these interactions? I would argue that voices become silenced because dialogue cannot be had when one already anticipates another's responses and strategizes accordingly. Recall the point above about imposition. An individual can anticipate speaking points, but should not force his or her point of view on others. He or she should listen and be willing to adapt their stance based on the information and points of view presented. In other words, be open to being influenced.

Foundational to the 'I-Thou' relationship is its concern with "reciprocity"- the 'I' and the 'Thou' "are interchangeable" (Murray, 2004, p. 338). Genuine dialogue is a relationship in which "each of the participants really has in mind the other or others in their present and particular being and turns to them with the intention of establishing a living mutual relation" (Buber, 1965, p. 19; cited in Murray, 2004, p. 337). But dialogue can only occur in the "unreflective action of dialogue" (Arnett, 2004, p. 85). Buber attends that "[m]onologic reflection upon the event of reciprocity destroys" it (Ibid.) and the connection is lost.

Levinas (1994) criticizes this notion of reciprocity. In its place, he insists on the asymmetry of dialogue. Unlike Buber, he sees "the Other ... [as] morally 'above' the self" (Murray, 2004, p. 338) and believes that we are each "responsible for the Other 'without requiring reciprocity"' (Levinas, 1994, p. 44; cited in Murray, 2004, p. 338). This is interesting as it speculates that dialogue is possible if only one individual engages with an Other. In spite of this difference, Murray (2004) proposes that Levinas and Buber do not diverge significantly in their overall views on dialogue. Although both Habermas and 
Buber discourage coercion or influence in dialogue, Levinas believes that a "rhetoric of disruption" 10 can be used to challenge strongly-held ideologies or stereotypes and that it can be disruptive without being adversarial. A rhetoric of disruption can be used as a pathway to dialogue, however such "a dialogue towards ethics-requires both a rhetoric of disruption and a rhetoric of supplication" (Murray, 2004, p. 342) the latter meaning a rhetoric “designed to solicit and empower the Other's voice through the creation and maintenance of a communicative environment conducive to that announcement" (p. 343). Yet, to be effective, active listening is encouraged and even necessary. Thus, Murray (2004) concedes that reciprocity is needed, but it is not always symmetrical. Sometimes all that dialogic reciprocity needs is "the graciousness to accept" (Murray, 2004, p.343). It is also important to not lose sight of the fact that

one is in turn the Other's Other...So while the ethical summons to respond, which is announced in the Other's face, calls upon one to practice a rhetoric of supplication and to open oneself to the Other's disruptive rhetoric, one too deserves justice. And so, one's own face similarly calls upon one's neighbor to be open to one's plea for justice and to seek one out in dialogue. Hence a full dialogic relationship consists of four distinct rhetorics: the rhetorics of disruption of Other and self and the rhetorics of supplication of self and Other" (Murray, 2004, p. 345).

Without meaning to complicate the study of dialogue further, Murray's combination of Buber and Levinas' thinking reveals an important element of dialogue that has repercussions in the study to follow. Levinas' amendment "means that one's obligation to the Other includes the effort to make him or her a better person, to make him or her conscious of other people's pain, to make him or her fully human” (Murray, 2004, p. 346). With this higher, moralistic goal in mind, purposeful challenges to firmly-held beliefs become acceptable.

\footnotetext{
${ }^{10}$ A rhetoric of disruption "advances 'specific moral positions' as it attempts to 'alter a person's values or behaviors"” (Chase, 2000, p.1-2 in Murray, 2004, p. 340).
} 


\subsection{David Bohm: the Dimensions of Dialogue}

Dialogue is an inherent part of human interactions; still it is difficult to understand. This likely stems from a difficulty to apply dialogue empirically. Many have been puzzled by dialogue and its transcendent possibilities, and apart from openness and inclusivity, the boundaries and limitations of dialogue are frequently unknown. These frustrations were the inspiration for Mario Cayer's (2005) article about the qualities of Bohm's dialogue. In it, he divides Bohm's writings into five dimensions of dialogue and explains them in a way that helps to remove some of the ambiguities of the process. These dimensions are: (1) dialogue as conversation; (2) dialogue as inquiry; (3) dialogue as creating shared meaning; (4) dialogue as a participatory process; and (5) dialogue as cultural meditation. These analytical categories are by no means exclusive, and in fact overlap. Still, they are distinctive enough to warrant a discussion of each in turn. In what follows, each dimension will be summarized and the implications for dialogue in practice will be discussed. By supplementing Habermas and Buber's work with Bohm's articulation of the same phenomenon, the key attributes of dialogic interactions will be further illuminated and their practical utility will become clearer.

\section{Dialogue as...}

The first dimension of dialogue is as a conversation. This involves listening without judgement to the other. It also means that respect for others is vital. Like Buber, Bohm says that dialogue involves the giving of oneself, as the other gives to you (reciprocity); 
and like Levinas and Habermas, Cayer (2005) emphasizes intentionality, saying that this "is an essential element in the practice of dialogue. [Because] The participant gets involved in this dimension...not for the purpose of getting more content but rather to understand the experience of the other" (p. 174). Buber is less certain of the ability of a person to 'strike up a dialogue' and is more of the opinion that dialogue happens when several circumstances converge; it cannot be predicted or planned, nor can a time limit be placed upon it. This presents a challenge. Thus, when two groups meet with the goal of entering into a dialogue, this is not a certainty; nevertheless, openness to the potential for dialogue may make it more likely (e.g., suspending judgement).

A second dimension of Bohm's dialogue is 'dialogue as inquiry'. This does not involve the search for truth or validity claims (as Habermas has articulated) rather it is a search to understand our own biases, points of views, perceptions of reality; and to recognize how they condition our interactions (read: norms). As Wreme (1999) says, "We need to use our capacity for abstraction to deal with complex issues and deal with everyday life. However, we often forget our thoughts are abstractions and treat them as facts, forgetting how these opinions and facts were created in the first place," (p. 7). True dialogue means that individuals are open to the possibility of altering their view of reality. Dialogue is not possible if you maintain an unrelenting belief that you are already correct. If such is the case, you are no longer open to experiencing another's views. Dialogue calls for a willingness to learn, to understand, to challenge your assumptions, or to be transformed (See Cayer, 2005, p. 175-177). Friedman (1996) recounts an example where a therapist is speaking with a new client. Given his or her professional experience, parallels will inevitably be raised between this new client and past cases. Yet, a caution 
must be made not to overlook the uniqueness of the new case. A good therapist would listen and be open to the individual in front of him or her, and then based on what is heard, think to past encounters to determine where acquired knowledge may apply (p.24). This example overlaps several characteristics of dialogue, but is noted here to highlight the need for inclusivity as Buber defined it: not as empathy, "but experiencing the other side of the relationship... while at the same time remaining on your own side" (Ibid.).

The third and fourth dimensions of Bohm's dialogue are 'dialogue as the creation of shared meaning' and 'dialogue as a participatory practice'. The first is the very act of exposure to numerous points of view and openness in your consideration of them. You must let them penetrate deep into your mind and then decide if you are going to accept them at the risk of being transformed by the experience (See Cayer, 2005, p. 178-180). As others have articulated, dialogue is about inclusiveness and communication across a level playing field ${ }^{11}$ (e.g. dialogue as a participatory practice). For Bohm, participation involves more than access, but rather to be deeply embedded in the process (recall that dialogue involves the giving of oneself); the removal of perceptual barriers (such as observer/observed; dialogic roles) and thus the emergence of a new consciousness founded in this interaction (See Cayer, 2005, p. 181-183).

The final dimension is 'dialogue as collective meditation'. This means meeting the other with attentiveness "to what is without judging" (Cayer, 2005, p. 184). This overlaps with earlier aspects that discussed the lack of an agenda and freedom from "an ends". Bohm says, "This kind of dialogue, where people are not trying to do anything in particular, is a collective meditation" (Bohm \& Kelly, 1990, p. 463; cited in Cayer, 2005,

\footnotetext{
${ }^{11}$ Recall, Levinas did not believe that a level playing field (or reciprocity) was necessary. One must only be concerned with his or her openness and [ethical] treatment of The Other.
} 
p. 184). Collective meditation lacks restrictions and allows for deeper insight, creativity, and "a form of enlightenment" (Cayer, 2005, p. 185). According to Cayer (2005), this is what most distinguishes Bohm's views on dialogue from those articulated by Buber, for example. To Bohm, dialogue is a process of just being in open, directionless communication with another $^{12}$ (See Cayer, 2005, p. 184-187).

Table 2.1-The Five Dimensions of Dialogue (As articulated by Bohm)

\begin{tabular}{|l|l|}
\hline As CONVERSATION & $\begin{array}{l}\text { To talk freely, without agenda; to listen; to respect } \\
\text { the other; to seek understanding; intentionality; } \\
\text { interpersonal reasoning; reciprocity }\end{array}$ \\
\hline As INQUIRY & $\begin{array}{l}\text { Collective inquiry into beliefs, feelings; into the } \\
\text { content \& process of interactions; openness and } \\
\text { courage; the art of questioning; reflexivity; } \\
\text { unlearning in order to learn }\end{array}$ \\
\hline $\begin{array}{l}\text { As CREATING SHARED } \\
\text { MEANING }\end{array}$ & $\begin{array}{l}\text { Meaning circulates around and through participants; } \\
\text { diverse points of view; shared content of } \\
\text { consciousness; meaning as a form of being; accept } \\
\text { risk of being transformed (i.e. openness to change); } \\
\text { suspend judgment; }\end{array}$ \\
\hline As PARTICIPATORY PROCESS & $\begin{array}{l}\text { Absence of hierarchy; new way of looking at the } \\
\text { world, new form of consciousness; embedded in the } \\
\text { whole; perceive each other's interconnectedness; } \\
\text { decreased attachment to conceptual language; being } \\
\text { of each thing arises in participation }\end{array}$ \\
\hline As COLLECTIVE MEDITATION & $\begin{array}{l}\text { Accept present moment without attempt to alter } \\
\text { people, behaviours, situations, etc.; }\end{array}$ \\
\hline
\end{tabular}

Adapted from: Cayer (2005) The five dimensions of the practice of Bohm's dialogue. In Dialogue as a means of collective communication. B.Benathy \& P.M. Jenlink (Eds.) USA: Kluwer Academic/Plenum Publishers, 173-187.

It is clear from this analytical framework, that dialogue could easily be perceived as a luxury that requires a lot of time and effort; nevertheless, Habermas would not conceive of it thusly. Yes, dialogue lacks efficiency; it lacks direction. Conflict between groups,

\footnotetext{
${ }^{12}$ It should be noted that Cayer (2005) is aware of the contradictions, paradoxes and tensions in this model. He asks, "How can one reconcile the no-goal characteristic of meditation with the purposes of other dimensions, for example the creation of shared meaning, the surfacing of the collective assumptions, etc." (p. 187) but concludes this is why dialogue is so important. We must continue to practice dialogue, avoid attachment to our formulations of what it entails, and constantly be open to "our capacity to create" (Ibid).
} 
like the kind that will be discussed in the case studies detailed in chapter 4 , is premised on a hierarchy of decision-makers. Ultimately, someone must make the final decisions and it is often this very inequality in decision-making power that aggravates the issue. For Habermas though, dialogue is a natural component of human interactions and not something that can be separated or viewed as optional. Dialogue is the process through which norms are tested and established. Agreement and consensus are not only possible; they are the primary functions of these interactions. It is perhaps this popularized notion that dialogue is a luxury that undermines its seeming potential in group interactions. The more that it is considered an abstract concept that can only be used when timelines are not a factor, the more likely that service providers will justify its continued non-use, therefore resulting in an endemic failure to take advantage of the dialogic potential found in all human interactions.

While is it useful to list these ideal dialogic markers, Bohm's model, like others before it, is not capable of being strictly followed in most social situations because it is too restrictive, exacts impossible standards, and is ultimately inconsistent with actually existing forms of communication.

\subsection{Dialogue in Practice: Community Consultation \& Information Sessions}

Dialogue is not usually considered a key component of consultation or informationsharing processes even though it is sometimes assumed to be a natural element of them. The study that follows contrasts a traditional model of community engagement with a dialogic model of engagement. What the previous literature is meant to illuminate is the 
overall absence of dialogue in these discussions and to suggest, based in particular on Habermas, that prevailing dissatisfaction with consultation and information sessions (as practiced) is partly rooted in the fact that dialogic ideals and suppositions are being omitted by the overly determined conceptions of the communicative process popularly held by service providers.

\section{Consultation: Expectations \& Reality}

While reflecting on the backlash that a supported housing project for several local psychiatric patients received from residents of a Scottish community, Cowan (2003) found that "although consultation was relatively unproblematically (sic) defined in terms of its function, the nature of consultation was found to be more elusive" (p. 383). Those individuals who objected to how the consultation was conducted were unable to list specific expectations of what the consultation should have entailed; they were however able to list the actions that were taken that did not meet their wishes or expectations (Cowan, 2003).

VanNijnatten and Gregoire (n.d.) define consultation as "a process for actively seeking public input in decision-making involving two-way communication between government and citizen participants" (p. 206). This definition reflects the authors' research topic of communication between bureaucratic actors and the public; nevertheless, it can be broadened to reflect two-way communication between more than one group of actors. Restated to reflect this, consultation then becomes:

A process for actively seeking public input in decision-making involving two-way communication between a decision-maker and those who will be affected by their 
decision. The decision-maker could be a government representative, but is not necessarily so. They could also be a corporation, an expert, another community member etc., as long as they are the individual/group of individuals with authority over the decision in question ${ }^{13}$

This conceptualization of the term is purposefully simple. Consultations can vary widely in their application, yet the word still engenders an "active" process in which those in a position of authority (e.g. final decision-makers) seek input and feedback on decisions that have not yet been finalized. Always there is the implication that citizens can influence the process, but consultation does not commit to such. Input may be sought, but what the seeker does with that information is left open. Partly for this reason, consultation has earned a bad reputation. In some instances is it nothing more than tokenism and not the democratic process it is touted to be. As such, context is important; it is valuable to study how consultations are conducted in real settings, rather than to assume that every process that is given the title "consultation" unfolds in the same manner.

If done well, consultation has many advantages, such as setting the foundation for a positive long-term relationship with neighbourhood residents. Consultation, more than an information session, is open to the possibilities of dialogue. The process fulfills a perceived moral obligation to community residents and it may also provide a way to raise awareness of a project. Good consultations are about accessing local knowledge. Local residents know the strengths and weaknesses of their neighbourhood better than anyone else. Thus knowledge can be invaluable in relation to the smooth establishment of a facility (Cowan, 2003).

\footnotetext{
${ }^{13}$ This definition is a combination of VanNijnatten and Gregoire's previously cited one and my own additions and amendments.
} 
Consultation is also a valuable tool to planners. By engaging the community, developers decrease the risk of delays and opposition to developments. In some instances, consultation can speed up the process if it is done early enough. Royal (2008) writes, "Good consultation can sit neatly between informing and placating. Informing is essential. However, the placation gives areas for negotiation. This builds a feeling of partnership, an area where change can bring both sides benefit, which is at the heart of an effective consultation, and it is more likely to be acceptable" (p. 49). Organizers of public consultations should see the process as one of "elicitation, a mechanism for extracting relevant opinions and incorporating them into the process of government" (Lezaun \& Soneryd, 2007, p. 292). One weakness in the structure of these public forums is that the stated goal of "elicitation always depends on shaping, restraining and harnessing particular forms of sociality, often in accordance with theoretical models of what proper communications and citizenship ought to look like. These models," Lezaun and Soneryd (2007) argue, "are always in play—even when their ostensible purpose is to allow the public to frame the process in their own terms" (p. 292; emphasis original). Stakeholders tend to have predetermined views and are more likely to enter the consultative process with "their opinions...hardened, [and] their positions entrenched" (Ibid., p. 293). Conversely, the "general public" is seen as mobile, "as fundamentally moveable" (Ibid.). Consequently, in processes where the goal is opinion change, consensus, or acceptance; this mobility is seen as quite valuable. 


\section{Straddling the Line: Information-Sessions in the Public Process}

Information-sharing sessions are frequently used by organizations who want to inform the public about their project, but who wish to avoid the implication that their operation is up for discussion. As such, these sessions are understood to be different from consultation. While the communicative goals of information meetings may be clear in the minds of organizers, area residents do not always comprehend (or choose to acknowledge) the differences between receiving information on a project, and having the ability to influence the process. Different expectations of neighbourhood meetings often lead to conflict which puts organizers in a difficult position. A failure to partake in a form of community consultation is seen "as morally wrong" (Cowan, 2003, p. 384); nevertheless, in the case of service providers, they must also consider the right to privacy and equal treatment that their clients deserve.

The process of consultation is seen very differently by organizers and by those whom they consult (Lezaun and Soneryd, 2007, p. 292). A representative of Commsupport, a group whose efforts to establish a supportive living facility for psychiatric patients in Arlington, Scotland, was met with some backlash, explained: "I think that people do look for consultation and, I think, in our experience, what they're looking for is the right to veto. [...] I think what people have the right to is information, but not consultation" (cited in Cowan, 2003, p. 383). Based on this distinction, citizens are not necessarily entitled to consultation if it means that residents feel entitled "to choose their neighbours" (quoted in Cowan, 2003, p. 383). In fact, a failure to establish what the reasonable expectations of a community meeting are, may work counter- 
productively and actually increase public discord. The potential link between information meetings and the siting process was an important finding in Antos Arens's (1993) study of residences for the mentally-ill in New York. She found:

Many community members believe that they are invited to the meeting to express their opinion about whether or not a particular group home is suitable for their neighborhood and believe, further, albeit mistakenly, that they have a legal right to exclude mental health facilities from their communities if they don't want them. Once it becomes clear that, on this issue, it is not a matter of democratic process people feel tricked and betrayed and seek a target for their resentment (p. 242).

Like with consultations, organizers of information sessions want to mobilize the public, although less effort is placed on community input. In a sense, mobilization is desired, but the community is rendered passive. Their role, if any, is to sit and listen and to ask questions within the parameters of what is discussed. In contrast, consultations are by their very nature interactive; the role of the public, more involved. "There is a desire to generate narratives of change, even conversion, as the key utility of deliberation and the measure of its productivity; proof that the individuals who come out of the process are not exactly the same who entered it, that attitudes and opinion have been affected by the exchange of viewpoints" (Lezaun \& Soneryd, 2007, p. 293). Consultations then, are quite different than information sessions. Although the same material may be proffered to the crowd, what they are able to do with that information differs significantly. It is for this reason that the distinction between the two events must be clear. Like Antos Arens made clear, citizens who believe that they are going to be allowed to contribute to the process at an information session should have their expectations tempered. In fact, as we saw, information sessions cannot claim to be dialogues. Dialoguing is not simply the passing of select information back and forth, it is the giving of oneself wholly, the opening of 
oneself to be changed. The organizers of information sessions and consultations should be careful of labelling their interactions with the public as "dialogue" unless they are equally willing to be changed by outside input; one cannot expect the public to mobilize in favour of a project without having equal attention paid to their beliefs and concerns.

\subsection{Concluding Questions}

Lezaun \& Soneryd (2007, p. 294) remark that consultation distils multiple and varied individuals into one static group, "the public." In this sense, "the public's" opinion/ viewpoint can be outlined, but the nuanced responses are lost in translation. Unlike dialogue whose ultimate goal is a deeper understanding or another's viewpoint, the goal of consultation is mobilization; yet even if consultation is designed for the organizers' utility, they are still useful since the movements (actions, behaviours, opinions) of those consulted cannot be predicted. Rather than basing success solely on how accurate "the public" is represented, "we should also include among our metrics of political value the way in which [consultations] produce new articulations of the issues under deliberation, and the degree of mobility they generate—not only in those who are consulted, but also in those who consult" (p. 295). This expands our conceptualization of the success of intergroup conflict to include understanding on both sides of the issue and thus recalls Murray's (2004) reminder that we are "the Other's Other"; the impact of dialogue travels in both directions.

It has been emphasized numerous times in this chapter that the ideals of dialogic communication have not traditionally been transferred to mundane problem-solving 
situations, but it is possible to do so. In the case studies outlined in chapter 4 , the principles of dialogue discussed here (e.g. openness, ability to be influenced, nonjudgement etc.) will be evaluated in an instance of intergroup conflict over a special needs residential facility; one each in Ottawa and Toronto, Ontario. But first, the next chapter details the process that was used to collect empirical data on these two cases. 


\section{Chapter 3}

\section{RESEARCH METHODOLOGY}

\subsection{Introduction}

This chapter explains the approach that was used to collect research material and to recruit interview participants for this study. In addition to procedural information, this chapter highlights why the research design complements the stated research goals.

As previously outlined, this project theorizes about the active tension between philosophical ideals of intergroup communication, and the practical use of dialogue as a means to conflict-resolution in site-disputes arising from special needs residential facilities. To do so, the use of dialogue and consultation in two conflicts over such housing was studied. A media scan, document analysis and qualitative interviews were completed. The media coverage was used mostly as a source of information, but it also served as a barometer of public knowledge about the case study projects and general reactions to them. In addition, the thematic analysis of the news coverage helped to inform the interview questions (see Appendix B).

This study was also enriched by the analysis of several government documents on housing in Ontario, organizational guides about NIMBYism, and several other promotional materials about the case study projects (i.e. project brochures, handouts, and website write-ups); together these documents revealed the broader context within which these individual incidents were located. Lastly, interviews were done with key actors in the case study examples; these interviews comprised the bulk of the empirical data collected for this project. 
Interviews were completed in early 2010 in both Ottawa and Toronto, Ontario. They were predominantly with the service providers in charge of the case projects and with resident association members from the host-neighbourhoods. Additional interviews were done with other actors such as a news columnist, a local politician, ${ }^{1}$ other service providers, and community members. All of the interview participants were individuals with a unique perspective, who were able to speak to the key issues raised in these discussions: organizational strategies to inform the public about controversial housing projects, public reception to such projects (and to community engagement efforts), background on housing issues in the case study city/neighbourhood, as well as projectspecific questions.

Gathering information from several different sources helped to contextualize research findings. It was essential to gain an understanding of the facility-organizers' thought processes and how they approached their interactions with sceptical area residents. Equally important was an understanding of the public's receptiveness to each project, and to the information-sharing process. It was discovered early on in the datacollection phase that individuals on both sides of the issue had misperceptions about the other's intentions and/or made assumptions about each other's actions. As a result, interviews were adapted to investigate these issues in more depth. The goal then shifted from gauging general public knowledge and opinions about these projects, to a purposive study of the beliefs and reflections of several key interlocutors. These interviews served

\footnotetext{
${ }^{1}$ Only Gord Perks, Parkdale's local Councillor, was able to accept my invitation for an interview. Maria McRae, the Councillor for Carlington's Ward was contacted on several occasions, but attempts to schedule an interview were not successful. Jim Watson, then-Member of Provincial Parliament for Carlington and Provincial Housing Minister was unable to speak with me due to his busy schedule. Several months after this response from a staff member, it was announced that Watson would be resigning his post and running in the next Ottawa mayoral election scheduled for the fall (2010).
} 
to illuminate the realistic use of the theoretical concepts and models discussed in chapter

2. It should be noted that while the analysis looked at all of the data sources outlined above, the forthcoming findings and discussion section gives most prominence to the interview data.

\subsection{Qualitative Research Methods}

Methodological decisions used to carry out analysis reflect both practical and theoretical considerations. Some of the dominant factors in question include time and practical decisions (e.g. funds, access), the scope and nature of the study, and research objectives. Recalling the literature reviewed in the first chapter, numerous studies have been done on NIMBYism. Popular methods of analysis on this topic include the use of survey data (Walsh, Warland \& Smith, 1993; Takahashi \& Dear, 1997; Zippay and Lee, 2008), qualitative interviews (Antos Arens, 1993; Zippay, 1997; Hubbard, 2005) historical analysis of documents (Philo, 1987) and content analysis (Hubbard, 2005). Others have conducted focus group studies because of their capacity to reveal the deeper reasoning affecting individual beliefs and actions (Smith and Marquez, 2000; Galster et al. 2002). In many instances, more than one source of data is used. For example, Groothus and Miller's (1994) study of economic decision-making in NIMBY debates began with survey data, which was later converted for statistical analysis.

The purpose of qualitative research is to attempt to understand an event or occurrence in considerable detail and from the perspective of those being studied. An important element of qualitative research is that it "seeks depth rather than breadth," 
(Ambert et al., 1995, p. 880). It also focuses on a small sample, rather than studying a large representative group. For this study, the use of qualitative research methods was important given that the research objective was to acquire personal accounts of how intergroup communication efforts were perceived. To do so, two case studies were used since case studies permit the researcher to focus on the dominant actors relevant to a particular social situation (Orum, Feagin \& Sjoberg, 1991b, p. 274). Orum and Feagin (1991) describe the case study as "a method that relies on the examination of a single instance of a phenomenon to explore, often in rich detail, the hows and whys of a problem" (p. 121). Case study research dates back as far as 1929 when Helen and Robert Lynd studied particular questions tied to cities and communities (Ibid.). Like with other qualitative methodologies, these studies value detail and a holistic approach to datagathering; notably, through the use of several data sources. "The case study is usually seen as an instance of a broader phenomenon, as part of a larger set of parallel instances," (Orum and Feagin, 1991, p. 121).

Case studies in the social sciences are sometimes confused with the work of a historian. While a historian "seeks to describe the unique configuration of events and people" (Orum \& Feagin, 1991, p. 125), the social scientist goes a step further and uses the method of "imaginary analytic induction" - a phrase coined by Orum (1991), which means that the researcher must orient him or herself to "draw inferences of a more general sort...that will enable other observers to make comparisons with their cases, to prove or disprove assertions" (Orum \& Feagin, 1991, p. 125). Nevertheless, context and history still remain important elements for the social scientist. 
Orum, Feagin and Sjoberg (1991) list several advantages of case study research; it permits the study of a phenomenon up-close and in its natural environment, and the information is gathered from numerous sources and points of view over time (p.6). Ideally case studies consider an issue diachronically; however, this requires a minimum of several years of study and observation. Resultantly, time restrictions permitted only a snapshot account of the phenomenon, although numerous points of view are represented in this study.

\section{Qualitative Interviewing}

Semi-structured interviews were conducted for this research. Semi-structured interviewing is a less rigid means of collecting data. Unlike their structured counterpart, this method asks respondents a list of questions from an interview guide (see Appendix C). This method allows for the conversational and flexible nature of an informal interview to be preserved, but maintains some structure so that a set of pertinent topics/themes are covered. It is widely believed that semi-structured interviews "provide greater breadth and depth of information, [and] the opportunity to discover the respondent's experience and interpretation of reality, and access to people's ideas, thoughts, and memories in their own words rather than in the words of the researcher" (Blee \& Taylor, 2002, 92-93). In both of the cases considered here, the opposition was short-lived and news coverage of the projects was modest. This methodology fit the research aims since one of the benefits of semi-structured interviews is that they are "particularly useful in research on loosely organized, short-lived, or thinly documented 
social movements and in studies that explore issues for which it is difficult to gather data through structured questionnaires, field observation, or documentary analysis" (Blee and Taylor, 2002, p. 93). A slight drawback to this methodology is that its flexibility limits the researcher's "ability to make systematic comparisons between interview responses" (Blee \& Taylor, 2002, p. 93; see also Patton, 1987, pp. 110-117). Given my interest in individual perspectives on the same cases, potential challenges with the comparability of responses were not deemed a significant risk; in essence, all of the respondents would be

discussing one of two cases where similar themes were likely to be discussed. In addition, sixteen interviews was a manageable number of responses to evaluate. In fact, response variability was seen as a research finding in itself.

\subsection{Procedures: Data Collection}

\section{REVIEW OF NEWS COVERAGE}

A simplified thematic analysis of the news articles was conducted as a way to understand the information that was readily available to city residents. It also helped to map the range of spoken arguments in favour of, and opposed to, the housing sites. This provided insight on the nature of media representations on these two projects.

A selection of news articles about the case facilities was collected over the period 2009-2010. The sample consisted of news articles from two major newspapers and two local papers: The Toronto Star, The Ottawa Citizen, The News EMC (Ottawa), and the Parkdale Liberty-Villager (Toronto). The first three newspapers were searched using the 
Canadian Newsstand online database; however the Parkdale Liberty-Villager was not accessible through this catalogue, so it was accessed using LexisNexis Academic News database. The two community newspapers were included because of the local-focus of these cases. Preliminary research confirmed that media interest in site-conflicts that don't lead to aggressive, organized protest is short-lived and almost-completely localized. In order to generate a full and representative sample, both newspaper strata were used (See Appendix D).

\section{REVIEW OF KEY DOCUMENTS}

Several documents dealing primarily with NIMBYism and with housing in Ontario were collected and reviewed. They were evaluated in a manner similar to the research articles that were gathered and examined in the literature and theory chapters. Each document was read, sometimes more than once, and key points/arguments were culled from them. There was no formal method of analysis, which differed from how the interview transcripts were reviewed.

\section{QUALITATIVE INTERVIEWS}

This project was designed to study theoretical concepts at an empirical level. The goal was to analyze real cases of community engagement and then to compare them to some of the guiding principles of dialogue gleaned from the existing theory base. Interview 
data was an essential source to help inform an improved strategy to surmount/lessen community opposition — the "action agenda" goal of this research.

\section{a) Selection of Case Studies}

As stated in the introduction, the first case was decided at the community information session (which also served as the catalyst for this study). The second case was chosen later. Originally the plan was to investigate the Ottawa-case because of its controversial Managed Alcohol Program (MAP) $)^{2}$ alongside another MAP that currently operates out of Clairmont House in Hamilton, Ontario. The goal would have been to determine if this support program is a cause for considerable community-level concern. Thus, the focus would have been on communication relating to controversial harm reduction programs, rather than relating more broadly to housing. However, a preliminary investigation into the news coverage on Clairmont's MAP was unfruitful. The program had been very quietly introduced in 2006 and very few media articles were written about it. Unlike the Ottawa case that was unfolding in real time, the lapse in time for this second case created doubts about the availability of research materials and/or interview recruits who would have been able to recall their feelings and actions from four years earlier.

In late November 2009, while I was still contemplating the limitations of this second case, I was made aware of a Community Forum on Homelessness being hosted in Ottawa by the Alliance to End Homelessness. The keynote address was given by Terence

\footnotetext{
${ }^{2}$ Managed alcohol programs (MAP) are a spin-off of wet shelters whereby individuals with alcohol addiction are not required to abstain from alcohol altogether, but their consumption is monitored and limited to a set amount per hour. MAPs as a harm reduction program are not widely-known nor are they numerous. Only three of such programs currently exist in Canada: one each in Toronto, Ottawa and Hamilton, Ontario.
} 
Williams ${ }^{3}$ on behalf of PARC's ambassador program. Inspired by that talk, I decided to replace the Hamilton case with PARC's Edmond Place development. This necessitated a revision to my research focus to now assess communication about the housing development more generally, rather than to narrowly focus on the support program(s) being offered. In relation to the focus of this study, this change was quite minor. Like with The Oaks, PARC's Edmond Place was also mid-process when it was selected as a case. News coverage was relatively recent and ongoing, and PARC's community engagement strategy was still top of mind. This made data easier to collect and afforded interviews with individuals who were able to access their immediate feelings towards the project. Even more advantageous was the opportunity to study PARC's unique ambassador program and to compare it with the Shepherds of Good Hope's more traditional information-sharing process. This created a valuable opportunity to reflect on dialogue and consultation in new ways.

\section{b) Selection and Recruitment of Interview Participants}

Research participants were recruited for one-on-one interviews beginning in midDecember 2009. These interviews were scheduled between January and March, 2010. All of the interviews were audio recorded and transcribed by the researcher (see Appendix E).

Project participants were chosen based on their proximity to the issue (i.e. given their professional positions, expertise, or personal involvement with the focus of this

\footnotetext{
${ }^{3}$ Howard was accompanied by one of the ambassadors who also spoke about the project.
} 
study and/or the case studies outlined); in other words, key informants ${ }^{4}$ were sought using a purposive method (Patton, 1987). In the first stage of recruitment, an effort was made to recruit participants from all sides of the issue: service providers, community members, politicians and others who either advocate in favour of, or in opposition to, the initiatives in question. This was later revised for practical reasons. ${ }^{5}$ Initially, a request was sent out using publicly-accessible contact details (e-mail or telephone) to request each individual's participation in this study. If the prospective participant agreed to take part or indicated an interest in participating, a letter of information providing further details and a consent form was sent to them (see Appendix F). Once participation in the study was confirmed and the terms of the study were agreed to, a time and location for an interview was scheduled.

In total, sixteen separate interviews were conducted in English, one of which consisted of a group interview with 3 participants; therefore, 18 individuals were spoken to in a total of 16 interviews (See Appendix G). Table 3.1 below breaks down the interviews by individual affiliation and, as is evidenced and despite best efforts, very few community members agreed to be a part of this study. In addition to the interviews, several comments from a community member that were e-mailed to me, were included in the study after acquiring permission to do so.

\footnotetext{
${ }^{4}$ Defined by Patton (1987) as "people whose insights... prove particularly useful in helping an observer understand what is happening" (p. 95).

${ }^{5}$ Most notably, responses to a recruitment advertisement in a local newspaper proved fruitless (with the exception of one respondent). As such, the recruitment goals were modified to directly target people, rather than casting such a wide net. Some other limitations to this study are discussed in Chapter 5, Section 5.3
} 
Table 3.1-Interviews by Group

\begin{tabular}{|l|c|c|c|}
\hline Group & \multicolumn{3}{|c|}{ Number of Interviews } \\
\hline & CS1 $^{* *}$ & CS2 $^{* *}$ & TOTAL \\
\hline $\begin{array}{l}\text { Case Study-Affiliated Service Providers, Project } \\
\text { Partners and/or Participants }\end{array}$ & 3 & 3 & 6 \\
\hline $\begin{array}{l}\text { Community/Residents Association } \\
\text { Representatives }\end{array}$ & 2 & 1 & 3 \\
\hline Government Officials & 0 & 1 & 1 \\
\hline Local Columnist & 0 & 1 & 1 \\
\hline Community Members* & 1 & 1 & 2 \\
\hline Other Service Providers & 2 & 1 & 3 \\
\hline TOTAL: & 8 & 8 & $\mathbf{1 6}$ \\
\hline
\end{tabular}

*Please note that the two community members interviewed are both active members of their local community/ residents associations but were speaking to the researcher as private residents, not on behalf of, or necessarily reflective of, their respective associations' positions, beliefs or experiences.

** CS1= Case Study 1 (Ottawa); CS2= Case Study 2 (Toronto)

\section{- Ottawa Interviews}

The Ottawa interviews were scheduled based on the interviewees' availability. These took place at a mutually-agreed upon location ${ }^{6}$, which was often a local coffee shop or the participant's office. These interviews were scheduled in January and February, 2010. A total of eight interviews were conducted. These interviews ranged in length from approximately 30 minutes to over an hour; most interviews were about 45 minutes in length. Each interview was conducted face-to-face, with the exception of two. These two interviews were conducted via telephone at the request of the participant. All of the interview participants granted permission for the discussion to be audio-recorded.

\footnotetext{
${ }^{6}$ Priority was given to a locale convenient for the participant.
} 


\section{- Toronto Interviews}

These interviews were conducted in much the same way as the Ottawa-area ones, although in a more condensed period of time. All of the interviews were scheduled between February $24^{\text {th }}$ and February $27^{\text {th }}, 2010$, while I was in Toronto. Once again there was an exception: one participant was interviewed by telephone in early March, 2010 . This last individual agreed to speak with me after being referred by someone whom I had previously interviewed while in Toronto. The lengths of the Toronto interviews mirrored the ones in Ottawa. Again, permission was given to audio-record all of the interviews.

\subsection{Data Analysis}

After the data was collected, it was analysed. Research findings are presented in the next chapter. For the media scan, particular attention was paid to the dominant theme(s) and core arguments of each article. While reading over the news coverage, several analytical questions were considered:

1. What is this article about? What is the dominant theme?

2. What tone is used to describe the project? (negative, neutral, positive)

3. What arguments are offered in favour/in opposition to the project?

4. Is the project specifically named, or simply referred to?

Peripheral interest was paid to the cited sources and the context of their quotes. The newspaper the article came from, the date of the coverage and the type of article (letter, 
profile, front section news) were also noted to contextualize the scope of the coverage.

Rather than a formal write-up, these findings were integrated into the background information on the case studies and used to supplement and contextualize, where needed, the discussion of interview findings.

Like with the media scan, a number of questions were posed of the interviews. Looking at the transcripts as a group, as well as individually, an attempt was made to answer them. In their book emphasizing organizational dialogue as a better interactional method than standard communication models with built-in expectations and boundaries, Ellinor and Gerard (1998) ask this crucial question in order to determine a business meeting's potential for dialogue:

- Were people trying to learn from one another so that they could see what was going on from a larger perspective, or were they trying to justify, explain, or defend their personal perspective? (p. 20)

In deciding which questions to ask of the interview data, I kept coming back to this one. It seems to probe at the heart of the issue. Fittingly, this question was used as the guiding question in the analysis with one slight amendment - the placement of the following question in front of it: "What is this?" Strauss \& Corbin (1998) explain that the research process sometimes requires you "to stand back and ask 'What is this?' In asking this question, we begin, even if unconsciously, to draw on properties from what we do know to make comparisons" (p. 81). This question helps to orient the researcher as he or she begins his/her analysis.

Several secondary questions were also asked of the data:

1. Are there any identifiable barriers to message reception?

2. How is dialogue represented and understood? 
3. How was information about the project communicated to residents?

4. What importance is placed on neighbourhood history and the social context as having an impact on neighbourhood acceptance or opposition to these projects?

5. What was done well? What wasn't done well?

6. How was responsibility represented in these texts?

To begin, each transcript was read in its entirety. Then, a second reading of each transcript was done with these questions in mind. Notations were made beside passages that corresponded to each question and/or related themes and the relevant passages were compiled and divided into separate documents based on these themes. Once all of the information from the separate transcripts was combined thematically, each document was read and findings/ answers to these questions were summarized. Select passages were chosen for use in highlighting these findings. This process used "open coding" (Strauss \& Corbin, 1998) in the sense that although there were questions to guide the analysis, attention was paid to other themes that came out of the documents and separate categories were made accordingly.

\section{- A Note on Reliability \& Validity}

All qualitative studies face questions about their reliability because of the contextual nature of the research. Reliability is most often associated with the "replicability" of a study (Orum, Feagin, \& Sjoberg, 1991,p.17-19); qualitative analysis cannot be replicated in a systematic way. While efforts are made to remain objective and to "let the data speak 
for itself," the final decision on what was included in the analysis (in terms of highlighting issues), and how it was interpreted, remains highly subjective (Strauss \& Corbin, 1998, p. 18). One way to increase the reliability of a study is to study more than one case of the same type of incident within a similar time period. This "create[s] an intersubjective and comparative basis for observations and thereby helps insure that observations will be roughly identical from one observer to the next" (Orum, Feagin, \& Sjoberg, 1991, p. 18; see also Strauss \& Corbin, 1998, p. 44). Consequently, the decision to study and compare two cases of opposition to supportive housing in different cities contributes to increased reliability.

There are also questions about validity. Ultimately the researcher is not privy to the validity of the claims and statements/ recollections made by interview participants. For example, claims that several residents opposed the housing because they were prejudiced against the people living there cannot be verified. Opponents may have been discriminatory, but they could also have been acting on the objective basis of past experience, valid concerns, or a misunderstanding. In light of these questions, careful analysis of the data was conducted and cross-referenced with news media and other relevant documents in an attempt to place the findings within a larger context. As Strauss \& Corbin (1998) explain, it is important to "gather data on the same event or phenomenon in different ways such as interviews, observations, and written reports" (p.44). This, what Denzin $(1978,1989)$ refers to as the "triangulation of data," increases validity claims since findings from one source are not accepted at face value but are evaluated within the pool of data collected. 


\subsection{Concluding Remarks}

This chapter outlined the procedures that were used in the data collection and data analysis. It also spoke to the rationale behind methodological decisions, as well as some case-specific considerations and measures to increase reliability and validity. In the next chapter, the results of the analysis outlined here will be presented and discussed in detail. 


\section{Chapter 4}

\section{CASE STUDIES: LOCAL COMMUNITY ENGAGEMENT EFFORTS}

Communities are always different and dynamic. Major issues of concern vary from community to community.

-No Community Left Behind, (2005-07)

\subsection{Introduction}

As outlined in previous chapters, residents often question the decisions public officials make that affect their community, whether or not the decision-maker has any legal obligation to consult them. In general, fears tend to be inflated in the earliest stages of the development - especially when little information has yet been publicly shared. Cases of NIMBYism attest to the phenomenon's complicated roots in economic theory and personal perceptions of financial (and other) risks; in psychology, through interests in emotional reactions and fears to local changes, inclusion of certain groups, frustrations at not being heard, or a feeling that one's rights have been denied etc.; and in communications, with which this study is centrally concerned, that looks at both what people communicate (content), and how they engage in discussion and dialogue (process), as possible key factors in intergroup conflict. In many studies on the topic, it's link to 'place history' or, as I have called it, 'place context' is also included, although it is not always emphasized. Place context is also misleading in that it seems to simplify the various and conflicting processes at work in any individual or community response to a social project; specialized housing is no exception. Also, place context is not insurmountable and dialogue goes a long way to bridging these intersubjective gaps. 
The Shepherds of Good Hope and PARC had remarkably different approaches to community engagement. Although their respective projects differed, they shared similar goals with respect to seeking community support. And although the PARC project took a decidedly more dialogic and deliberative focus, I will argue that this approach may not have been possible in Ottawa; however, this does not mean that the Carlington project would not have benefitted from a more dialogic approach to community relations. It is simply a note of caution that approaches to communication are often determined by situational context and cannot be easily grafted into other times or places. Before elaborating further, it is necessary to profile each community and facility project. In the second half of this chapter, a discussion of the research findings drawn from the analysis of the interview data is completed.

\subsection{Neighbourhood Profiles}

Carlington has been described as "a community of communities"1 (Darwin, Personal interview, Jan. 13, 2010). The area is composed of different types of housing and people of varying socioeconomic backgrounds. Parkdale is similarly pluralistic. Both Parkdale and Carlington have a history of hosting service centres for individuals living with mental illness. For example, the Royal Ottawa Hospital, a mental health facility, has been located in Carlington since $1968^{2}$; and the Parkdale Activity Recreation Centre (PARC), the main service provider behind Edmond Place, has had a storefront presence in

\footnotetext{
${ }^{1}$ Ironically, this phrase was used by twice to describe Carlington by two different interview participants. ${ }^{2}$ What is now known as the Royal Ottawa Hospital (ROH) was first established in 1910 as a sanatorium for the treatment of tuberculosis. It was not until 1968 that its name was changed from the Royal Ottawa Sanatorium to the $\mathrm{ROH}$ to reflect its new role treating psychiatric patients.
} 
Parkdale for thirty years. Although the Shepherds of Good Hope, the lead agency in the Carlington program, lacks the same legacy in Carlington that PARC has in Parkdale, the Shepherds remains a respected organization that is very well-known for its charity work in Ottawa's downtown core. The need for housing in both Ottawa and Toronto was emphasized by all of the service providers that were interviewed. These facts help illuminate the reasoning behind the initial concerns and fears voiced by area residents in light of these developments, as well as how successfully these issues were dealt with over time.

\section{Carlington: "the forgotten-ed community in Ottawa"3}

Carlington is a subdivision of Ottawa, Ontario. Its boundaries are Carling Avenue (to the north), Kingston and Caldwell Avenues (to the south), Fisher Avenue (to the east) and Maitland (to the west). It is an area noted for its cultural and linguistic diversity (City of Ottawa 2001-2010a; CDF, 2008), as well as its low levels of civic engagement and below-average income levels (CDF, 2008; Ottawa Neighbourhood Study, 2009). Community Association members indicated that while there are some citizen groups, the area's transitory population and its diversity mean that the majority of residents exist quite apart from one another. Long-time Carlington residents have a history of feeling forgotten (Stevens, 2009), a theme that runs throughout this discussion. There was a clear impression that many citizens of Carlington saw themselves as a reticent public: "the 'hard to hear' constituencies that are deemed excluded from the often cacophonous public

\footnotetext{
${ }^{3}$ Cited in Kostiuk, M. (Jan. 29, 2010) Personal Interview.
} 
debates" (Lezaun \& Soneryd, 2007, p. 279). At a December 2009 meeting of Carlington residents, one attendee said: "'I think the problem is we're not being heard....Nobody's listening,"' (Stevens, 2009). Several residents feel that they alone carry the burden of the social problems that affect their area and that the City, and other relevant authorities, does little to help resolve those issues: open drug use and prostitution, lack of recreation services and food stores, traffic and housing issues (Stevens, 2009). Former Ottawa Police Chief Vern White even described Carlington as a busy neighbourhood for police (Drudi, 2009).

In 2008, Carlington was profiled and ranked very low compared to other areas in the city based on a combination of socio-economic, health and access indicators (Shufelt \& Rupert, 2008); this is not the first time that this has happened. In the 1980s, the City of Ottawa did a Carlington Area Study that featured interviews with key informants. The lead researcher Nadya Tarasoff "found "classic examples of the types of problems that arise when there is a high concentration of people with limited personal resources (in terms of money, education and mobility)...people who feel powerless and lack any experience in positively influencing their environment"' (Tanner, 1999, p. 34). More recently, the Ottawa Neighbourhood Study (2009) identified Carlington as within the lowest socio-economic quintile. ${ }^{4}$ The Carlington Community Association's (CCA) President, Michael Kostiuk ${ }^{5}$, believes that the low opinion many hold of Carlington is reflected in this most recent survey. "Because of that community survey that ranked

\footnotetext{
${ }^{4}$ Individual and household incomes in Carlington are lower than the city average and thirty percent of Carlington's population is below the Low Income Cut-Off (LICO)-a measure used to indicate that these families spend a large proportion of their earned income on the basic necessities of living (food, clothing, and shelter) (Canadian Council on Social Development, 1994; Statistics Canada, 2008).

${ }^{5}$ Please note that Mr. Kostiuk has since stepped down as CCA President, however at the time of this interview he held that title and so he will be referenced as the President throughout this document.
} 
Carlington so low, anecdotally my impression is that I think some of the service providers do not have a high opinion of people who live in Carlington" (Personal interview, Jan. 29, 2010). He adds, "You can't whitewash the whole community and say: It's only this kind of person, with this kind of education and they're not able to understand it" (Ibid). The municipal counsellor for the ward in which Carlington is located, Maria McRae, recently echoed this need to change public perception: "I am fed up with the negative connotations that are consistently being attributed to this community. It's not deserved...There are so many things that have happened in Carlington in the last five years, three years, two years, that the residents should be proud of and they are proud of" (quoted in Drudi, 24 Aug., 2009). While there have been some improvements, a lack of community identity and cohesive engagement remain ongoing issues (Kostiuk, personal interview, 29 Jan., 2010).

\section{Case \#1: The Oaks (Carlington; Ottawa, ON, Canada)}

In June 2009 a report in the Ottawa Citizen announced that $\$ 6$ million in government stimulus money was being allocated towards the purchase and renovation of The Cardinal Suites Hotel (later renamed The Oaks) on Merivale Road for "a pilot project aimed at getting people off the streets" (Rupert, 2009). No other details on the project were provided at this time. News coverage of facility plans continued throughout August and into late summer when finally a community meeting was held in early September. Many of the ideas and viewpoints that were voiced at this meeting extended past project- 
specific concerns and touched upon longstanding issues within the community, like those discussed above.

The Oaks is a housing facility whose residents include (1) members of a managed alcohol program (MAP), (2) seniors in an aging at home program, and (3) individuals living with mental illness whose health will be managed through the project's supportive living component. Initially, there were multiple misconceptions about the project and many community members reacted with hostility to rumours that drug users, prostitutes and other undesirable people would be moving into the neighbourhood (See Appendix H). Carlington residents were also upset with the way in which they were informed about the project - as a fait accompli, which they learned about in a news report and to which they had never been asked to comment or discuss. The community meeting in September 2009 seemed to clear up some of these issues and to ease the anger that some community members harboured towards the project. Representatives from all three of the main partnering associations in this initiative-the Shepherds of Good Hope, Ottawa Inner City Health and the Canadian Mental Health Association-Ottawa Branch-spoke to residents and explained the project and their role in relation to it. They also spoke of their hope that the project would be a positive addition to the community. Following this meeting, the organizations made a concerted effort to communicate more clearly and consistently with the community as the project progressed. Frequent updates were passed along to the Carlington Community Association (CCA), a non-profit residents group, who made the information available to residents through their website (www.carlingtoncommunity.org). ${ }^{6}$ At present, opposition to the project seems to have

${ }^{6}$ As of August $4^{\text {th }}, 2010$ the forum on the 'Supportive living facility on Merivale Road' registered 947 views. Granted some of these views were made by the researcher, city staff members and David Darwin 
waned, and in June 2010, The Oaks hosted a successful open house where community members were finally invited to tour the facilities and meet their new neighbours.

\section{Choosing a Site for 'The Oaks'}

Carlington was one of several sites considered for the Shepherds' project. Ultimately, Carlington was chosen over a building in the Glebe because it is "a better community for [program participants] to have, realistically for them to have friends," (Muckle, personal interview, Feb. 10, 2010). The buildings on Merivale Road were also valuable because they consisted of single units; the project fit within existing zoning requirements, and it hadn't previously been used as housing which meant that there would be no risk of displacement (Muckle, personal interview, Feb. 10, 2010). Anecdotally it was mentioned in two interviews that the hotel was being used for prostitution prior to its purchase for this housing project, so there was a broader social benefit to cleaning up the building and making it a community asset. Interestingly, this point was not brought up at the September community meeting.

Of note, Carlington has some experience hosting support services for disadvantaged individuals and special needs clients. For example, the Carlington Community Health Centre, a non-profit "community-based health and social service

who is in charge of posting these news pieces, this number still represents a higher number of views than most of the other forum threads. Only two other threads in the "General Discussions" forum received more views: 'Carlington History' -a forum begun in 2008 to discuss Carlington's history (with 1295 views); and 'Neighbourhood study' -a forum from 2008 documenting news coverage of an Ottawa neighbourhoods study that included the Carlington area (1026 views). In terms of number of responses, the Merivale facility is ranked first with 35 replies; the next highest was 13 from the 'Royal Ottawa Health Care Centre's sign' thread. The Merivale facility thread is also the only thread out of 38 forums to have 4 pages of posts (most of the other threads only have 1 page of information; only one has 2 pages). Although the number of distinct views cannot be determined, these numbers still give a crude measure of community interest in the topic. 
centre" (CCHC, 2010) whose services include a drop-in, counselling, support groups, advocacy and medical services (Ibid.); and the Royal Ottawa Hospital (ROH; also known as the Royal Ottawa Health Care Group or the Royal Ottawa Mental Health Centre)--a facility for the treatment of individuals from Eastern Ontario living with severe mental illness. Among the clinical programs that the $\mathrm{ROH}$ attends to is the management of substance use and concurrent disorders (Royal Ottawa Health Care Group, p.1).

\section{The Oaks: Traditional Community Engagement ${ }^{7}$}

While the benefits of engagement and consultation are often lauded, actually encouraging and providing feedback is another challenge. The Shepherds of Good Hope and their partnering organizations used a traditional community engagement model by holding an information session to discuss their project, rather than actively seeking feedback through a consultative strategy. The community session was followed-up with information updates in the spirit of transparency and open communication - organizational values that they profess to hold. The goal was to inform and to smooth community fears. Recalling chapter 2, information sessions tend to be designed less for feedback than for information dissemination and control. They tend to "foster an 'us-them' dynamic..." (HomeComing, 2005, p. 23) where project authorities and invited speakers are authoritative (read: a hierarchy of speakers), which can complicate efforts at generating discussion, let alone achieving true dialogue. Representatives of the project spoke to the neighbours as a courtesy and to clear up misperceptions-some of which were rooted in early news

\footnotetext{
${ }^{7}$ This is called a traditional method because of its common use. Open houses are a standard practice (See HomeComing, 2005, p. 23)
} 
reports. Plans to engage in a conversation with community residents were ultimately rushed due to the unexpected announcement of the funding for their project in the media prior to the building purchase actually being completed. This is an important detail. It is often taken for granted that project organizers are in control of the timing and content of the information that is sent out. In actuality, other actors such as media outlets or private citizens may prematurely set the ball in motion.

Like with many information sessions, the expectations of residents went beyond what the session organizers had planned. In this case, Carlington residents were seeking long-term assurances, a sense of being respected, an opportunity to contribute to future decision-making and a forum to complain about their lack of information up to that point. These expectations, and the volume of individuals present, did not make for an environment that was conducive to dialogue in any sort of ideal sense. First, Carlington residents were powerless to affect the decision. As Wendy Muckle, Executive Director of Ottawa Inner City Health explained, "In this case, they didn't have a choice. We were zoned for it, we had the money to buy it, there was really nothing that community residents could do to stop it, but having said that, part of why we wanted to move to that community was to be part of that community so if we're moving into a community that doesn't want us there, we have a problem" (personal interview, Feb. 10, 2010). This does not in and of itself mean that dialogue was impossible, but it would be significantly more difficult to foster. The hostility some showed towards the service providers and the feelings of anger and exclusion from the process, closed people off from attempts to understand each other without prejudgment. 
Mr. Kostiuk was under the impression that the organizers "stacked" the September meeting with people from outside the community "to basically cheerlead" the group (personal interview, Jan. 29, 2010), and although Muckle gave assurances that this did not happen (personal interview, Feb. 10, 2010), there were nevertheless individuals associated with the Shepherds' programs at the meeting, some of whom spoke during the question and comment period. Muckle said in an interview that "it's not [the job of the people in the program] to...deal with hostile community members who want to question their lifestyle and their health issues and ...their choices" (Ibid.). This position is in direct contrast to PARC's ambassador program that gave agency to their clients to go out into the community and do just that-deal with community reactions. The next section outlines PARC's project as well as profiles the neighbourhood in which it is located, Parkdale, Toronto. Like Carlington, which boasts a diverse group of residents, the socioeconomic makeup of Parkdale also varies widely.

\section{Parkdale: A history-rich and tension-filled neighbourhood}

Parkdale is bordered on the north by Bloor Street West; to the east by railway lines and Dufferin Street; on the south boundary by Lake Ontario and Roncesvalles Avenue on its western border (Parkdale Village BIA, "History”). Today, Parkdale has a reputation as a diverse and vibrant area within the City of Toronto (Parkdale Village BIA, "Home"). In the same breath, Toronto Star columnist Joe Fiorito referred to it as "one of the coolest neighbourhoods in the city in terms of accepting people who are different" and "a place where there's... a certain amount of tension" (Personal Interview, 2010, Feb. 26). 
Years ago, Parkdale was an "enclave of the wealthy" (Parkdale Village BIA, "History"; See also Slater, 2005, p. 1-2) but as time passed, the area changed. Like other communities, it was affected by the Depression of the 1930s as well as an increase in working-class tenants after the Second World War. Some people also credit the Gardiner Expressway, which was built in 1959, as having an effect on the affluence of the neighbourhood because it reduced easy access between South Parkdale and Lake Ontario. As such, the area could no longer be advertised "as a waterfront location" (Slater, 2005, p. 1-2). More recently, Parkdale has increased its efforts to gentrify the area (see Slater, 2005, p. 3-5; Stren, 2007; Doolittle, 2007, Dec. 20; Hatfield, 2008, Feb. 11). Still, this process is rife with tension. Slater (2005) found that while improvements and reinvestment in South Parkdale are necessary, they are at odds with the potential displacement of low-income groups (ex-psychiatric patients and new immigrants are two groups identified) and the affordable housing the neighbourhood is known for. Slater cautions that "unbridled gentrification is at the expense of a low-income population that has no say in these 'improvements' and for whom a very different kind of improvement is required" (p. 6). PARC (3 May, 2009) says the reality is that there is a persistent lack of housing options available to a rooming house population that consists mostly of single, middle-aged men. This fact is often ignored in the telling of the area's history (p. 6).

\section{A History of Mental Health Services in Parkdale}

In the 1970s, the Queen Street Mental Hospital was deinstitutionalized, which left many people with special needs seeking housing (Parkdale Village BIA, "History"). The 
Provincial government largely distanced itself from the responsibility of housing this group of individuals. As a result, existing infrastructure was converted into boarding homes, rooming houses, and so-called "bachelorette" apartments "resulting in one of the highest concentrations of such housing in the city" (Slater, 2005, p. 3), which became an ongoing source of tension and conflict between low-income tenants and neighbouring homeowners (Ibid., p. 5-6). The proximity to the Queen Street Centre for Addictions and Mental Health to Parkdale has been identified as "a crucial factor underpinning the changing social geography of South Parkdale [from the early 1970s onward]" (Slater, 2005, p. 2). The facility was the largest of its kind in the country and when the Provincial Government rallied "community-based care," a large influx of psychiatric patients migrated the short distance into South Parkdale although the area lacked sufficient housing for them all. This occurrence in the early 1980s "compound[ed] the effects of the 1979 closure of the nearby Lakeshore Provincial Psychiatric Hospital" (Ibid.).

For many years, this reflected badly on the area and the neighbourhood was variously described as a 'ghetto' and all-around unsafe place to be. "Instead of seen as being people in need, the deinstitutionalized were frequently portrayed as crazy, potentially dangerous transients, a blot on Toronto's reputation for liveability and harmony," (Slater, 2005, p. 3). Resident Warren Sheffer expressed the view that Parkdale "has an unfair share of such[social] housing" while another resident Sheila Lippiatt is quoted telling a reporter that the neighbourhood is "'overburdened" by its mentally ill population (Vincent, 2007, Apr. 18). 


\section{Neighbourhood PARC: A community fixture ${ }^{8}$}

The Parkdale-Activity Recreation Centre (PARC) was an idea conceived in 1977 (Talbot, 2010, Apr. 1) to assist adults living in neighbourhood rooming houses. It officially opened in 1980 . The idea was conceived by volunteers who remarked that Parkdale had a lot of adults with mental health and addictions struggles who needed daytime supports (Ibid.). PARC's "central focus is on low-income psychiatric survivors who have no place to go during the day," (City of Toronto, 1998-2010). Members can visit the Centre to receive a meal, to shower, to use a computer, for assistance from the staff, or just for fellowship with others. The Centre is designed to be an inclusive and welcoming atmosphere. PARC staff value dignity and respect and have been strong advocates for the equal and fair treatment of psychiatric survivors. PARC has also been a voice in the community, highlighting the need for more housing options. The Centre is well-respected for their work. In 2007, it was awarded an Access Award for Disability Issues (See City of Toronto, 1998-2010). In that same year, PARC was awarded the rights to redevelop the building at Dowling and Queen.

\section{Case \#2: Edmond Place (Parkdale, Toronto, ON)}

Edmond Place is a housing project under renovation on the corner of Dowling and Queen Streets. The building's namesake, Edmond Yu, fell through the cracks of the city's

\footnotetext{
${ }^{8}$ When I visited the Centre in March, I had difficulty locating the building from the street address. I ducked into a coffee shop to ask for directions and the man working at the counter said, "Ah, PARC--infamously discreet". This comment stayed with me and seemed to speak volumes about the work that they do.
} 
patchy mental health system. Edmond never received proper housing or support for his mental illness, factors which many attribute to his untimely death 12 years ago on a city bus after police shot him because of his suspicious behaviour. Mental health advocates say that the outcome may have been different had Edmond been able to locate stable housing and supports (Henderson, 2009).

\section{If these walls could talk: a brief history of 194 Dowling, Ave.}

The original building at 194 Dowling, Ave. opened in 1913 as luxury apartments, but as time passed and the neighbourhood changed, the building gradually deteriorated. By the 1990s, after multiple renovations and general neglect, the building was used as a boarding house. By that time, the number of apartments jumped from 12 to 55 (Balkissoon, 2010, Apr. 8). In 1998, a deliberately-set fire led to the death of two people and the displacement of 49 others as there was severe damage to the building (Hatfield, 2009, Oct. 21; Balkissoon, 2010, Apr. 8). Following this, the building remained empty for almost a decade until 2007 when the city of Toronto stepped in and revoked the rights to the building from its then-owner who had left the building in disrepair. Since the proprietor was unable to deliver a concrete plan to bring the building back up to standards, the city sought other proposals and eventually awarded the structure to PARC and Habitat Services for redevelopment. Renovations are still underway, with an expected move-in date in late 2010 . In total, the building will contain 29 units "for people with mental health and addiction histories" (CanadaHelps, n.d.). 
Victor Willis, the Executive Director of PARC, explains the project not simply as affordable housing, but as supportive housing, whereby residents will have access to supports and services from the PARC agency housed next-door, as well as others that have been "built into the development plan" (Willis, 2007, Apr. 20). Willis described the initial community feedback to PARC's proposal as negative. According to him, resident associations and other area agencies protested against the plans. In contrast, Dirk Townsend, the President of the Parkdale Residents Association (PRA) has suggested that this opposition may have been inflated. ${ }^{9}$ In his estimation, opposition significantly died down once PARC won the project bid. Regardless of the actual level of dissent, Willis' legal need to consult with the public (due to a rezoning requirement) and his personal belief that the public was apprehensive about this project, led to the PARC ambassador program. This program utilized what has long been recognized as PARC's key asset: its members. Several program participants were trained as project ambassadors to go into the community and directly meet and talk to the people who feared them. Their goal was to help clear up misconceptions about supportive housing in general, and this project in particular. Over a sustained period of time, this innovative community-relations approach proved successful and has been heralded as a model practice.

\footnotetext{
${ }^{9}$ This characterization of opposition was anecdotally shared by Willis in an interview dated Feb. 24, 2010. In an interview done on the same day with the Parkdale Residents Association (PRA) President Dirk Townsend, he pointed out that there was a news article that "played up the opposition" by quoting a man who was identified as a member of the PRA. Townsend remarked that a reporter who's not careful could mistakenly think that the PRA is a cohesive whole, when in fact anyone who walks into their office off the street and pays the fee can become a member. As such, this man's opinion did not reflect the opinion of the PRA as one unit, but it was presented as such. Townsend noted that the people at PARC and elsewhere who read that article were quite shocked, but again, this man's opinion was not an accurate barometer of resident opinion on the project. While the opposition may not have been as absolute or broad as previously stated, there was without a doubt some level of opposition. The ambassadors who were also interviewed that day echoed Willis and spoke of several "naysayers" they encountered who had reservations and fears about the project at the early stages of the redevelopment.
} 
In a presentation at the 2009 Community Forum on Homelessness held in Ottawa, Terence Williams, PARC's ambassador coordinator, outlined the success of the experiment, even entitling his talk 'From NIMBY to YIMBY' ${ }^{10}$ to signal new community acceptance. Williams' talk and subsequent interviews with PARC's Executive Director Victor Willis and several ambassadors, confirmed area residents' receptiveness to this unorthodox community engagement strategy. PARC ambassadors have since been asked to share their experience with other groups throughout the non-profit housing sector in Canada and there is great interest in the possibility that this approach could be successfully applied to other projects. Although Williams premised his talk on the ability to do so, this assumption will be challenged later in this chapter.

\section{PARC Ambassadors}

In all of their outreach material, PARC frames the project in a positive light. A community meeting invitation dating back to December 1, 2007, characterized the role of ambassadors as "sharing thoughts and feelings about the transformation of this neglected and derelict building [194 Dowling Avenue] into a remarkable community asset" (Edmond Place Community Liaison Committee, 2007, Dec. 1; emphasis added). PARC was very clear that its work would enrich the community, and given the history of the building, this was not difficult for the community to believe. Still, like with other housing projects there was opposition.

The Ambassador program was born of a desire to change these negative perceptions, not simply in the short-term (for the Committee of Adjustment hearing) but

\footnotetext{
${ }^{10}$ Not in my backyard (NIMBY)/ Yes in my Backyard (YIMBY)
} 
as part of a long-term goal to eliminate negative stereotypes about people with mental illness. The project also emphasized client-empowerment. Two of its stated goals were "To develop and utilize the lived experience, veracity, and social assets with the community so that PARC members can act as messengers and representatives for Edmond Place housing development" and "To develop local voices that can better represent the experiences of their community of interest instead of bringing consultation 'experts' in from outside the community" (PARC, May 3, 2009). Ironically, it was one of these so-called 'experts' that came up with this idea.

Paul Dowling...the consultant [...] met with us and put together the plan ...he sort of saw how PARC worked. He said listen, 'you know, you could hire me to do this but really, you may be in a better position to do this because you're already very well-engaged with the community; you have a very public presence, and so... that's probably your best bet.' And so in some ways, Paul is responsible for the development, or the initial idea, of the ambassador program because he kind of recognized that we had that... our ability to engage the community was very much within our hands (Willis, personal interview, Feb. 24, 2010).

It is worth noting that the reputation that PARC had already established in the area was a key component in the conception of this idea. The ambassador model also builds upon the philosophies of other "community based capacity building responses like: The Dream Team, [and] Voices from the Street" ${ }^{\prime 11}$ etc. (PARC, n.d., p. 2). The question that PARC tested with the ambassador program was: "Is it harder to voice discriminatory opinions when 'those' people are in the room, at your door, and part of the debate instead of having professionals and proxies representing them as clients?"12 By all estimations, this

\footnotetext{
${ }^{11}$ Both the Dream Team and Voices from the Street have an educational component where team members (i.e. people who have experienced homelessness, mental illness and/or addictions) give presentations/workshops in schools, board rooms, etc. on these issues - highlighting their own personal experiences and passing on their perspectives. These presentations are requested.

${ }^{12}$ This question was printed on a handout about Terence Williams' talk entitled "PARC ambassadorsFrom NIMBY to YIMBY" presented at the 2009 Community Forum on Homelessness.
} 
question can be answered in the affirmative. PARC expected difficulties in their rezoning application, but there were none. Charmaine Frado explains the short-term victory saying,

[...] we worked really, really hard training PARC members who have mental health issues to go out and talk to the community and educate the community, residents and businesses alike. And we overcame the stigma that existed around us building more affordable supportive housing, but it's still there it's still pervasive in our society (quoted in Talbot, 2010, Apr. 1)

Although some ambassadors dropped out of the program because of various stresses (psychological, emotional; see PARC, n.d., p. 3), many others enjoyed being part of a project that could potentially have ripple effects on low-income housing provision strategies across the city. "More often than not, the type of discrimination that was expressed against the development of PARC's new building grows out of xenophobia. If this is so, what better way to combat discrimination and foster understanding than by having the perceived outsiders come to meetings, businesses and front doors to provide information and answer questions?"' (PARC, May 3, 2009). While the Ottawa and Toronto projects were similar in their shared goal of successfully introducing a supportive living facility into a community, they diverged significantly in their community outreach approaches. Table 4.1 highlights some of the similarities and differences. 
Table 4.1 Community Introduction to Project: Carlington versus Parkdale

\begin{tabular}{|c|c|c|}
\hline NEIGHBOURHOOD & Carlington & Parkdale \\
\hline Project Title & The Oaks & Edmond Place \\
\hline $\begin{array}{l}\text { Community Engagement } \\
\text { Model }\end{array}$ & $\begin{array}{l}\text { Traditional: Information } \\
\text { session to inform the public } \\
\text { (after project announcement); } \\
\text { follow-up with in-progress } \\
\text { updates (through the } \\
\text { community association and } \\
\text { the local newspaper); open- } \\
\text { house for residents }\end{array}$ & $\begin{array}{l}\text { Dialogic: Long-term } \\
\text { ambassador project. Sought } \\
\text { and trained clients who went } \\
\text { out into the community to } \\
\text { discuss and advocate on } \\
\text { behalf of the project; } \\
\text { multiple information } \\
\text { sessions to hear and deal } \\
\text { with concerns; posters, } \\
\text { leaflets, and door-to-door } \\
\text { discussions within a } 500 \\
\text { meter radius of the property; } \\
\text { various other related } \\
\text { committees }{ }^{3}\end{array}$ \\
\hline Initia & $\begin{array}{l}\text { Mixed; vocally-mostly } \\
\text { negative }\end{array}$ & $\begin{array}{l}\text { Mixed: mostly negative } \\
\text { (anecdotally from PARC's } \\
\text { Executive Director); not } \\
\text { very much opposition after } \\
\text { PARC won RFP (according } \\
\text { to the Parkdale Residents } \\
\text { Association President) }\end{array}$ \\
\hline $\begin{array}{l}\text { Principle concerns voiced } \\
\text { by existing area residents }\end{array}$ & $\begin{array}{l}\text { Already too many problem- } \\
\text { groups in the neighbourhood; } \\
\text { concern/stigma surrounding } \\
\text { client-base; concerns about } \\
\text { housing values, safety; upset } \\
\text { over the process }\end{array}$ & $\begin{array}{l}\text { Too many consumer- } \\
\text { survivors already in the } \\
\text { neighbourhood; } \\
\text { concern/stigma surrounding } \\
\text { client-base; concerns about } \\
\text { housing values }\end{array}$ \\
\hline Result & $\begin{array}{l}\text { Community has (seemingly) } \\
\text { lost interest in the project; no } \\
\text { more concerns have been } \\
\text { voiced }\end{array}$ & $\begin{array}{l}\text { Immediate approval (without } \\
\text { any letters of complaint) at } \\
\text { the Committee of } \\
\text { Adjustment; anecdotally, } \\
\text { opposition is now almost } \\
\text { nonexistent }\end{array}$ \\
\hline
\end{tabular}

\footnotetext{
${ }^{13}$ It is true that there were some related Committees established relating to Edmond Place, nevertheless they won't be emphasized given that they were short-lived and the Ambassador model is of more interest to this study.
} 


\subsection{FINDINGS}

"In any planning system, anywhere in the world, consultation is king, or should be. Whatever the local planning regulations in any country you care to mention, ignoring the 'community view' is a sure fire way of making life extremely difficult"

-Royal (2008, p. 48)

\section{Barriers to communication}

There were many barriers to communication identified in the case studies. In Ottawa, the facility initially received bad publicity in the media, in large part due to an article that misrepresented the project. Additionally, news about the project was released prior to the building purchase being complete. Consequently, there was a lag in time from the public announcement of the project and when project organizers officially addressed it. A number of residents took this early non-communication as an indication of secrecy and a hidden agenda. Muckle said that this initial feedback actually had some unintended benefits: "it kind of helped us target what it was that we wanted to talk to people about and to anticipate some of the questions that people would have and also to kind of know who in the community we needed to be communicating with" (personal interview, Feb. 10,2010). Another challenge unique to the Ottawa project was the nature of their services. ${ }^{14}$ Harm reduction strategies are difficult to communicate because they run contrary to certain normative standards regarding addictions and support. Even when scientific evidence attests to their success (like it does with MAP; see Podymow et al.,

\footnotetext{
${ }^{14}$ To be fair, The Oaks is not only for people in the MAP. It also has a senior resident population and several individuals with CMHA portfolios. While there were some concerns voiced about the seniors (since it was stated at the community meeting that they are unable to live in city-run retirement homes because of their behaviour) the bulk of the anxiety about the project was directed at the MAP and its participants.
} 
2006), it is difficult to justify to a skeptical public the wisdom in providing controlled substances to addicts.

Supportive housing providers are encouraged to take a strong stance in protecting the rights of their clients at all costs. HomeComing Community Choice Coalition (2005), a group that was formed in Toronto in 2003 to promote the housing rights of individuals with mental illness, writes in their guide to service providers that they "are not asking a favour from the neighbours to allow [their] tenants to live next door" (p. 5). Barbara Hall of the OHRC echoes this stance (See Appendix I). While this is perfectly reasonable from a legal perspective, it is also adversarial and has the possibility of producing new communication problems by pitting existing residents against incoming clients. In the Ottawa case, some community residents deeply mistrusted the project partners' motives and perceived a lack of transparency on their part to be part of a hidden agenda. One Carlington resident expressed his anger saying, "The SOGH [Shepherds of Good Hope] and their programmers at Inner City Health...strategy is simple - work behind the scenes, do everything in secret then spring it on the community when it's fait accompli. Their socalled community comment was all after the fact, a total sham," (personal communication, Jan. 19, 2010). In Parkdale, concerns were voiced about the type of housing. Parkdale already has a lot of social housing, rooming, and boarding house units and some were concerned about what they described as the ghettoization of the area. Overall, the barriers to communicate in Parkdale were much less pronounced than in Carlington. Unlike Carlington, PARC's project was not 'sprung on' the community without warning because of the circumstances surrounding the building. The City of Toronto expropriated the building first, before PARC applied for and then won the bid 
for redevelopment. The politics of the property on Dowling also lent value to a lengthy public engagement strategy, and since PARC had to apply for rezoning, some form of consultation was legally required. Combined, these conditions necessitated a certain long term and open process in Toronto that were not required of the Ottawa-project. PARC's success can be attributed to a number of factors such as ongoing issues surrounding other neighbourhood buildings that detracted attention ${ }^{15}$ away from PARC and from $E d m o n d$ Place specifically. Also, unlike the Carlington facility, PARC had an established reputation in the community and an ongoing outreach orientation. While there was reportedly some opposition stemming from discrimination, Councillor Perks made it clear that discrimination would not be tolerated and these issues would not be considered legitimate concerns (personal interview, Feb. 26, 2010).

While Councillor Perks's stance is admirable, it is also problematic. It is a short jump between labelling neighbours' reaction to a housing project NIMBYism, and claiming that these same neighbours are discriminatory. "It is only discrimination if the opposition is based on the characteristics of the people who will be housed" (HomeComing, 2005, p. 9; emphasis original). This judgement is harder to validate when residents have not cast judgements on the people moving in, but rather on the process; on the organizations in charge of these projects. Unsubstantiated accusations that residents can only object to a housing project on the grounds of discrimination are insulting and isolate residents whose concerns are not of this nature from the project planning process. There was a perception among several residents of Carlington that Paul Soucie, Executive Director of the Shepherds of Good Hope, and Wendy Muckle had called

\footnotetext{
${ }^{15}$ In an interview, Councillor Perks recounted his support for the legal designation of the so-called "Pope Squat" (An abandoned building on King Street) as a rooming house as a peripheral issue that aroused public dissent towards him.
} 
residents discriminatory. "Right away two of them DeSouci [sic] and Wendy Muckle said that the community was discriminatory against them" (personal interview, Mar. 17, 2010). Again, this pitted residents against organizations and made them feel as though they had to defend themselves rather than seek to understand the project and its broader social value.

Finally, another barrier was fear. Fear is powerful because it "... is based on a whole set of what-ifs and the actual circumstances tend to be a lot less exciting..." (Gareth Park, personal interview, Feb. 8, 2010). Fears were expressed about property values, security, safety, crime rates and accountability. The Ottawa organizations felt that "...the issues that people raised tended to not actually have anything to do with us or the facility" (Muckle, personal interview, Feb. 10, 2010). Residents however, felt that these community issues had a place in the discussion because once the facility opened it would effectively become part of the community and as such, be responsible for helping to find solutions. Two residents, Bob Crout and Grace McLelland-Crout, wrote in an open letter posted on the Carlington Community Association's website that "It is critical that the Shepherds now consider themselves part of our neighbourhood, and therefore must want to take actions that show they want to be good neighbours" (2009).

Table 4.2-Barriers to Communicate (by area)

\begin{tabular}{|l|l|}
\hline \multicolumn{1}{|c|}{ Carlington } & \multicolumn{1}{|c|}{ Parkdale } \\
\hline $\begin{array}{l}\text { Misperceptions about the program/project } \\
\text { organizers; lack of trust }\end{array}$ & $\begin{array}{l}\text { Prejudice towards the type of facility } \\
\text { (special needs housing is considered to be } \\
\text { overrepresented in the area) }\end{array}$ \\
\hline $\begin{array}{l}\text { Fears (increased crime, impact on oneself, } \\
\text { house, community) }\end{array}$ & Fears of ghettoization \\
\hline Difficult program to explain or justify (MAP) & Political mistrust \\
\hline NIMBYism (the label, the attitude) & $\begin{array}{l}\text { Labels ("those people" i.e. PARC } \\
\text { members) }\end{array}$ \\
\hline $\begin{array}{l}\text { Anger \& feeling disrespected by project } \\
\text { partners (lack of esteem) }\end{array}$ & \\
\hline
\end{tabular}




\section{Advice for Supportive Housing Providers Moving Forward: Is YIMBY possible?}

Muckle subscribes to the belief that NIMBYism isn't something that can be avoided; it is a natural reaction. Still, she advocates for clear and open communication as the way to dispel some of the myths that fuel these negative reactions (personal interview, Feb. 10, 2010). Relationships must be built over time and, as she explains, you can’t “...tell people that they have to trust you because they're not going to trust you. Why should they? They don't know you," (personal interview, Feb. 10, 2010). This position is supported in the literature on NIMBYism. Lake (1993) writes,

Rather than automatically disparaging NIMBYism as irrational obstructionism, we should recognize it for what it is: an expression of people's needs and fears. As such, it is an expression that is no more or less rational and legitimate than the market mechanism and the profitability of capital. We can no more eliminate NIMBY than we can eliminate private development capital and the market mechanism. We are saddled with both sides of the dialectic (p. 91).

So what then are the opportunities for dialogue?

In an effort to prepare for opposition, project partners anticipate the responses of residents. Not only that, but they focus a lot of their efforts on expected negative reactions. Several interview respondents who were not service providers (i.e. community/ residents association members or private residents) spoke of their frustration at having their concerns framed in unintended ways. By their estimation, the implication was frequently made that they were discriminating against the population of individuals moving into their neighbourhood. Recalling Buber, true dialogue involves the meeting of two (or more) entities, free of judgement, expectation, or outcome. Habermas's ideal speech situation equally values such an open and non-coercive environment. In practice 
though, this formulation of dialogue clashes with the very premise of consultation. Consultation is used by organizations/ businesses/ governments with a stated goal of agreement. More than that, a decision must ultimately be made, and that decision is often made by the instigators of the consultation (i.e. those in charge of the project). While Buber, Habermas and Bohm all conceive of dialogue as essentially a symmetrical activity; in practice, groups in dialogue are rarely ever equals. A further complication is the conceptual utility of Buber, Habermas and Bohm for these case studies given that one of the interlocutors is an organization and the other is a group of individuals. Arguably their philosophies of dialogue are more relevant to smaller-groupings where interactions are more intimate. Is dialogue possible when "the Other" is unevenly represented (the many versus the one)? This is an important question that cannot be fully considered within the parameters of this study, but which would profit from further study on its own; nevertheless, for the purposes of this discussion, it is believed that the unequal strength on both sides of the issue is irrelevant. If anything, it is the environment and the process within which dialogue is attempted that is the problem.

Parkdale's ambassadors showed dialogic potential in their small and local interactions whereas Carlington suffered from the absence of such intimacy. Removing the titles of "project organizer" and "area resident" leaves both simply as actors in a network of communication. It is the forum that makes dialogue possible and large community meetings oriented towards consensus do not encourage true understanding of different perspectives and life experiences. For this reason, the North Carolina Housing Coalition (n.d.) advises smaller meetings as they are more manageable. They recommend that a maximum of a dozen people be in attendance (p. 14). Allen (2007) similarly 
advises using more creative outreach efforts such as door-to-door canvassing (e.g. Prince George, 2006, p. 1) or small house meetings (slide 17, slide 23; see also Allen, 2002a). What Parkdale did was effective, but can it be used in all contexts? Carlington, for example, would have profited from the discussions represented in such a door-to-door engagement strategy, but the lack of organizational history and the dynamics of the community meant that residents and organizers suffered from an inability to easily access such a process. If one adheres to Levinas' argument, ethical dialogue concerns itself with the individual and does not require reciprocal action. Thus, if I listen uncritically and leave myself open to change (perhaps because of a strong case put forth, as Habermas would argue), then dialogue can still occur even if the surrounding environment was hostile to the process. According to this logic, dialogue is an ethical practice that comes from within.

In any event, project organizers have a responsibility to communicate about their project to residents. Paul Soucie says that the absence of transparency and the attempt to quietly establish a program without anyone knowing it is "arrogant" (Personal interview, Jan. 6, 2010). ${ }^{16}$ Victor Willis also revealed by his effort to go above and beyond the consultative requirement of his project, that he values community dialogue. Yet interestingly, HomeComing (2005) states that during the consultation process "is not the

\footnotetext{
${ }^{16}$ Interestingly, in her study of the siting strategies of mental health agencies in Massachusetts, Zippay (1997) correlated advance notice of group housing developments (or the collaborative approach) with an increased likelihood of encountering neighbour opposition. In contrast, agencies that took an autonomous approach and limited their community engagement attracted less attention and therefore, less opposition. Still, she does note that those agencies that used a collaborative approach were also more likely to attempt to develop longer-term relationships with neighbours (through community-building activities). Recall that community-building is an important component of these projects, and in the case of Carlington, neighbourhood compatibility was a key reason for the site choice. It is also considered bad practice among many service providers, to enter a neighbourhood under stealth (a choice that Parkdale could not have made given their rezoning requirements). Once word gets out, as it likely would, it would be that much more difficult to build trust and goodwill with neighbours. It is a classic case of short-term versus long-term forethought.
} 
time to educate the public about mental illness, poverty or other issues" (p. 5). While education and issue-awareness are important parts of non-profit work, there is a time and place for it.

HomeComing (2005) advises that "[supportive housing providers] do not want to suggest that neighbours have the right to choose their neighbours. Nor do [they] want to violate [their] tenants' rights to privacy" (p. 5). There are a few things that are striking about this statement: firstly, it speaks to organizations' internal tensions about the protection of clients versus agency transparency; this ties into the second issue which is a limitation on possible topics of discussion. This does not bode well for dialogue and is actually counter to PARC's ambassador model that combined an education mandate with the Edmond Place planning approval process. Their success means that perhaps dialogue can be a part of a successful consultation. Again though, complete dialogue cannot be planned or predicted; it simply comes in fleeting moments of connection. To be sure, several factors can influence the likelihood of dialogue occurring (e.g. openness). The Ambassador strategy, perhaps more than traditional methods of community engagement, has the potential to at least put into practice some of the dialogic principles that were discussed in chapter 2. Councillor Perks remarks,

I think a project like Edmond's Place [sic] allows for a moment for people to feel like they're contributing positively to the lives of people that that they would otherwise feel frightened of and that's a huge cognitive leap for people and I think it allows them to walk down the street and see somebody who's dressed badly who probably needs a shower and is muttering or yelling, and feel an affinity for them that they wouldn't have if it wasn't for a project like Edmond's Place that they might have donated ten dollars to one time, or been to a public meeting to one time and thought, well this is a good thing. So, there's a very important cognitive step in seeing, in having empathy and seeing humanity in others that a project like Edmond's Place accomplishes (personal interview, Feb. 25, 2010). 
If people allow themselves to meet each other in difference, then perhaps such an ideal is possible. However, heeding Murray's (2004) words, dialogue travels in both directions. It is not enough for the community to be willing to listen, it is equally important for those doing the talking to open an ear. This study revealed that this is the area in which service providers can most improve. Despite the best of intentions, more attention is paid to their own messaging strategy to mobilize the public towards their point of view and/or support, than to hearing and acting on the concerns of residents. Given that the legal rights favour their side, seeking community feedback (and in many instances expertise) is given less priority, and in some cases, is overlooked altogether. To be fair, this takes time and resources that non-profit housing organizations may lack. Still, a fundamental element of intergroup conflict resolution is the feeling of being heard, considered and accepted. An imbalance in this process tends to breed apathy, anger and mistrust. One must only consider Carlington's persistent self-described identity as 'the forgotten community' to validate this claim.

One other issue of interest to this study was the context and history of the project environments. It is not that neighbourhood context is ignored altogether in the literature; it is actually acknowledged in many instances; the issue instead is whether these contexts are accepted as a legitimate basis for concern. The NIMBY guides almost all cite the concern that specialized housing tends to be concentrated in certain areas and that the proposed project either does not suit the area, or that the area already has an abundance of such projects. Without debating whether these statements are factually true, the dominant organizational discourse ignores these claims altogether. Instead, they call upon a higher sense of morality which serves to undermine these concerns. As such, citizens perceive 
certain topics to be off limits and/or fear being painted as discriminatory. In Carlington, the objections to The Oaks that were shared at the September community meeting, in subsequent interviews, and in online comments, were not all concerning the incoming residents themselves, but spoke to underlying issues and frustrations within the community. In Parkdale, Councillor Perks admitted that not all of the issues brought forth about PARC's renovation of the building on Dowling were discriminatory; a number of them were minor concerns that were easily resolvable within the regular planning process (personal interview, Feb. 25, 2010). Unfortunately, sometimes hasty judgements of the public's intentions by organizers, prematurely discredits otherwise valid questions.

Organizations need to do their homework. They need to familiarize themselves with the area. HomeComing (2005) suggests as a first step that housing providers "Find out how the community first responded to other supportive housing in the neighbourhood" (p. 17). They elaborate, "You cannot assume that your past successes will guarantee your project is well-received" (p. 17). This point may explain why the anecdotal evidence provided at the September community meeting in Carlington was not well-received. It was clear as an outside observer that residents wanted the organizational representatives to acknowledge the contextual differences (cultural, social, demographic, political) of Carlington; to equate a successful project in another part of the city as evidence that Carlington's residents' concerns were unwarranted was insensitive to this search for distinction. 


\section{Neighbourhood context and history in the planning process}

\section{a) Carlington}

One of the challenges is "... that there are some facilities... that are completely unresponsive to the community when issues arise so the assumption was, 'well you know, you're going to come in and you're going to be just like these people. [...] part of the NIMBYism is based on their past experience, if we want to change that we have to behave differently" (Muckle, personal interview, Feb. 10, 2010). The organization that has been unresponsive in the past is the Royal Ottawa Hospital (ROH). A long-time resident remarked that despite assurances of tight security, there have been many gaps in the hospital's services which recently contributed to the escape of a pedophile into the surrounding community (see Hurley, 2010; Spears, 2010; Ambroziak, 2010). This same resident was accused of being biased against the facility in her attempt to seek more information. She explains, "you have to know about something to make a judgment and I said, "I don't know enough to be against it-l'm asking" (personal interview, Mar. 17, 2010). Another long-time resident of Carlington had similar issues with the ROH and feared that the Shepherds of Good Hope would also operate their facility as "poorly and unprofessionally" as he believed the hospital had done (personal communication, Jan. 19, 2010). Thus, negative experiences have the potential to taint the reputation of new organizations. Unsurprisingly, Muckle felt that The Oaks got unfairly swept up into the discourse of concern about prostitution, drugs and other neighbourhood crime. In one news article a Carlington resident was quoted as saying, "[Carlington] has enough 
problems. We already have drugs and alcohol and prostitution. Now here comes another dumping ground.” (Sibley, Sept. 2, 2009).

Place context in Carlington is defined here in a negative way-as a cause of conflict or source of discrimination; overshadowed is the potential for a neighbourhood's context and history to pave the wave for positive community relations and a successful proposal bid and planning process. Using Parkdale as a model, there is some evidence to suggest that a neighbourhood's history could do just that.

\section{b) Parkdale}

As discussed throughout this chapter, Parkdale is both similar and strikingly different than Carlington. It is these differences that facilitated PARC's successful use of dialogue through their ambassador program.

Door-to-door canvassing about neighbourhood projects and developments is not unheard of. In fact, it has been acknowledged as an effective "'early outreach' strategy, [that should be] timed before rumours have begun to circulate" (HomeComing, 2005, p.22). What was unique about Parkdale's ambassador program was that rather than sending paid administrative staff door-to-door to speak on behalf of the clients who would benefit from their housing projects, clients spoke for themselves and for others like them. In so doing, they exhibited the face of the unknown "Other"; concurrently, they became the project "experts". As always, the trustworthiness of the speaker is important. PARC counted on the ambassadors surprising people with their candidness and their earnest support for the project. It is more difficult to discriminate against someone when 
you meet them face to face. "Stigma is the societal embodiment of disempowerment...it promotes expectations in both the public at large and many individual consumers that people with serious mental illness are incapable of the responsibilities commensurate with living independently" (Corrigan, 2002, p. 223). The consumer-survivor movement recognizes the valuable role people who have been diagnosed with mental illness can play in advocating for themselves and others with similar backgrounds (Frese and Davis, 1997). When consumer-survivors are given an active role in challenging mental health stigmas, it can be empowering and may lead to a quicker recovery and smoother community (re)integration (Corrigan, 2002). While many frame the ambassadors as a positive undertaking, there are some who question it. For example, one Dream Team member criticized the program saying,

To put it on the shoulders of the people requiring supportive housing,...to make the community amenable to it, is an unfair burden, although it's nice to see that they've actually achieved that with the help of staff time and an extra couple hundred thousand dollars. ...it's unfair to ask for them to go begging. It's like saying, "Well if you want people to allow Chinatown to extend past Spadina Avenue, then you're gonna have to have those Chinese people go door-to-door and explain to everyone that they're not harmful". I find that distasteful and repugnant (Lyle, Personal Interview, Feb. 26, 2010).

Instead he advocates for working through the legal process. Still, he credits Parkdale residents with accepting the project and changing their views. He partly ties this acceptance to the area's high number of consumer-survivor residents. Although it is impossible to determine a direct cause for the program's success, it is likely that some of the factors highlighted earlier in this chapter: PARC's history and reputation, the building's need for redevelopment, the demographics of the area; and the models employment of dialogic principles; all contributed to the program's ultimate success. 


\section{Exporting PARC's ambassador model: Would it work in other contexts?}

In his overview of business strategy literature Franklin (1996) cautions against the unexamined application of successful "concepts, insights and experiences which are gained in one firm/industry, to another...." (p. 213). This he calls "the fallacy of...intended and unintended association" (p. 212, emphasis in original) and he notes that many authors are guilty of implying that knowledge learned in one case can be transferred to another case/setting, usually without paying enough regard to the original context. This caution warrants being extended to PARC's ambassador model. At the 2009 Community Forum on Homelessness, PARC's ambassador program was introduced to a community of experts with the belief that this model could be widely adopted; but, it cannot be disregarded that reactions to Edmond Place were "over-determined by the historical context [of the building]" (Perks, personal interview, Feb. 26, 2010). So much so that Councillor Perks believed that without PARC's history in the community it would have been much more difficult for them to succeed. He said, "if a stranger had come in and tried ...this project I think it would have been a huge disaster" (Ibid.).

Without questioning the effectiveness of PARC's strategy, it may be premature to export this program to other neighbourhoods who lack the long term community presence and built-up goodwill that PARC has fostered over its thirty years in Parkdale. To extend this model of community engagement to other cities without proper consideration of each city's unique history and project context may be more damaging than effective. For example, recall that the ambassadors had extensive training and guidance throughout the process, which was further aided by PARC's organizational capacity and their many 
years of local engagement in other contexts and on other occasions. Most of the ambassadors also had some prior experience advocating for PARC and its programs and this proved extremely valuable in the initial orientation phase. All of this is not to say that PARC's dialogic approach should be disregarded; quite the opposite-it should be considered critically and then carefully adapted to complement specific situational contexts. Stated another way, although the ambassador model as it was used at PARC could probably not be used in the same manner in a neighbourhood like Carlington, the dialogic principles gathered from it can, and should be. These include its emphasis on openness, non-judgement, inclusivity, lack of pretence, and persistent communication over time which led to trust and perhaps some measure of understanding.

\subsection{Concluding remarks}

This chapter detailed the specific characteristics of Carlington and Parkdale that may have contributed to the choice and relative success of each project's community engagement models. PARC's ambassador model was innovative and dialogic (based on the theoretical standards presented in chapter 2 ). While its success was partly situationalbound and historically-determined, this context also served as a facilitator of dialogue. Importantly, The Oaks, unlike Edmond Place, was opened by organizations that lacked a similar history and familiarity with the neighbourhood that PARC had. Carlington's facility was opposed in part because of delayed notice of the project and perceptions that the project organizers were accusing neighbours of being discriminatory towards the facility residents. These perceptions only furthered neighbours' resolve that this project was being thrust upon the community. 
Although there were many factors that served as obstacles to dialogue in Carlington, the dialogic principles modelled by PARC's ambassador-driven outreach should be aspired to while remaining cognizant of the context of the neighbourhood in which they are operating. Door-to-door promotion of The Oaks by program clients would likely have done more damage and alienated area residents, but a method of engagement that fit the community—perhaps smaller group meetings that better encourage dialogue, or door-to-door information-sharing by the project organizers-would have potentially resolved the stated concerns with lack of trust and knowledge of the project. As such, a dialogic engagement model could have been effectively mobilized in Carlington; it would simply have required more effort, capacity and perhaps a different approach by project organizers who were stuck in a mode of engagement that valued information-sharing to the exclusion of community feedback and other principles based on reciprocity. Although many of them professed an intention to "open a dialogue", in practice these intentions fell short of ideals. In fact, many still equate information proliferation as dialogue, but this is incorrect and at its most basic, lacks the dynamism characteristic of the latter. While project organizers in Carlington failed to conceive and act on these potentials, Parkdale's ambassadors capitalized on them. 


\section{Chapter 5}

\section{CONCLUSIONS}

"We are wise to be skeptical about dialogue, but unwise to be dismissive" -Anderson, Baxter, \& Cissna ${ }^{l}$

\subsection{Revisiting the research questions}

This study looked at the role of dialogue in communication activities to resolve conflict arising from the establishment of special needs housing. Two different approaches to community engagement were looked at in two different cities. The first case study in Ottawa, Ontario revealed a traditional model of engagement where a town hall meeting was held and information was shared largely flowing in a unilateral direction from the project organizers to the citizens. In contrast, the approach used in Toronto, Ontario was more dialogic, where information flowed between parties on both sides of the issue (the informers and those being informed). The consultation literature has largely ignored the importance of dialogue. The contribution that this study makes is to emphasize its importance.

The following questions were asked of both cases:

(1) What ongoing barriers to successful communication exist between service organizations and community members?

(2) How do service organizations view public communication?

(3) What approaches can service organizations use to successfully communicate with citizens when introducing a controversial housing project into their neighbourhood?

(4) What additional value does dialogue bring to community consultation versus traditional one-way information-sharing?

\footnotetext{
${ }^{1}$ In Dialogue: Theorizing Difference in Communication Studies (2004), USA: Sage Publications, p. 16
} 
(5) What tensions exist between approaches to consultation that focus on achieving long-term consensus and those that emphasize short-term strategic gains?

(6) What obligation and responsibility (perceived or real) do service organizations have towards members of the host community?

(7) Is there any evidence to suggest that the history and makeup of the site-host neighbourhoods is a factor in how these housing projects were received by area residents (cf. Keith and Pile, 1993)?

As we saw in the previous chapter, barriers to communication persist between groups.

These barriers can be as simple or natural as prejudgments about an individual or group, or they can be complicated by expectations about the project and its long term impacts. In all instances, these barriers aggravate, if not outright cause, reactions that are so-labelled "NIMBY" sentiments. Often these barriers stem from procedural oversights. For example, information is not circulated quickly enough, organizations are not transparent enough, and residents are excluded from influencing decisions. Sometimes challenges present themselves because of fundamental differences in the prioritization of rights, fears, prejudices, and the labelling of opponents (e.g. if they don't want us here, they are discriminatory; they are NIMBYs). Whether these accusations are real or simply perceived; warranted or not; they block understanding and the attempt to even consider "the Other's" point of view.

Many believe that NIMBYism is not altogether unavoidable, although most admit that it can be tempered. Successful communication can aid in resolving issues quickly and efficiently and may lead to long-term benefits. It was found that the approach cannot be completely isolated from the neighbourhood context. PARC's ambassador model with its dialogic orientation was both innovative and successful, but a similar method of 
community engagement cannot be uncritically applied elsewhere. The existing community dynamic in Parkdale (i.e. PARC's long history and positive reputation in the area) contributed to the model's overwhelming success. ${ }^{2}$ These features of the model also provide insight into its success. First, it was transparent-the ambassadors went out and shared their story, without any pretence or organizational rhetoric of trying to "sell the project". Second, they engaged people where they were at and inquired into their opinions. They didn't push, but they were inquisitive and persistent with follow-up attempts, while remaining friendly and respectful. Thirdly, they were on even ground with those they spoke to. If anything, they were more vulnerable. All of these characteristics mimic the ideal principles of dialogue discussed in previous chapters. What PARC's strategy actually did was to reconceptualise consultation via dialogic commitments. The ambassadors sought feedback and they listened. While they had a goal, they did not have an agenda. PARC's model may be imperfect, but it does aspire to adopt (or at the very least, attempt) many of the characteristics of dialogue outlined in chapter 2.

\subsection{Buber, Habermas, \& Bohm: Is true dialogue possible and desirable?}

There is an inherent frustration in efforts to apply the philosophical principles of dialogue to actual examples of interactions. Intergroup conflict between local residents and an organization/business/political leader is fraught with problems from the start. For

\footnotetext{
${ }^{2}$ Success here is measured by the lack of complaints at the committee of adjustment and the absence of appeals to the OMB. There is no way of knowing whether the program's goals of changed attitudes was successful, although anecdotally, it appears that they were successful in these efforts as well.
} 
example, Habermas, Buber, and Bohm all describe dialogue as a symmetrical process, yet real world interactions are inherently political and hierarchical (in the sense that there are differences in decision-making power). This hearkens to similar frustrations with the democratic process, which in some ways also aspires to these philosophical, dialogic ideals, but which finds them equally unsustainable in practice. It is no wonder why NIMBY opponents often cite shortcomings in the democratic process. Buber and Bohm both say that dialogue cannot be planned, and this again is cause for question. Buber further contends that the instant that one reflects on his or her dialogue with another, the connection is lost. How then can one practice true dialogue ${ }^{3}$ with another (in an effort to gain understanding), without also using strategic means (which would effectively invalidate these dialogic attempts)?

The philosophical discourse about dialogue is perhaps most useful for what it offers: ideals. It is impossible to say that these principles will never line up and true dialogue can never occur in practice, but it is less likely to occur in interactions of the scale discussed in this study. Perhaps, as considered in a previous chapter, true dialogue is only possible within small circles where the "I" (apropos Buber) is clearly occupied by an individual, not a group of individuals (which you could argue, only serves to abstract an individual or set of opinions from the self). In sum, if one accepts that the ideals of true dialogue cannot be applied in full measure to oriented discussions-understood here as interactions organized with a specific purpose in mind-then these ideals can still be usefully re-evaluated as aspirational benchmarks.

The tensions between strategic communication and communicative action can only tenuously be resolved in site conflicts. The former involves instrumental means to

\footnotetext{
${ }^{3}$ Understood in a philosophical sense
} 
an end, while the latter rests on gaining understanding; where 'truth' comes out of the best argument, not the most coercive. Even with the best intentions, project organizers enter into conversation with the "Other" or set of "Others" with a purpose in mind: to inform, to educate, etc. Recall that Levinas (1994; Murray, 2004) does not believe that dialogue requires reciprocity. If the intention of dialogue is to better one's humanity and to persuade for a moral argument (which service providers are apt to do in their pleaded case for housing rights and the equal treatment of the vulnerable), then purposeful dialogue may still be valid. Nevertheless, one must be open to being changed and to being surprised in these interactions. This was predictably the one element of the dialogic process that was absent in both cases. This ideal is a fundamental challenge in dialogue/ consultation/ information sessions. Individuals on both sides of these debates join these processes with preconceived notions. Not all are negative, nevertheless, the stronger the opinion is prior to it being challenged, the more difficult it will be to change.

Thus, the goal of "understanding" each other in their own humanity, can be incorrectly framed as a luxury for people who are not on deadlines, lack limitless resources, or have a clear stake in the outcome. Without question, entering into true dialogue is time-consuming and it necessitates that decision makers make themselves vulnerable and that they give equal weight to questions, comments, arguments and concerns that they are not legally required to deal with (Carlington), or willing to do (Parkdale). Ultimately it comes down to the willingness of the participants, and the strength of their commitment to the course. If the priority is on efficiency, then dialogue will be limited. But recall the counterfactual nature of Habermas' theory. Even though steering processes are present and operational in everyday dialogue (be they embedded 
norms, opinions, strategy, money, power or something else), they do not justify the full abandonment of dialogue. Even in imperfect models, such as PARC's ambassador model which still, to some extent, limited the topics that were discussed and which profited extensively from the weighty support of the city Councillor who would not entertain concerns that he deemed discriminatory; what remains of value is the attempt to implement dialogic ideals. These efforts still produced positive benefits that should be encouraged.

On the whole, the barriers to communication were quite similar to issues that were identified in the literature. Both PARC and the project organizers in Ottawa operated with the best of intentions and an effort towards transparency. The short-cycle of these locational conflicts suggests that their efforts to assuage public fears must have aided to some extent, if we take seriously the reduction of media attention and any obvious or visible expressions of public discontent. Of course, it is possible that media silence does not mean that all of the pressing issues and concerns in the neighbourhood have been resolved, it may perhaps mean that they have been abandoned due to the belief that nothing more can be done. The fears, resentment, and anxiety that some residents expressed may still be present. This calls into question the potential repercussions for future projects and whether they will face increased challenges if these same concerns surface again. Many studies have shown that a well-maintained project can actually lead to improved community perceptions of similar projects, still there is no way of knowing what the outcome will be until it is tested 


\subsection{Some Methodological Limitations}

This research was undertaken in a fairly limited period of time. Ideally, these cases could have been studied at all points in the timeline: announcement of the project, meetings about the project, project construction, project completion, and follow-up. This constraint affected the possible range of study, and meant that analysis could only be done on a particular moment in the event timeline. Time also provided a challenge in another way. Initial complaints from the September, 2009 community meeting in Carlington seemed to dissipate quickly, if not disappear altogether. As such, recruiting interview participants was challenging and similar difficulties were experienced in Parkdale. As a result, broadrange recruitment was abandoned in the place of a targeted approach. Specific individuals believed to be of value to this study were approached directly.

These obstacles were not completely unforeseen for two reasons: (1) early investigation showed that the housing projects being studied lacked sustained interest by community members; and (2) there is an unavoidable recruitment bias in research of this nature whereby willing participants hold views on either of the far sides of the spectrum (strongly support or vehemently disagree with some aspect of the project). It was suspected that out of those who were likely to respond, the supporters may have seen no need to share their views given the green light-status of both facilities; and of those who were less supportive, fear of being misunderstood and/or labelled "discriminatory" may have outweighed their interest in contributing to this research. These suspicions were discussed more fully in the introduction (chapter 1) and later in the findings section (chapter 4). 


\subsection{Moving forward: The disallowed discussion (or how many are too many?)}

A recurring point of contention in the literature and interviews on social housing projects was the belief that certain areas already hosted too many of these units and it is important to spread them around the city. This argument is often pitted against the equal-rights doctrine that nobody has the right to determine who can live where. Ken MacLaren, the Director of Ottawa Inner City Ministries says that a large part of NIMBYism towards housing projects is "because [people think they] have the right to have the...freedom to be exclusive without consideration for other components of our society who want to be included [and] that's a fundamental problem," (personal interview, Feb. 4, 2010). Even so, one of the principles of dialogue is to be able to be open to all points of view and as Lake (1993) writes, "It is politically easier to castigate community opposition to affordable housing than to reexamine a political economy that perpetuates poverty so that we have to create places for poor people to live" (p.90).

Part of what makes Carlington and Parkdale ideal sites for supportive housing are the existing services in the area. People are also drawn to areas that are affordable and accessible by public transit and other services (HomeComing, 2005, p. 26). Yet, genuine dialogue about the concentration of supportive and affordable housing in any one area is generally disallowed on the basis that this is not a valid point of view. One long-time resident of Parkdale was particularly concerned with this. Jeffries casts himself as both "supportive and critically supportive" of Edmond Place (personal interview, Mar. 2, 2010). He explains saying that you can agree with the argument that people need housing and that housing is a right (which he does) yet by only engaging with these narrow 
arguments and this predetermined understanding of the issue, the types of discussions that can be had are limited. For example, asking the question: "Is there an optimal proportion [of these housing projects]? ...is considered heretical among the agencies' discourse" (Ibid.). The implications this has for dialogue is that it is at risk of "not taking in another voice, another point of view" (Jeffries, personal interview, Mar. 2, 2010). From a dialogic standpoint, even if one is morally in disagreement with an argument or point of view, as a partner in dialogue, an effort must be made to set aside these differences and attempt to meet each individual where he or she stands. As housing demands continue to rise, engaging in broader discussions and dialogue around these questions will become increasingly important.

\subsection{Final Thoughts}

Neveu (2002) evaluated the debate over a planned site for the treatment of hydrocarbon polluted soils from a slagheap between two French villages. She found that although residents generally thought well of the project, its usefulness, and had sufficient trust in the company proposing it "[w]hat they did not accept was that they were not given the possibility to fully intervene in a democratic debate concerning it, and that they were once again considered as moved only by specific selfish motivations" (p. 63). This led to her conclusion that there must be more consideration of "democratic opportunities for (local) citizens... [in the form of]... local public spheres" (p. 63). Put another way, it is important that residents' input and opinions be heard and considered in the decisionmaking process. Even if their views are 'value-laden', it does not mean that they lack legitimacy. Like Neveu, the process of community dialogue at the project site in 
Carlington suffered from exclusion in the process. In contrast, the Toronto process was much more interactive and resultantly, had more measurable success. In the future, service providers should heed Neveu's advice and seek for ways to encourage the creation and involvement of 'local public spheres' surrounding a project site, while still remaining cognizant of the particular dynamics of the neighbourhood in question.

I would like to end by quoting the Russian literary scholar, Mikhail Bakhtin, who wrote:

To be means to communicate dialogically. When dialogue ends, everything ends. Thus dialogue, by its very essence, cannot and must not come to an end.... All else is the means; dialogue is the end. A single voice ends nothing and resolves nothing. Two voices is the minimum for life, the minimum for being (Bakhtin, 1973, p. 252; cited in Nikulin, 1998, p. 395)

In our everyday interactions, we often take dialogue for granted. Dialogue is assessed as a luxury we can either afford (given time, money and other practical considerations) or it is something we pass up or ignore altogether. Yet, there exists the potential for dialogue in every human interaction. Whether we choose to enter into that dialogue reflects the value we place on those interactions and may also, as I have attempted to demonstrate with this research, be foundational to truly living as a community with mutual understanding and respect for difference. 


\section{References}

Alliance to End Homelessness. (2008, Jan-Dec). Experiencing Homelessness: Report on ENDING Homelessness in Ottawa. Retrieved from http://www.endhomelessnessottawa.ca/documents/2008ReportCardonEndingHomelessne ssinOttawa.pdf

Allen, M. (2002a). Opening the Door: Why not in Our Back Yard? Planning Commissioners Journal, 45, 1-2.

Allen, D.S. (2002b). Jürgen Habermas and the search for democratic principles. In S.L. Bracci \& C. G. Christians (Eds.), Moral Engagement in Public Life: Theorists for contemporary ethics (pp. 97-122). New York: P. Lang.

Allen, M. (2007, Jul. 11). Six Steps to Building Community Support for Affordable Housing and Services. National Alliance to End Homelessness. Relman \& Dane, PLLC. Retrieved from http://www.endhomelessness.org/files/1746_file_AllenWhoseBackyard.ppt

Ambert, A.M., Adler, P.A., Adler, P., \& Detzner, D.F. (1995). Understanding and evaluating qualitative research. Journal of Marriage and Family, 57(4), 879-893.

Ambroziak, P. (2010, April 16). Residents concerned about hospital security measures. Ottawa West EMC, p. 1

Anderson, R., Baxter, L.A. \& Cissna, K.N. (2004). Texts and contexts of dialogue. In R. Anderson, L.A. Baxter, \& K.N. Cissna (Eds.), Dialogue: Theorizing difference in communication studies (pp. pp. 1-17). Thousand Oaks, CA: Sage Publications.

Antos Arens, D. (1993). What do the neighbours think now? Community residences on Long Island, New York. Community Mental Health Journal, 29 (3), 235-345.

Arnett, R.C. (2004). A dialogic ethic 'between' Buber and Levinas: A responsive ethical 'I'. In R. Anderson, L.A. Baxter, \& K.N. Cissna (Eds.), Dialogue: Theorizing difference in communication studies (pp. 75-90). Thousand Oaks, CA: Sage Publications.

Balkissoon, D. (2010, April 8). Parkdale rooming house restored to Georgian glory. Toronto Star. Retrieved from http://www.thestar.com/News/GTA/article/792463

Barbaro, G. (2006). Defining realities: Why community consultation needs to start with the problem, not the solution. Journal of Communication Management, 10(1), 44-54.

Baynes, K. (1995). Democracy and the rechtsstaat: Habermas's Faktizität und Geltung. In S.K. White (Ed.), The Cambridge companion to Habermas (pp. 201-231). USA: Cambridge University Press. 
Berson, Y. \& Sosik, J.J. (2007). The relationship between self-other rating agreement and influence tactics and organizational processes. Group \& Organizational Management, 32(6), 675-698.

Birnbacher, D. \& Krohn, D. (2004). Socratic dialogue and self-directed learning. In R. Saran and B. Neisser (Eds.), Enquiring Minds: Socratic dialogue in education (pp. 9-14). Great Britain: Trentham Books Limited.

Blee, K.M. \& Taylor, V. (2002). Semi-structured interviewing in social movement research. In B. Klandermans \& S. Staggenborg (Eds.), Methods of social movement research (pp. 92-117). Minneapolis, USA: University of Minnesota Press.

Boholm, Å., \& Löfstedt, R. (2004). Introduction. In Boholm \& Löfstedt (Eds.), Facility Siting: Risk, Power and Identity in land use planning (pp. xii-xxv). Sterling, VA: Earthscan.

Boyer, M. (Mar. 2008). How can the NIMBY syndrome be avoided? Montreal Economic Institute. Retrieved from http://www.nimbyexperts.com/uploads/1/7/3/9/1739724/ how_can_the_nimby_syndrome_be_avoided.pdf, 1-4.

Bracci, S. L. (2007). A conversation about communication ethics with Sharon L. Bracci. In Pat Arneson (Ed.), Exploring Communication Ethics: Interviews with influential scholars in the field (pp. 21-36). New York: Peter Lang Publishing Inc.

Burningham, K. (2000). Using the language of NIMBY: a topic for research, not an activity for researchers. Local Environment, 5(1), 55-67.

Cain, S. (1996). Dialogue and difference: 'I and thou' or 'we and they'? In Maurice Freidman (Ed.), Martin Buber and the Human sciences (pp. 135-145). Albany, NY: State University of New York Press.

CanadaHelps. (n.d.) Charity Profile-PARC. CanadaHelps.org. Retrieved from http://www.canadahelps.org/CharityProfilePage.aspx?CharityID=s39165

Canadian Council on Social Development (1994). Excerpt: A working definition of Statistics Canada Low Income Cut-offs (LICOs). In D. Ross, E.R. Shillington, \& C. Lochhead, The Canadian Fact Book on Poverty. Retrieved from http://www.ccsd.ca/pubs/archive/fb94/ fs_povbk.htm

Canadian Mental Health Association (CMHA) (2009, May). Issue: Supported housing for people with mental illness and/or addictions. BC election, CMHA. Retrieved from http://www.cmha.bc.ca/files/IssueSheet09_Housing_General.pdf

Carlington Community Health Centre (CCHC). (2010). About Us-Who we are.... Retrieved from http://carlington.ochc.org/Who.htm 
Cayer, M. (2005). The five dimensions of the practice of Bohm's dialogue. In B. Benathy \& P.M. Jenlink (Eds.), Dialogue as a means of collective communication (pp. 173-187). New York: Kluwer Academic Plenum Publishers.

CDF (2008). Carlington Area. Community Development Framework. Retrieved from http://www.cdfottawa.ca/carlington.html

Chase, K. R. (2000, November). Infinite freedom and public moral discourse. Unpublished paper presented at the annual meeting of the National Communication Association, Seattle, WA.

Cheung, F.M. (1990). Brief program report: People against the mentally ill: Community opposition to residential treatment facilities. Community Mental Health Journal, 26 (2), 205-212.

City of Calgary. (2006). Straight talk about affordable housing. City of Calgary- Faculty of Environmental Design at the University of Calgary. Retrieved from http://www.calgary.ca/docgallery/bu/cns/homelessness/straight_talk_ah.pdf

City of Ottawa. (2001-2010a). CDF Neighbourhoods. Community Development Framework. Retrieved from http://www.ottawa.ca/residents/cdf/cdf_neighbourhoods _en.html

City of Toronto. (1998-2010). Access, Equity and Human Rights Awards: 2007 recipients. City of Toronto [Online]. Retrieved from http://www.toronto.ca/civicawards/ 2007winners.htm

Colon, I. \& Marston, B. (1999). Resistence to a residential AIDS home: An empirical test of NIMBY. Journal of Homosexuality, 37 (3), 135- 145.

Cook, J. R. (1997). Neighbors' perceptions of group homes. Community Mental Health Journal, 33(4), 287-299.

Corrigan, P.W. (2002). Empowerment and serious mental illness: Treatment partnerships and community opportunities. Psychiatric Quarterly, 73(3), 217-228.

Cowan, S. (2003). NIMBY syndrome and public consultation policy: the implications of a discourse analysis of local responses to the establishment of a community mental health facility. Health and Social Care in the Community, 11(5), 379-386.

Critical Conversations (2010, Jan. 30). Panel \#2 Impact on the sector (Marion Wright, CMHA- Ottawa) A Critical Conversation - Working through the Economic Crisis: The Future of Canada's Nonprofit and Voluntary Sector. Carleton University. Retrieved from http://www.cvsrd.org/eng/sustainability-leadership/sl_critcon.html 
Dear, M. \& Taylor, S.M. (1982). Not on our street: Community attitudes to mental health care. London: Pion.

Dear, M. (1992) Understanding and overcoming the NIMBY syndrome. Journal of the American Planning Association, 58(3), 288-300.

Denzin, N.K. (1978). The research act: A theoretical introduction to sociological methods. 2nd Ed., New Jersey, USA: Prentice Hall.

Denzin, N.K. (1989). The research act: A theoretical introduction to sociological methods. 3rd Ed., New Jersey, USA: Prentice Hall.

De Wolff, A. (2008, May). We are neighbours: The impact of supportive housing on community, social, economic and attitude changes. A Community University Research Project: Wellesley Institute with The Dream Team and the University of Toronto. Retrieved from http://www.new.homecomingcoalition.com/wp-content/uploads/2009/06/ WeAreNeighboursReportMay1908.pdf

Doolittle, R. (2007, December 20). Parkdale is a better place to be. Toronto Star. Retrieved from http://www.parkdaleliberty.com/pdf/star_OSF_Dec20_07.pdf

Drudi, C. (2009, Aug. 24). Carlington changing for the better. The Ottawa Citizen. Retrieved from http://www.carlingtoncommunity.org/forums/

viewtopic.php? $\mathrm{f}=20 \& \mathrm{t}=210$

Edmond Place Community Liaison Committee (2007, Dec. 1). Community update meeting, 194 Dowling Avenue. Retrieved from http://www.gordperks.ca/park_post /2007/12/01/community-update-meeting-194-dowling-avenue/

Ellinor, L. \& Gerard, G. (1998). Dialogue: rediscover the transforming power of conversation. New York: J. Wiley \& Sons.

Edwards, P. (1970). Buber and Buberism: A critical evaluation. The Lindley Lecture, University of Kansas, November 3, 1969.

Farr, A.L. (2009). Critical theory and democratic vision: Herbert Marcuse and recent liberation philosophies. USA: Lexington Books.

Fischel, W.A. (2001). Why are there NIMBYs? Land Economics, 77 (1), 144-152.

Frado, L. (2006). Why is progress so slow on supportive housing? Crosscurrents, 10(1), 20.

Franklin, P. (1996). Dialogues in strategy. Strategic Change, 5, 211-221. 
Fraser, N. (1992). Rethinking the public sphere: A contribution to the critique of actually existing democracy. In C. Calhoun (Ed.), Habermas and the Public Sphere (pp. 109-142). Cambridge, MA: MIT Press.

Frese, F.J. and Davis, W.W. (1997). The consumer-survivor movement, recovery, and consumer professionals. Professional Psychology: Research and Practice, 28(3), 243245 .

Freidman, M. (1996). Martin Buber's “Narrow Ridge” and the Human Sciences. In M. Freidman (Ed.), Martin Buber and the human sciences (pp. 3-25). USA: State University of New York Press.

Galster, G., Pettit, K., Tatian, P.A., Santiago, A.M., \& Newman, S.J. (1999). The impacts of supportive housing on neighbourhoods and neighbours in Denver. The Urban Institute. Washington, DC, USA.

Galster, G., Pettit, K., Santiago, A., \& Tatian, P. (2002). The impact of supportive housing on neighbourhood crime rates. Journal of Urban Affairs, 24(3), 289-315.

Galster, G., Tatian, P., \& Pettit, K. (2004). Supportive housing and neighbourhood property value externalities. Land Economics, 80(1), 33-54.

Gibson, T. (2005). NIMBY and the civic good. City \& Community. 4(4), 381- 401.

Goetz, E. (2008). Words Matter: The importance of issue-framing and the case of affordable housing. Journal of the American Planning Association, 74(2), 222-229.

Groothus, P.A. \& Miller, G. (1994). Locating hazardous waste facilities: The influence of NIMBY beliefs. American Journal of Economics and Sociology, 53(3), 335-346.

Gryn, N. (2003). David Bohm and group dialogue or The interconnectedness of everything. The Jewish Quarterly, 93-97.

Guidotti, T.L. \& Abercrombie, S. (2008). Aurum: a case study in the politics of NIMBY. Waste Management \& Research, 26, 582-588.

Habermas, J. (1975). Legitimation crisis. T. McCarthy (Trans.), Boston: Beacon Press.

Habermas, J. (1984). The theory of communicative action (vol. 1). T. McCarthy (Trans.). Boston: Beacon Press.

Habermas, J. (1989). The structural transformation of the public sphere. T. Burger (Trans.) USA: The MIT Press.

Hackworth, J. (2009) Political marginalization, misguided nationalism and the destruction of Canada's social housing systems. In S. Glynn (Ed.). Where the other half 
lives: Lower income housing in a neoliberal world (pp. 257- 277). London, New York: Pluto Press.

Hatfield, E. (2008, February 11). Gussying up Parkdale means good things for business. Parkdale-Liberty Villager. Retrieved from http://www.parkdaleliberty.com/pdf/ GussyingUp_Parkdale.pdf

Hatfield, E. (2009, October 21). The past comes to life at historic Queen West building. Inside Toronto. [Online]. Retrieved from http://www.insidetoronto.com/news/local/ article/156679--the-past-comes-to-life-at-historic-queen-west-building

Henderson, H. (2009, August 15). 'Housing saves lives,' mental health activist says. Toronto Star. L2.

Herbst, S. (1994). Politics at the margin: Historical studies of public expression outside the mainstream. USA: Cambridge University Press.

HomeComing: Community Choice Coalition, (2005 edition). Yes, in my back yard. Retrieved from http://www.new.homecomingcoalition.com/wp-content/uploads/ 2009/08/YIMBY.pdf

HomeComing: Community Choice Coalition, (2005, Oct. 11). Can any neighbourhood have "too much supportive housing?" Retrieved from http://www.new.homecomingcoalition.com/wp-content/uploads/2009/06/fairshare.pdf

Hove, T. (2008). Understanding and efficiency: Habermas's concept of communication relief. Communication Theory, 18, 240-254.

Hubbard, P. (2005). Accommodating otherness: anti-asylum centre protest and the maintenance of white privilege. Transactions of the Institute of British Geographers, $30(1), 52-65$.

Hubbard, P. (2006). NIMBY by another name? A reply to Wolsink. Transactions of the Institute of British Geographers, 31(1), 92-94.

Hulchanski, J. D. (2009, February 18). Homelessness in Canada: Past, Present, Future. Conference Keynote Address. Retrieved from http://www.scribd.com/doc/14126679/ Homelessness-Past-Present-Future-Hulchanski-2009

Hurley, M. (2010, March 6). Second time missing pedophile had fled Royal Ottawa centre. The Ottawa Citizen, C.3.

Johannesen, R. L. (1996). Ethics in human communication (4th Ed.). Prospect Heights, IL: Waveland. 
Keith, M. \& Pile, S. (1993). Introduction part 1: The politics of place. In M. Keith and S. Pile (Eds.) Place and the Politics of Identity (pp. 1-21). New York: Routledge.

Kensen, S. (2000). The dialogue as basis for democratic governance. Administrative Theory and Practice, 22(1), 117-131.

Kim, S. (2003). An almost ideal solution to the siting problem of publicly provided indivisible goods. International Tax and Public Finance, 10, 357-375.

Lake, R.W. (1993). Planners' Alchemy transforming NIMBY to YIMBY: Rethinking NIMBY. Journal of the American Planning Association, 59(1), 87-93.

Levinas, E. (1994). Apropos of Buber: Some notes. In M. B. Smith (Trans.), Outside the subject (pp. 40-48). Stanford, CA: Stanford University Press.

Lezaun, J. \& Soneryd, L. (2007). Consulting citizens: technologies of elicitation and the mobility of publics. Public Understanding of Science, 16, 279-297.

Lyon-Callo, V. (2001). Making sense of NIMBY: poverty, power and community opposition to homeless shelters. City \& Society, XIII(2), 183-209.

Markovà, I. (1990). Introduction. In I. Markovà and K. Foppa (Eds.), Dynamics of dialogue (pp. 1-22). New York, USA: Springer-Verlag New York, Inc.

McAvoy, G.E. (1999). Controlling Technocracy: Citizen rationality and the NIMBY syndrome. Washington, D.C.: Georgetown University Press.

McCarthy, T. (1978/1981). The critical theory of Jürgen Habermas. Cambridge, Massachusetts: MIT Press.

McClymont, K. \& O'Hare, P. (2008). “We're not NIMBYs!" Contrasting local protest groups with idealized conceptions of sustainable communities. Local Environment, 13(4), 321-335.

McGann, A. (2005). The Problem of Consensus in Habermas and Rawls: Rethinking the Basis of Deliberative Democracy. Unpublished paper prepared for the Annual Conference of the American Political Science Association, Washington, DC, September 1-4, pp. 1-27. Retrieved from http://www.allacademic.com//meta/ p_mla_apa_research_citation/0/3/9/8/9/pages39891/p39891-1.php

Miller, D. (1983). The competitive model of democracy. In G. Duncan (Ed.), Democratic theory and practice. Cambridge, UK: Cambridge University Press.

Murray, J.W. (2004). The face in dialogue, Part II: Invitational thetoric, direct moral suasion, and the asymmetry of dialogue. Southern Communication Journal, 69(4): 333347. 
NCHC (n.d.). Overcoming the challenges of NIMBYism. North Carolina Housing Coalition. Retrieved from http://www.nchousing.org/advocacy-1/messagingstrategy/nchc-housing-comm-manual/

Overcoming\%20the\%20Challenges\%20of\%20NIMBYism.pdf

Neveu, C. (2002) Nimbys as citizens: (re)defining the 'general interest'. FocaalEuropean Journal of Anthropology, 40, 51-66. Retrieved from http://www.nimbyexperts.com/uploads/1/7/3/9/1739724/nimbys_as_citizens.pdf

Nikulin, D. (1998). Mikhail Bakhtin: A theory of dialogue. Constellations, 5(3), 381402.

OED. (1989/2 ${ }^{\text {nd }}$ Ed.). Dialogue. Oxford English Dictionary Online. Retrieved from http://dictionary.oed.com

OHRC (Ontario Human Rights Commission).(2008, July 8). Backgrounder \#2: The human side of rental housing. Retrieved from http://www.ohrc.on.ca/en/resources/news/ e_bg2_housing-consultation-report

OHRC. (2009, October 5). New Policy shows how to provide human rights in rental housing. Retrieved from http://www.ohrc.on.ca/en/resources/news/policylaunch

OHRC. (2010, March 1). Campaign promotes "Housing as a human right." Retrieved from http://www.ohrc.on.ca/en/resources/news/housingcampaign

OHRC. (2010, June 21). The OHRC introduces a new resource for human rights and mental health. Retrieved from http://www.ohrc.on.ca/en/resources/news/ mentalhealththeme

Orum, A.M. \& Feagin, J.R. (1991). A tale of two cases. In J.R. Feagin, A.M. Orum \& G. Sjoberg (Eds.). A case for case study (pp. 121-147). USA: The University of North Carolina Press.

Orum, A.M., Feagin, J.R., \& Sjoberg, G. (1991). Conclusion. In J.R. Feagin, A.M. Orum \& G. Sjoberg (Eds.). A case for case study (pp.269-278). USA: The University of North Carolina Press.

Ottawa Neighbourhood Study. (2009). Neighbourhood Profile: Carlington. Retrieved from http://137.122.133.36/neighbourhoodstudy.ca/profiles/index.php?page=Carlington

Our Place. (n.d.). Good neighbours agreement. Our Place. Retrieved from http://www.ourplacesociety.com/good_neighbour

Outhwaite, W. (Ed.) (1996). The Habermas reader. Cambridge, UK: Polity Press. 
PARC. (2009). Parkdale Activity-Recreation Centre: Jane's Walk May 3, 2009. [Handout]. 2009 Community Forum on Homelessness.

PARC. (n.d.). The PARC ambassador project. [Handout]. 2009 Community Forum on Homelessness, p. 1-3.

Parkdale Village BIA. (n.d.). History. Parkdale Village BIA. Retrieved from http://www.parkdalevillagebia.com/history

Parkdale Village BIA. (n.d.). Home. Parkdale Village BIA. Retrieved from http://www.parkdalevillagebia.com/home

Patton, M.Q. (1987). How to use qualitative methods in evaluation. USA: Sage Publications, I.N.C.

Perinbanayagam, R.S. (1991). Discursive acts. New York: Aldine De Gruyter.

Pettigrew, T.F. (1998). Intergroup contact theory. Annual Review of Psychology, 49, 6585 .

Philo, C. (1987). 'Not at our seaside': community opposition to a nineteenth century branch asylum. Area, 19(4), 297-302.

Podymow, T., Turnbull, J., Coyle, D., Yetisir, E. \& Wells, G. (2006). Shelter-based managed alcohol administration to chronically homeless people addicted to alcohol. Canadian Medical Association Journal. 174(1), 45-48.

Prince George (2006). Creating housing for homeless people: A case study. Office of Housing and Construction Standards-Housing Policy Branch (Government of British Columbia. Retrieved from http://www.housing.gov.bc.ca/housing/nimby/

CS_Prince_George.pdf

Rasmussen, T. H. (1992). Not in my backyard: The politics of siting prisons, landfills, and incinerators. State and Local Government Review, 24(3), 128-134.

Roberts, J.J. (26 May, 2010). NIMBY is really FIMBY - Fear in my Backyard. Poverty Insights. Retrieved from http://www.povertyinsights.org/2010/05/26/nimby-is-reallyfimby-\%e2\%80\%93-fear-in-my-backyard/

Royal, R. (2008, Jan/Feb). Community consultation. Renewable Energy Focus, 48-49.

Royal Ottawa Health Care Group (n.d.) Royal Ottawa Mental Health Centre. Retrieved from http://www.rohcg.on.ca/about/documents/ROMHC.pdf, 1-2.

Rupert, J. (2009, July 1). Ottawa housing gets $\$ 54 \mathrm{M}$ boost; $\$ 47 \mathrm{M}$ to repair social housing; $\$ 7 \mathrm{M}$ to help homeless people. Ottawa Citizen. $\mathrm{Cl}$. 
Sibley, R. (2009, September 2). Group home splits Carlington. The Ottawa Citizen. Retrieved from http://www.ottawacitizen.com/health/Group+home+splits+Carlington/ 1952493/story.html

Shufelt, T. \& Rupert, J. (2008, March 18). Troubled Carlington rates poorly in study. The Ottawa Citizen, C.1 Retrieved from http://www.canada.com/ottawacitizen/news/city/ story.html?k=12010\&id=b5c88b1d-006c-4224-b2f2-aa55fda982ac

Slater, T. (2005, May). Toronto's South Parkdale Neighbourhood: A brief history of development, disinvestment, and gentrification. Centre for Urban and Community Studies. CUCS Research Bulletin \#28, 1-8. Retrieved from http://www.urbancentre.utoronto.ca/pdfs/ researchbulletins/CUCS-RB-28-SlaterParkd.pdf

Smith, E. R. \& Marquez, M. (2000). The other side of the NIMBY syndrome. Society and Natural Resources, 13, 273-280.

Spears, T. (2010, March 8). London police nab pedophile who walked out of mental facility. The Ottawa Citizen. B.6.

Statistics Canada (2008, June). Low income cut-offs for 2007 and Low income measures for 2006. Income Research Paper Series, Income Statistics Division. Retrieved from http://www.statcan.gc.ca/pub/75f0002m/75f0002m2008004-eng.pdf

Stein, D. (2008, December 29) Overcoming NIMBY opposition before it stalls your project. Multi Housing News Magazine online Retrieved from http://www.gcastrategies.com/uncategorized/321/overcoming-nimby-opposition-beforeit-stalls-your-project/

Stren, O. (2007, August). Parkdale. Toronto Life. Retrieved from http://www.torontolife.com/ features/block-parkdale/

Stevens, R. (2009, December 20). 'Nobody's listening': Carlington residents gather to find solutions. Ottawa West EMC. Retrieved from http://www.carlingtoncommunity.org/ forums/viewtopic.php?f=20\&t=290

Strauss, A. \& Corbin, J. (1998). Basics of qualitative research: Techniques and procedures for developing grounded theory. ( $2^{\text {nd }}$ Ed.). USA: Sage Publications, Inc.

Sylvestre, J., George, L., Aubry, T., Durbin, J., Nelson, G., \& Trainor, J. (2007). Strengthening Ontario's system of housing for people with serious mental illness. Canadian Journal of Community Mental Health, 26(1), 79-95. 
Takahashi, L. M. (1997). Information and attitudes toward mental health care facilities: Implications for addressing the NIMBY syndrome. Journal of Planning Education and Research, 17, 119-130.

Takahashi, L.M. \& Dear, M. J. (1997). The changing dynamics of community opposition to human service facilities. Journal of the American Planning Association, 63(1), 79-93.

Takahashi, L.M. (1998). Homelessness, AIDS, and stigmatization: The NIMBY syndrome in the United States at the end of the Twentieth century. New York: Oxford University Press.

Talbot, M. (2010, April 1). PARC: Thirty years of rebuilding lives. CityNews.ca Retrieved from http://www.citytv.com/toronto/citynews/news/local/article/73621--parcthirty-years-of-rebuilding-lives

Tannen, D. (1998). The argument culture: Moving from debate to dialogue. New York: Random House.

Tanner, F. (1999). Carlington: can you build community across class lines? Community Service Centres of Ottawa-Carleton: A history. Retrieved from http://www.coalitionottawa.ca/coalition/ content/files/documents/HistoryEnglish.pdf , pp.34-38.

Taylor, S.M. (1989). Community exclusion of the mentally ill. In J. Wolch \& M. Dear (Eds.), The power of geography (pp. 316-329). Boston: Unwin Hyman.

Teeple, G. (2000). Globalization and the decline of social reform: into the twenty-first century. ( $2^{\text {nd }}$ Ed.). Aurora, ON: Garamond Press.

Thornton, B. \& Knox, D. (2002). "Not in my back yard": The situational and personality determinants of oppositional behaviour. Journal of Applied Social Psychology, 32(12), 2554-2574.

UN-HABITAT. (2004, May 31). United Nations Housing Rights Programme (First Phase): Contributions to the Full and Progressive Realization of the Human Right to Adequate Housing. Retrieved from http://www.unhabitat.org/downloads/docs/ 798_32059_UNHRP-ProDoc-PublicX.pdf, p. 6-12.

VanNijnatten, D.L. \& Gregoire, S. (1995). Bureaucracy and consultation: the Correctional Service of Canada and the requirements of being democratic. Canadian Public Administration, 38(2), 204-221.

Vincent (2007, April 18). Parkdale housing project opposed: Home for drug abusers among 10 city ventures. Toronto Star. B08. 
Vogel, M. (1996). Is a dialogical theology possible? In Maurice Freidman (Ed.). Martin Buber and the Human sciences (pp. 51-64). Albany, NY: State University of New York Press.

Walsh, E., Warland, R., \& Clayton Smith, D. (1993). Backyards, NIMBYs, and incinerator sitings: Implications for social movement theory. Social Problems, 40(1), 2538.

Willis, V. (2007, April 20). Parkdale lacking proper housing. Toronto Star. Opinion.

Wolch, J.R. (1996). Community-based human service delivery. Human Policy Debate, 7(4), 649- 671.

Wolsink, M. (2000). Wind power and the NIMBY-myth: institutional capacity and the limited significance of public support. Renewable Energy, 21(1), 49-64.

Wolsink, M. (2006). Invalid critique impedes our understanding: a critique on the persistence of the language of NIMBY. Transactions of the Institute of British Geographers, 31(1), 85-91.

Wreme, E. (1999). How to use dialogue as a practical way to start applying the principles of complexity theory to a traditional organization. Unpublished paper presented at the The $17^{\text {th }}$ International Conference of The System Dynamics Society and the $5^{\text {th }}$ Annual Australian \& New Zealand Systems Conference. Retrieved from http://www.systemdynamics.org/conferences/1999/PAPERS/PARA236.PDF

Zippay, A. (1997). Trends in siting strategies. Community Mental Health Journal, 33(4), 301-310.

Zippay, A. \& Lee, S.K. (2008, Sept.). Neighbors' perceptions of community-based psychiatric housing. Social Service Review, 395-417. 


\section{Interviews Cited}

Darwin, D. (2010, Jan. 13). Personal Interview

Fiorito, J. (2010, Feb. 25). Personal Interview.

Jeffries, J. (2010, Mar. 2). Personal Interview.

Kostiuk, M. (2010, Jan. 29). Personal Interview.

Lyle, P. (2010, Feb. 26). Personal Interview.

MacLaren, K. (2010, Feb. 4). Personal Interview.

Muckle, W. (2010, Feb. 10). Personal Interview.

Park, G. (2010, Feb. 8). Personal Interview.

Perks, G. (2010, Feb. 26). Personal Interview.

Soucie, P. (2010, Jan. 6). Personal Interview.

Unnamed. (2010, Jan. 19). Personal Communication - email.

Unnamed. (2010, Mar.17). Personal Interview.

Willis, V. (2010, Feb. 24). Personal Interview. 
Appendix A

Poster from the City of Toronto's campaign for housing rights

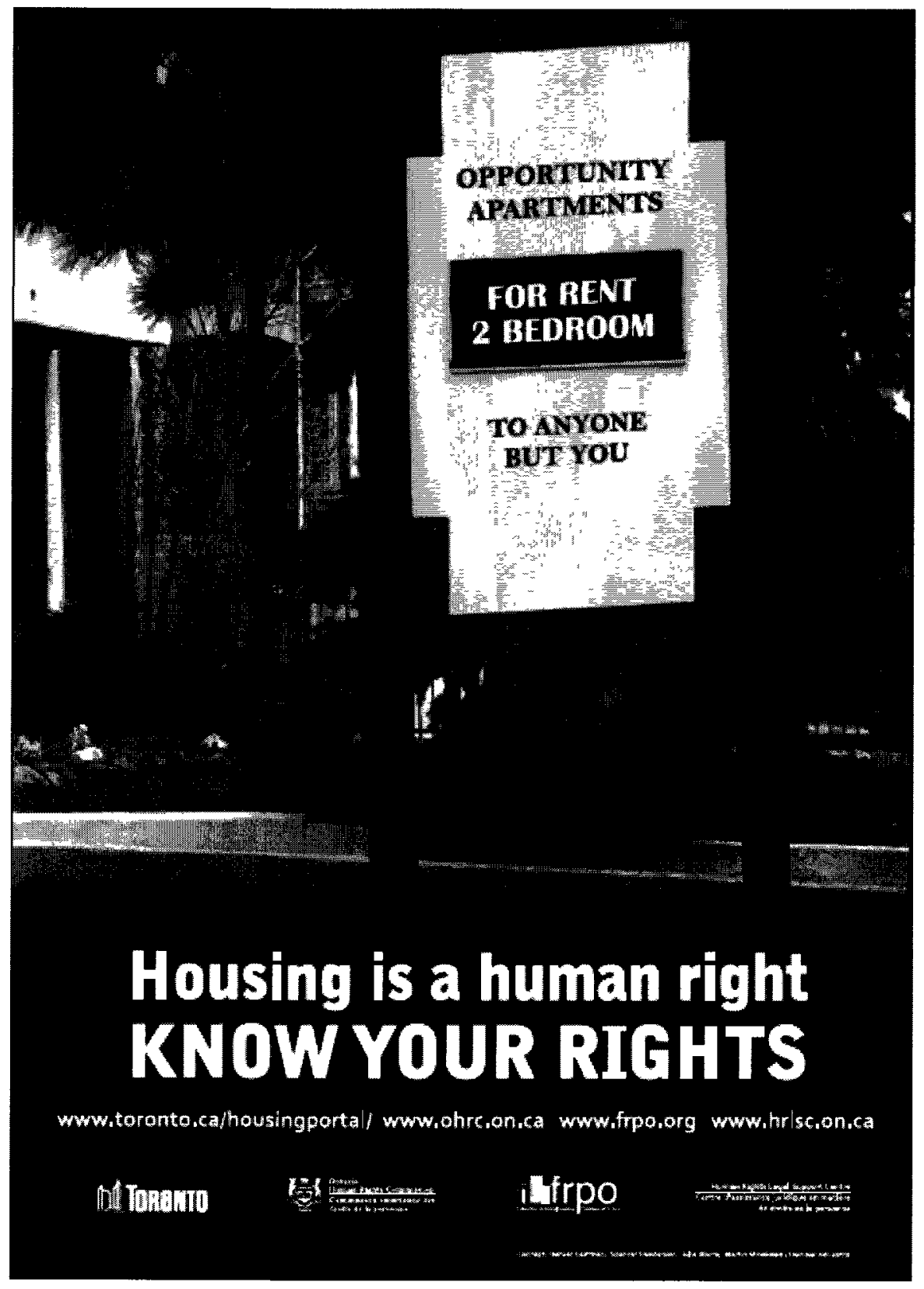

Source: http://www.toronto.ca/affordablehousing/pdf/anyone_butyou.pdf More information: http://www.toronto.ca/affordablehousing/human_rights.htm 


\section{Appendix B}

\section{$\underline{\text { Sample Interview Questions }}$}

The questions asked during the interviews varied slightly to reflect the roles of the different actors. Sample questions include:

1. What does it mean to you to be a "good neighbour"?

2. What impact do you think [name project] will have/has had on the community? Why do you think that is?

3. Can you think of any strategies that failed to resonate? Can you tell me about them and your impressions of why they were unsuccessful? Can you tell me about the most successful strategies that were used?

4. How do you account for this [opposition or support] in the planning process? Are there any strategies you [service provides] use to offset negative public reactions to your presence in the neighbourhood?

5. What responsibility, if any, does [an/your] organization have to the local residents when it introduces a new project into [their/your] neighbourhood? 


\section{Appendix C}

\section{$\underline{\text { Interview Guide (Sample) }}$}

\section{Interview Guide A}

Interviews are intended to be semi-structured, taking on more of a conversational, than formal tone. A series of open-ended questions will be posed, with time for discussion left between each one. There will be some latitude for research participants to deviate from the questions in their responses, as long as the discussion is still centred on the themes underlying the questions below (i.e. public impressions of harm reduction initiatives, newspaper coverage of these programs, organizational strategies to counteract possible public opposition, examples of successes/failures and what may account for them etc.)

Interviews are expected to take approximately 45 minutes to complete.

\section{Sample (Opening Script):}

"Hi. Thank you for agreeing to meet with me today. Before we start, I'd like to go over what we'll be discussing in the next 45 minutes or so. I am going to ask you a series of open-ended questions, with time between each one for discussion. The topics we'll be touching on range from your general impressions of the public's understanding of harm reduction initiatives, to the strengths and weaknesses of newspaper reporting on these services and your organization's strategies to counteract possible public opposition. At any point during the interview you may choose not to answer a question, to speak on a matter confidentially, or to end the interview. This interview will be [audio] recorded. Do you have any questions before we begin? Shall we begin?"

\section{Sample Interview Questions}

\section{Group A: Service Sector Workers/Frontline Workers}

1. Many harm reduction initiatives are controversial (such as needle exchange programs, safe injection sites, wet shelters etc.).

a) When establishing a program of this nature, what is the expected community reaction?

b) Do you think that the type of program is a factor in how the community responds (i.e. safe injection site versus managed alcohol program)?

2. Where do you think that community members' impressions $/$ knowledge of these initiatives comes from?

3. Please describe how your organization communicates with members of the public.

a) What is your organization's relationship with local news media? 
b) Initially how did your organization communicate to the public regarding this [name project]?

c) Would you characterize your initial feedback as mostly opposed, mostly supportive, or mixed?

d) Why do you think that was?

4. What responsibility, if any, does your organization have to the local residents when it introduces a harm reduction project into their neighbourhood?

5. What does it mean to you to be a "good neighbour"?

6. What are the most common complaints or concerns you've heard from the public regarding the [name program]? Can you tell me about some of the encouragement you've received by community members regarding [name project]?

7. How do you account for this [opposition or support] in the planning process? Are there any strategies you use to offset negative public reactions to your presence in the neighbourhood? For example, how do you respond to accusations that your managed alcohol program (MAP) simply 'gives alcohol to alcoholics' and therefore enables program participants' addictions?

8. Can you think of any strategies that failed to resonate with the public? Can you tell me about them and your impressions of why they were unsuccessful? Can you tell me about the most successful strategies you've used?

9. The Managed Alcohol Program (MAP) has been operating for a few years now. In your experience, has public opinion changed since you've begun your program?

- [If yes]:

- How long did it take for locals to accept the program?

- Can you think of any reasons why this may have occurred? (I.e. issue naturally died down; some socialization activity organized to make the community feel more at ease; a shift in media coverage etc.)

- [If no]:

- Why do you think nothing has changed?

- Are you actively working to gain community support?

- What do you think it would take to achieve this support? 


\section{Appendix D}

\section{Thematic Analysis Procedure}

\section{- Toronto Coverage}

Using the LexisNexis database, the following terms were searched": "Parkdale Activity Recreation Centre" or "PARC" or "Edmond Place" or "supportive housing" or "194 Dowling" or " 1499 Queen". The search was edited to specify the geographic location of Canada or Ontario, Canada from All English-language news, full-text. The search parameters also included a specified timeframe of January 1, 2005 to April 30, 2010. This was purposely broad to ensure that all relevant articles about the project, from its inception to the present, would be pulled from within the database. This search yielded more than 3000 results, only 380 of which were from newspapers ${ }^{2}$.

Within the newspaper field, results listed under Toronto Star-Metroland Newspapers (15 results) and The Toronto Star (62 results) were sorted and all of the relevant articles were collected in a file ${ }^{3}$. Articles that appeared more than once in the coverage were removed from the final sample. The final sample yielded 38 results, only 7 of which directly mentioned the project by name.

\section{- Ottawa Coverage}

Using the Canadian Newsstand database, the following terms were searched: “"“The Oaks" OR "Cardinal Suites" OR "Merivale Road". The search parameters included all articles between January 1, 2009 to April 30, 2010; searched in "Citation and document text". The project was first announced in the news in the summer of 2009. The search was refined to only include results from the following publication titles: Ottawa West EMC, Ottawa South EMC, and The Ottawa Citizen. This search yielded more than 203 results. The articles were reviewed for relevance leading to a total sample of 15 . The articles were then sorted and any repeats were removed from the final sample and necessary additions were made ${ }^{5}$. The final sample yielded 23 articles.

\footnotetext{
' The terms were searched 'match any term'

${ }^{2}$ The LexisNexis database lists search results by category: newswires \& press releases, newspapers, magazines $\&$ journals, etc. This feature was very helpful in limiting results to newspaper articles.

${ }^{3}$ Consideration was given to including The Globe and Mail as representative of national coverage, however the search results from this paper were looked at and none of them were relevant to the case study project(s). This again speaks to the singular local-interest in these projects and/or conflicts.

4 'Merivale Road' was searched because the hotels that were purchased for this project are located at one of its intersections. Some articles failed to mention the project by name, but did list it by location (ex. Funding was provided for a project being run out of a former hotel on Merivale Road)

${ }^{5}$ The final sample was cross-referenced with news collected by the Carlington Community Association's (CCA) Director of Communications, David Darwin. Darwin collected news stories related to this project and posted them on the CCA website under a titled forum link. Since the CCA website is frequented by local residents, these articles were likely sources of information for residents concerned/interested in this development. As such, these articles were included in the news sample and cross-referenced with the others collected from the online database. The CCA's news articles were a useful initial source for information on this topic and in fact, influenced the inclusion of the term "Merivale Road" in the online search.
} 


\section{Appendix E}

Interview Transcription Procedure

\section{Transcription of Interview Recordings}

Interviews were transcribed by the researcher. Frequently, the conversation was transcribed exactly as it occurred; nevertheless, slight editing did occur in the following instances:

i. Comments of acknowledgement (e.g. uh-huh, yes, okay etc.) that were heard in the background of the main speaker's comments were not transcribedmerely the main questions/comments and the interviewees answers/remarks.

ii. Filler words (e.g. um, ah) were not included in the final transcription.

iii. Segments of the conversation that lacked relevance to the interview were not transcribed (i.e. introductory or closing remarks whose point of focus diverged from the topic of study). In telephone interviews, the recording device was on prior to the interviewee being called. In line with this project's ethics guidelines, approval to record was granted in advance of the conversation. Nevertheless, given the simplicity of the recording process, the researcher lacked the ability to turn the device on and off at will. Thus, the full conversation was recorded, including the introductory hellos and other closing comments at the end of the interview. If these comments were deemed irrelevant to the subject under study, they were not transcribed - simply the conversation that occurred once the interview formally began until it came to its conclusion.

These exceptions were justified on the basis of the focus of study. Unless the comments and/or words outlined in (i) or (ii) spoke to a larger issue, or were indicative of an interviewee's response to a question, then they were not included. Studying the transcript was facilitated once the filler words and irrelevant segments were eliminated from the document. 


\section{Appendix F}

Letter of Information and Consent Form (Sample)

\section{Carleton \\ Canada's Capital University}

\section{Letter of information}

[Date]

Dear: [Name of Participant],

My name is Natalie Brulé and I am a graduate student at Carleton University with the School of Journalism and Communication. Under the supervision of Dr. Joshua Greenberg, I am completing a master's thesis that examines community impressions of special needs residential facilities, in particular the new [facility name]. I am interested in the strategies used by those in the service sector to consult with members of the public, and the methods they use to convey the value of their programs to the community. Would you be willing to speak with me about your impressions of the [organization running the facility's name] new housing facility?

\section{Interview Process:}

Interviews will take place during the months of January and February, 2010. If you are willing to speak with me on the issue outlined above, I will arrange a meeting with you at your earliest convenience. Interviews will take approximately 45 minutes to complete. At any time you are able to decline answering a question or to request an end to the interview. Interviews will be audio recorded and the discussion will be transcribed for research purposes only. Participants who complete the interview will be provided a $\$ 10$ gift card from Tim Horton's or Starbucks.

\section{Personal Information and Security:}

All personal information obtained through the interview process will be kept in a password-protected file on my computer and shared only with my thesis supervisor. After a period of 5 years, the document containing this information will be permanently deleted from the computer hard drive. All recordings will be digitally-archived and kept on a password-protected computer. The recordings will be backed up on an external harddrive and kept in a secure location. After a period of 5 years, these recordings will be permanently deleted. 


\section{Ethics, Confidentiality, Anonymity, Disclosure:}

This project has already been subject to review and clearance by Carleton University's Research Ethics Board. This research poses minimal risks to participants; however, should you at any time feel uncomfortable speaking to an issue or continuing with the interview, you may decline an answer or request an end to the interview. At your request, you may choose to be represented through pseudonyms and not personally identified in any thesis chapters, research articles or presentations made relating to this research. You may also request in writing to be withdrawn from this study up to 14 days after the interview has been completed. Should you choose to do so, you may decide at that time if I may use the information you have provided or you may request that it be destroyed. If you have any questions or concerns about your involvement in this research, you may contact the chair of Carleton University's Ethics Committee (whose contact information is provided at the end of this letter). By signing the attached consent form, you acknowledge the terms of this research, and agree to participate.

\section{Implications:}

Special needs residential facilities, such as the supportive and affordable housing units provided to clients at the Carlington facility, are an important way for residents to manage and improve their lives. Even so, many community members feel that they are not properly consulted on, or informed of these projects on instances when they are being introduced into their neighbourhood. This study will be of value to the public as it will offer insights into the ongoing barriers to effective dialogue that continue to exist between service workers and the public. It is the hope that these insights will enable service workers to communicate more openly and proactively with their "new neighbours".

\section{Contact:}

If you are interested in contributing to this research, please contact me via e-mail at nbrule@connect.carleton.ca to arrange a meeting. You may also contact Carleton University's Research Ethics Committee Chair, Prof. Antonio Gualtieri or my supervisor, Dr. Joshua Greenberg via the contact information provided below.

I look forward to speaking with you,

Natalie Brulé (Researcher)

Master's Candidate, Communication

Carleton University

nbrule@connect.carleton.ca 
For more information, please contact:

Prof. Antonio Gualtieri, Chair

Research Ethics Committee

Carleton University

1125 Colonel By Drive

Ottawa, ON K1S 5B6

Tel: 613-520-2517

ethics@carleton.ca
Prof. Joshua Greenberg, PhD

(Supervisor)

School of Journalism \& Communication

Carleton University

Room 316A St. Patrick's Building

1125 Colonel By Drive

Ottawa, ON K1S 5B6

Tel: $613-520-2600 \times 1965$

joshua_greenberg@carleton.ca 


\section{CONSENT FORM:}

I, have read the above letter and understand that I am participating in a research project and I voluntarily agree to participate.

(Signature of Participant)

(Date Signed)

Interviews will be audio-recorded in order to make accurate transcriptions.

$\square$ I agree to be audio-taped

$\square$ I decline to be audio-taped 


\section{Appendix G}

Interview Participants

Interviews Jan.-Mar., 2010

\section{Ottawa, ON:}

The following people were interviewed regarding The Oaks facility in Carlington:

- Paul Soucie, Executive Director, Shepherds of Good Hope

- Wendy Muckle, Executive Director, Ottawa Inner City Health

- Gareth Park, Housing Program Manager, Canadian Mental Health Association (Ottawa Branch)

- Lynne Browne, Coordinator, Alliance to End Homelessness

- Mike Kostiuk, President, Carlington Community Association

- David Darwin, Vice President \& Head of Communications, Carlington Community Association

- Ken MacLaren, Executive Director, Ottawa Inner City Ministries

- Two Carlington residents, speaking anonymously:

- Only one was an interview, the other consisted of comments that were sent to the researcher privately. Permission was granted to include these comments in the analysis and discussion. Both of these individuals are long-time residents of Carlington. In subsequent discussions they are referred to simply as "a long-time resident"

\section{Toronto, $\mathbf{O N}$ :}

The following people were interviewed regarding the Edmond Place facility in Parkdale:

- Victor Willis, Executive Director, Parkdale Activity-Recreation Centre (PARC)

- Laura, Glen, \& Phil, PARC members \& Ambassadors

- Leslie McDonald, Habitat Services

- Gord Perks, Councillor for Ward 14 (South Parkdale)

- Dirk Townsend, President, Parkdale Residents Association (PRA)

- Joe Fiorito, Columnist, Toronto Star

- Peter, Member of The Dream Team

- John Jeffries (pseudonym), Long-time resident of Parkdale 


\section{Appendix H}

\section{Reader Comments (Carlington)}

An article appeared in The Ottawa Citizen following the community meeting on September 1, 2009 that was held to discuss The Oaks. These are some sample comments that were posted online in response to it. They serve to highlight initial reactions by several community members.

Article: Sibley, R. (2009, Sept. 2). Group home splits Carlington. The Ottawa Citizen. p. C3.

\begin{tabular}{|c|c|l|}
\hline $\begin{array}{l}\text { Total number of unique } \\
\text { comments }\end{array}$ & $\begin{array}{l}\text { Number of individuals who } \\
\text { objected to the project site }\end{array}$ & $\begin{array}{l}\text { Number in favour of project } \\
\text { site }\end{array}$ \\
\hline 44 & 32 & 12 \\
\hline
\end{tabular}

- Sample Comments

*Please note that grammar/spelling errors have not been corrected. Comments are as posted.

\begin{tabular}{|c|c|}
\hline $\begin{array}{l}\text { Posted by: } \\
\text { Judy } \\
\text { September } \\
09,2009 \\
8: 21 \text { PM }\end{array}$ & $\begin{array}{l}\text { I really object to the fact that this large facility is being IMPOSED on } \\
\text { Carlington. There was no discussion or debate - its just arriving and that's } \\
\text { it. There's no doubt in my mind that this is happening in Carlington } \\
\text { because many residents are poor and don't have the political clout that } \\
\text { other more affluent neighbourhoods have. I also think that there is an } \\
\text { assumption, incorrect I might add, that we will just roll over and let this } \\
\text { happen. Carlington already has a number of problems - Caldwell and } \\
\text { other such lovely streets that are full of problems - the police are there on } \\
\text { a daily basis. Why not spread out these people into other communities. I } \\
\text { know they deserve a chance and its good for them to be part of a } \\
\text { community but lets not dump all the problems into Carlington and end up } \\
\text { with a second Vanier. Every neighbourhood should do its part. Paul } \\
\text { Soucie, co-executive director of the Shepherds, said the facility would be } \\
\text { fenced and made secure with exterior lighting and monitoring cameras. } \\
\text { He promised it would be "an asset to the community." I have to laugh at } \\
\text { this. How can a facility that is fenced and has monitoring cameras be an } \\
\text { asset to the community. It would be an eyesore with problems. Do you } \\
\text { think we're stupid? Call it what it is. A problem coming to an area that } \\
\text { already has lots of problems. Where has Maria McRae been in all of this? } \\
\text { Maria has become a puppet of the establishment. Where ever you see the } \\
\text { mayor you see Maria. What does that tell you? I thought she was to } \\
\text { represent the people. I don't think so. }\end{array}$ \\
\hline $\begin{array}{l}\text { Posted by: } \\
\text { Total } \\
\text { Arrogance } \\
\text { September } \\
03,2009\end{array}$ & $\begin{array}{l}\text { To quote the pr spokesperson for Shepherds Inc Paul Soucie: "it will } \\
\text { allow us to create a community there" As if Carlington was an empty } \\
\text { parking lot they found. } \\
\text { Newsflash you arrogant outsider-- we have a community here already. }\end{array}$ \\
\hline
\end{tabular}




\begin{tabular}{|l|l|}
\hline 6:06 PM & $\begin{array}{l}\text { We don't need your help. See these are not the words of nieghbours but a } \\
\text { corporate shill. } \\
\text { Also this gem when pressed on the lack of ANY community consultation: } \\
\text { "I don't know how much more you want us to do. You want a public } \\
\text { consultation about what? Whether you're going to allow us to buy the } \\
\text { building or not? Well no, we're buying the building." }\end{array}$ \\
Translation - we dont care what you think. [...]
\end{tabular}




\begin{tabular}{|c|c|}
\hline $\begin{array}{l}\text { September } \\
02,2009 \\
\text { 5:44 PM }\end{array}$ & $\begin{array}{l}\text { opinions and actually listen. I have lived in this neighborhood all my life, } \\
\text { Im not rich, I cant afford anywhere else. Ive seen drug addicts, } \\
\text { prostitutes, alchoholics, and just people who are out right not good for } \\
\text { anyone. So now we have no choice but to live with this because we are } \\
\text { not rich folk. I think this is discrimination against us who would like for } \\
\text { our kids to grow up in a happy, safe, healthy environment but cant } \\
\text { because we are not rich and we have to be bombarded with all of these } \\
\text { negative people. [...] I think this is completely unfair and we should have } \\
\text { a say. [...] How can our neighborhood help these individuals when all } \\
\text { they are going to run into is people just like them or worse??? dont they } \\
\text { need a neighborhood that is better off and they dont have to see people } \\
\text { hustling and what not?? [...] EVERYONE NEEDS TO WAKE UP AND } \\
\text { REALIZE THAT THIS NEIGHBORHOOD NEEDS HELP AND THE } \\
\text { GOV IS OBVIOUSLY NOT GOING TO BE THE ONES TO DO IT, } \\
\text { WE ALL NEED TO PUT A STOP TO THIS OURSELVES SOME } \\
\text { HOW. }\end{array}$ \\
\hline $\begin{array}{l}\text { Posted by: } \\
\text { Open } \\
\text { Minded } \\
\text { September } \\
02,2009 \\
\text { 4:04 PM }\end{array}$ & $\begin{array}{l}\text { To the person who questioned my attendance at the meeting. Yes, I was } \\
\text { there, and I based my assessment on the volume of applause and a count } \\
\text { of how many people actually raised direct problems with the Shepherd. } \\
\text { Most people who had a bone to pick, if you were paying attention, did so } \\
\text { with McRae and how we've been ignored by the city politicians. That's } \\
\text { got nothing to do with the Shepherds and the other agencies. I also saw } \\
\text { some of our most vocal neighbours taking the time to shake hands and } \\
\text { talk with the people who came to meet with us. I even overheard an } \\
\text { apology, and this made me proud to be from Carlington. We have } \\
\text { opinions and we want to be heard, but we are also fair minded people. [...] } \\
\text { if you bother to look beyond our own neighbourhood you'll see that } \\
\text { almost EVERY part of Ottawa has housing like what's planned for } \\
\text { Cardinal Suites: Westboro, Old Ottawa South, the Glebe, Lowertown. } \\
\text { Poverty is getting worse and worse. Why? Because politicians and } \\
\text { corporations are greedy. The rich get richer and the poor get poorer. } \\
\text { These organizations are helping poor people who are down on their luck } \\
\text { and in a rut. We should support them, not treat them like the rich fat cats } \\
\text { treat us. We have major problems in Carlington and I don't dispute that. } \\
\text { But I don't think the Cardinal Suites project will make things worse. IF } \\
\text { anything these people have shown us they are very good at getting } \\
\text { attention from City Hall and making stuff happen when they set their } \\
\text { minds to it. Maybe we can learn from them and stop playing the bloody } \\
\text { victim for a change. I'm so sick of hearing over and over from all of my } \\
\text { neighbours how little power we have. Let's take control of our } \\
\text { neighbourhood but let's be smart and build bridges where it makes sense. }\end{array}$ \\
\hline $\begin{array}{l}\text { Posted by: } \\
\text { No choice }= \\
\text { no voice. } \\
\text { September } \\
02,2009\end{array}$ & $\begin{array}{l}{[\ldots] \text { this has nothing to do with the less fortunate -- We did not victimize }} \\
\text { these people. We have had more than our fair share of social balm applied } \\
\text { to our neighbourhood thank you. [...] } \\
\text { It has to do with a corporation coming into our neighborhood uninvited }\end{array}$ \\
\hline
\end{tabular}




\begin{tabular}{|c|c|}
\hline $1: 22 \mathrm{PM}$ & $\begin{array}{l}\text { and settig up shop. And as taxpayers we are told to 'stuff it'. } \\
\text { Carlington is the victim here -- not Shepherd Inc. }\end{array}$ \\
\hline $\begin{array}{l}\text { Posted by: } \\
\text { Confused } \\
\text { September } \\
02,2009 \\
10: 41 \mathrm{AM}\end{array}$ & $\begin{array}{l}\text { You say the neighborhood is full of meth and crack addicts...prostitution } \\
\text { is rampant and you have to keep a baseball bat by your door? And you're } \\
\text { worried about this thing bringing down your "property values"? Sounds } \\
\text { like the area could use more people like the Shephard's of Good Hope } \\
\text { who are trying to better the community. I would think potential buyers } \\
\text { would be more worried about the drug addicts and street crime than about } \\
\text { a bunch of people who are actively trying to get their life sorted out. }\end{array}$ \\
\hline $\begin{array}{l}\text { Posted by: } \\
\text { DAN L } \\
\text { September } \\
02,2009 \\
10: 38 \text { AM }\end{array}$ & $\begin{array}{l}\text { I think the residents are over reacting ! [...] } \\
\text { Where else are centres like this suppose to go? Do not blame the affect of } \\
\text { something until you're willing to fight the cause! Most are not willing to } \\
\text { do so. }\end{array}$ \\
\hline $\begin{array}{l}\text { Posted by: } \\
\text { Wendy } \\
\text { September } \\
02,2009 \\
\text { 9:40 AM }\end{array}$ & $\begin{array}{l}\text { This is the biggest scam there ever was. The residents themselves had to } \\
\text { hand deliver the information meeting circulars because the Shepherds } \\
\text { were very selective who received them. This area is indeed the City's } \\
\text { dumping ground. We are very concerned about our property values. } \\
\text { There is wide spread prostitution, crack, meth and everything inbetween } \\
\text { in this area. We are tax payers too! I wish our only concern was, "Big } \\
\text { Box stores" like the Glebe. Maria sure cares about her, "Glebe". Take a } \\
\text { picture of the future looking Carlington area for the paper! haha. Our } \\
\text { backyards were full with what the City has dumped in this area. I had a } \\
\text { crack head in my garage not too long ago and thank God that we had our } \\
\text { baseball bat by the door! Does anybody else besides our neighbourhood } \\
\text { have baseball bats beside every front door? What has been done to us } \\
\text { could happen to your neighbourhood. These "fixes" are permanent and do } \\
\text { not move on in a couple of years. These "Associations" are not } \\
\text { "Associations" they are "treatment" centres employing nurses,doctors etc. } \\
\text { This is how public imput was not required for debate. This is NOT" } \\
\text { traditional Main street business!!! FIX THE law!!!! }\end{array}$ \\
\hline $\begin{array}{l}\text { Posted by: } \\
\text { SOS } \\
\text { Carlington } \\
\text { September } \\
02,2009 \\
9: 16 \text { AM } \\
\end{array}$ & $\begin{array}{l}\text { Just remember these } 3 \text { names next election Jim Watson, Alex Cullen, and } \\
\text { Maria McCrae and their willingness to throw the neighbourhood under } \\
\text { the bus repeatedly. }\end{array}$ \\
\hline $\begin{array}{l}\text { Posted by: } \\
\text { realist } \\
\text { September } \\
02,2009 \\
8: 33 \mathrm{AM}\end{array}$ & $\begin{array}{l}\text { this area has been a dump for decades. If the residents don't like it or feel } \\
\text { safe, they should move. Putting in a group home won't make it any worse. }\end{array}$ \\
\hline
\end{tabular}




\section{Appendix I}

OHRC: Letter to the Editor

Re: Intolerance of housing discrimination

Letters to the Editor

The Toronto Star

1 Yonge Street

Toronto ON

M5E 1E6

Dear Editor:

Re: Residents angry over housing project

The Ontario Human Rights Commission has identified discriminatory NIMBY "Not in My Back Yard" opposition as a human rights concern and a major barrier to the development of much needed affordable and supportive housing.

Questions about land use are a legitimate part of the planning process. However, meetings that allow people to determine who lives in their neighbourhood are another matter.

Persons and groups identified under the Ontario Human Rights Code should not have to ask permission from prospective neighbours before moving in. Efforts to keep out persons with disabilities, including mental illness, are no less offensive than preventing racialized persons from moving into a neighbourhood.

One in five Canadians will experience mental illness and yet be good citizens and good neighbours in every community across the province. There is no place for assuming a link between mental illness and criminality. I applaud Councillor Mammoliti for his efforts as chair of the affordable housing committee to prevent such stereotyping of persons with mental illness.

Yours truly,

Barbara Hall, B.A., LL.B, Ph.D (hon.)

Chief Commissioner

Source: Ontario Human Rights Commission [http://www.ohrc.on.ca/en/issues/housing/en/resources/news/nimby] 